\author{
UniVerSidADE DE SÃo PaUlo \\ Faculdade de Odontologia de Ribeirão Preto
}

\title{
Resposta Celular e Molecular do Tecido Conjuntivo de Camundongos a Medicações Intracanal
}

\author{
Maristela Soares Swerts Pereira
}




\section{Mari stela Soares Swerts Perei Ra}

\section{Resposta Celular e Molecular do Tecido Conjuntivo de Camundongos a Medi Cações I ntracanal}

Tese apresentada à Faculdade de Odontologia de Ribeirão Preto da Universidade de São Paulo, para obtenção do Título de Doutor em Ciências.

Programa: Odontopediatria

Área de concentração: Odontopediatria

Orientador: Prof. Dr. Marcos A. Rossi

Co-orientadora: Profa. Dra. Léa Assed Bezerra da Silva

Ribeirão Preto 


\section{AUTORI ZAÇÃo PARA REPRODUÇÃO}

Autorizo a reprodução e divulgação total ou parcial deste trabalho, por qualquer meio convencional ou eletrônico, para fins de estudo e pesquisa, desde que citada a fonte.

Ficha Catalográfica

Pereira, Maristela Soares Swerts Pereira

Resposta celular e molecular do tecido conjuntivo de camundongos a medicações intracanal, 2012.

85 p. : il. ; $28 \mathrm{~cm}$

Tese de Doutorado, apresentada à Faculdade de Odontologia de Ribeirão Preto/USP. Área de concentração: Odontopediatria.

Orientador: Rossi, Marcos A.

Co-orientadora: Silva, Léa Assed Bezzera da.

1. Compatibilidade biológica. 2. Hidróxido de cálcio. 3. Clorexidina. 4. Pasta triantibiótica. 5. RT-qPCR. 


\section{FolHA de APRovação}

Pereira MSS. Resposta celular e molecular do tecido conjuntivo de camundongos a medicações intracanal. Tese apresentada à Faculdade de Odontologia de Ribeirão Preto da Universidade de São Paulo, para obtenção do Título de Doutor em Ciências. Área de concentração: Odontopediatria.

Data da defesa:

I---- I---

\section{BANCA EXAMI NADORA}

Prof. Dr.

Instituição:

Julgamento:

Assinatura:

Prof. Dr.

Instituição:

Julgamento:

Assinatura:

Prof. Dr.

Instituição:

J ulgamento:

Assinatura:

Prof. Dr.

Instituição:

J ulgamento:

Assinatura:

Prof. Dr.

I nstituição:

Julgamento:

Assinatura: 


\section{Maristela Soares Swerts Pereira}

NASCI MENTO: 01 de agosto de 1972, Alfenas, Minas Gerais, Brasil

FI LI AÇÃO: J Jão Batista Dias Swerts e Alda Soares Swerts

1991- 1994: Curso de Graduação em Odontologia

Universidade J osé do Rosário Vellano - UNIFENAS

1995 - 1996: Residência Odontológica em Odontopediatria

Universidade J osé do Rosário Vellano - UNIFENAS

1996 - Atual: Cirurgiã-Dentista da Prefeitura Municipal de Alfenas

1997 - Atual: Professora da disciplina de "Odontologia Pediátrica" e do "Estágio em Odontologia Pediátrica I e II" do Curso de Odontologia da Universidade J osé do Rosário Vellano - UNIFENAS

1999 - 2001: Curso de Pós-Graduação (Mestrado) em Ciências - Ênfase em Saúde Área de concentração: Odontologia

Universidade J osé do Rosário Vellano - UNIFENAS

2001 - 2002: Especialização em Odontopediatria

Universidade Federal de Alfenas - UNIFAL

2002 - 2004: Curso de Pós-Graduação (Mestrado) em Odontologia

Área de concentração: Odontopediatria

Faculdade de Odontologia de Ribeirão Preto - USP

2006 - 2007: Especialização em Saúde Coletiva

Faculdade de Odontologia São Leopoldo Mandic

2008 - 2012: Curso de Pós-Graduação (Doutorado) em Ciências

Área de concentração: Odontopediatria

Faculdade de Odontologia de Ribeirão Preto - USP 


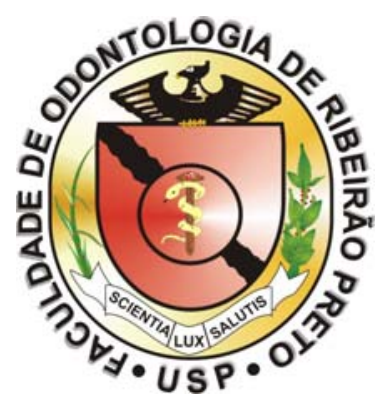

Trabalho desenvolvido no Laboratório de Cardiologia Celular e Molecular do Departamento de Patologia e no Laboratório de Imunoparasitologia do Departamento de Bioquímica e Imunologia da Faculdade de Medicina de Ribeirão Preto - Universidade de São Paulo, sob orientação do Prof. Dr. Marcos A. Rossi e co-orientação da Profa. Dra. Léa Assed Bezerra da Silva. 
A Deus, que me proporcionou saúde, coragem e persistência, para vencer mais este desafio. A certeza de Sua presença foi o alicerce que me guiou pelos caminhos tortuosos e imprevisíveis do crescer.

Aos meus pais, Toä Batista e CAlda, por todo apoio e amor incondicional em todas as etapas da minha vida e pela luta e sacrifício buscando favorecer minha formação moral e profissional.

Ao meu marido, Fleraldo, por acreditar nos meus objetivos e pelo companheirismo tanto nos momentos de prosperidade como nas adversidades. Seu incentivo constante, sua disponibilidade, generosidade, compreensão e dedicação foram fundamentais para mais esta vitória.

Ao meu querido e único filho, Guilherme, por retribuir minhas ausências com muito amor e carinho, sempre me apoiando e demonstrando que a perseverança é a base de qualquer conquista. 
Ao Prof. Dr. Marcos CA. Possi, pelo brilhantismo científico que orientou o presente trabalho. Obrigada por ter me aceito como aluna mesmo diante da impossibilidade de dedicação exclusiva. Pela grandeza em compartilhar seus conhecimentos e por me instigar a buscar, aprender, refletir, questionar, discutir e desenvolver cientificamente.

À Profa. Dra. Léa Ctssed Bezerra da Silva, por sua competência científica, que alia inteligência, experiência, segurança, dedicação e profissionalismo. Pelas imprescindíveis orientações que contribuíram para otimizar este trabalho.

À Profa. Dra. Gisele Garia, pelo empenho, dedicação, constante e extraordinária colaboração. Pelos valiosos ensinamentos e inesgotável paciência frente às minhas limitações. Por não permitir que as diversas intercorrências obscurecesse nossa meta, mas sim impulsionasse o crescimento científico. Acima de tudo, pela amizade e convivência.

Ao Prof. Dr. Paulo Olelson-Filho, exemplo de mestre e pesquisador. Pelo incentivo para que eu trilhasse mais esta etapa, acreditando nas minhas possibilidades e pela atenção dispensada sempre que solicitado. 
Ctgradecimentos

À Universidade de São Paulo.

À Faculdade de Odontologia de Ribeirão Preto da Universidade de São Paulo, na pessoa de seu atual Diretor Prof. Dr. Oswaldo Luiz Berzon e Vice-Diretor Prof. Dr. Waldemar Mallet da Rocha Barros.

À Coordenação do Programa de Pós-Graduação em Odontopediatria da Faculdade de Odontologia de Ribeirão Preto da Universidade de São Paulo, na pessoa da Coordenadora Profa. Dra. Léa CAssed Bererra da Silva e do Vice-Coordenador Prof. Dr. Paulo MelsonFitho, pela oportunidade de fazer parte do corpo discente deste conceituado programa de PósGraduação.

Ao Prof. Dr. Toäo Santana da Silwa, professor do Departamento de Bioquímica e Imunologia da Faculdade de Medicina de Ribeirão Preto da Universidade de São Paulo, pela disponibilidade na utilização do laboratório de Imunoparasitologia para realização do RT-qPCR.

À Profa. Dra. Cristina Pibiro de Barros Cardoso, professora do Departamento de Biologia Celular da Faculdade de Ciências Farmacêuticas de Ribeirão Preto da Universidade de São Paulo, por toda atenção desprendida para execução e análise do RT-qPCR, além das sugestões e discussões que muito contribuíram para o enriquecimento deste trabalho.

Aos docentes do Departamento de Clínica Infantil, Odontologia Preventiva e Social da Faculdade de Odontologia de Ribeirão Preto da Universidade de São Paulo, Profa. Dra. CAldevina Campos de Freitas, Profa. Dra. Ctlexandra Mussolino de Queirox, Profa. Dra. Andiara De Rossi, Prof. Dr. Fábio Lourengo Ramano, Prof. Dr. Tosé Farcisio Lima Ferreira, Profa. Dra. Mranya Victoria Diaz Serrano, Profa. Dra. Léa CAssed Bezerra da Silva, Prof. Dr. Mário Roberto Leonardo, Profa. Dra. Maria Bernadete Sasso Stuani, Profa. Dra. Maria da Conceigao Pereira Saraiva, Profa. Dra. Maria Pristina Borsatto, Profa. Dra. Mrian CAike Makame Matsumoto, Prof. Dr. Paulo Melson-Fitho, Profa. Dra. 
Raquel CAssed Bererra da Silva e Profa. Dra. Sada CAssed, pelos ensinamentos e exemplos de vida acadêmica.

Aos pós-graduandos do programa de Patologia da Faculdade de Medicina de Ribeirão Preto da Universidade de São Paulo, Dra. Mara Ruibia Olunes Celes, Dra. Cibele Maria Prado, Dra. Maria Tosé Figueiredo, Erica Carolina Campos Puluci, Valdecir Blefari, Lygia Maria Mouri Malvestio e Patricia Mara Ferezin, pela amizade, atenção e disponibilidade. Por compartilharem suas experiências por meio de contribuições intelectuais e orientações imprescindíveis para a conclusão deste trabalho.

Ao pós-graduando do programa de Patologia da Faculdade de Medicina de Ribeirão Preto da Universidade de São Paulo, Valdecir Blefari, pela indispensável colaboração durante os procedimentos cirúrgicos do presente trabalho.

À funcionária do Laboratório de Cardiologia Celular e Molecular da Faculdade de Medicina de Ribeirão Preto da Universidade de São Paulo, Maria Élena Riul, por todo carinho, ensinamentos, dedicação em suas atividades e pelo incansável esforço para atingir os melhores resultados no processamento histotécnico.

Às funcionárias do Laboratório de Cardiologia Celular e Molecular da Faculdade de Medicina de Ribeirão Preto da Universidade de São Paulo, Ligia Grecco O.B. Santoro e Monica Ctzevedo de CAareu, por todo apoio, presteza e agradável convivência.

Aos funcionários do Biotério do Departamento Patologia da Faculdade de Medicina de Ribeirão Preto da Universidade de São Paulo, Ctna Carolina Lourengo Peloni e Carlos Ftenrique de Carvalho Pibeiro, pelo importante auxílio e cuidado com os animais.

Às secretárias do Departamento de Patologia da Faculdade de Medicina de Ribeirão Preto da Universidade de São Paulo, Camila de Luca Zambonini Gimenes e Posangela Marzucato C. de Paiva, pela atenção e eficiência. 
À funcionária do laboratório de Imunoparasitologia da Faculdade de Medicina de Ribeirão Preto da Universidade de São Paulo, Cristiane Maria Milanezi, e ao pós-graduando do programa de Imunologia Básica e Aplicada da Faculdade de Medicina de Ribeirão Preto da Universidade de São Paulo, Gruliano Bonfá, pelas imprescindíveis orientações para a execução do RT-qPCR.

Aos funcionários do Departamento de Clínica Infantil, Odontologia Preventiva e Social da Faculdade de Odontologia de Ribeirão Preto da Universidade de São Paulo, Carmo Euripedes Eerra Barretto, Dra. Cardina Paes Eorres Mantovani, Dorival Gaspar. Fátima Ctparecida Tacinto Daniel, Fatima Ctparecida Rizoli, Filomena Leli Placciti, Dr. Francisco Wanderley Garcia de Paula es Silva, Marco Antonio dos Santos, Matheus Morelli Zanela, Milra Leticia Magalhäes e Renata Ctparecida Fernandes, pela cordialidade e atenção.

Ao funcionário do Departamento de Clínica Infantil, Odontologia Preventiva e Social da Faculdade de Odontologia de Ribeirão Preto da Universidade de São Paulo, OMarco CAntonio dos Santos, pelas orientações no processamento laboratorial.

À secretária da Pós-Graduação do Departamento de Clínica Infantil, Odontologia Preventiva e Social, Michele Cristina Leite Rovanholo, pela pronta assessoria, dinamismo e eficiência.

Às funcionárias da Seção de Pós-Graduação da Faculdade de Odontologia de Ribeirão Preto, Psabel Pristina Galino Sola e Pegiane Mroi Sacilotto, pela presteza e dedicação.

Aos colegas do Doutorado, Ctna Larissa Fernandes de Flolanda Soares, Carolina Paes Forres Mantovani, Pristiane Eomar Pocha, Pristhiane Ristum Bagatin Possi, Daniel Silva Hlerrog Flones, Fabricio Ritazono de Carvalho, Taciara Gomes Miranda Silva, Regina Ctparecida Segatto Saiani, Rodrigo Feixeira Macrie Soraya Cheier Diba Gongalves, pelos momentos de aprendizado e de amizade compartilhados.

À amiga, Dra. Denise Belucio Rewiére, pelas experiências transmitidas. 
À Universidade José do Rosário Vellano - Unifenas, em nome de sua magnífica Reitora, Profa. Maria do Posáric Ctracijo Delano, pela oportunidade de desenvolver a docência e por favorecer meu crescimento científico.

Ao Coordenador do Curso de Odontologia da Universidade José do Rosário Vellano - Unifenas, Prof. Tosé Ponaldo Miranda, pela compreensão irrestrita e colaboração.

Ao grande mestre e colega Prof. Dr. Toas Bosco Ribeiro de Oliveira e Silva (in memorian), responsável por minha iniciação no universo da Odontopediatria e por me motivar a perseguir os ideais da vida acadêmica e científica. Apesar da distância física, sinto a energia de seu incentivo.

Às minhas colegas e amigas das disciplinas de Odontologia Pediátrica e Estágio em Saúde Pública do Curso de Odontologia da Universidade José do Rosário Vellano - Unifenas, Prefa.

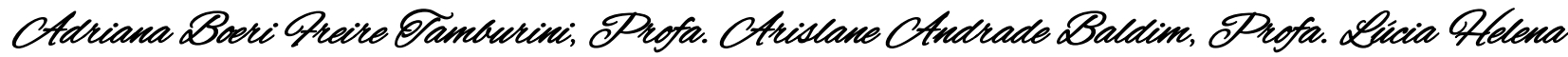

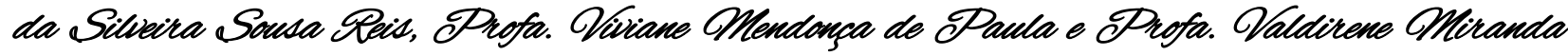
Estaves Orsi: As constantes colaborações e incentivos foram essenciais à conclusão deste curso, portanto, serei eternamente agradecida.

À Prefeitura Municipal de Alfenas, na pessoa do atual prefeito, Luiz CAntonio da Silwa, por acreditar na importância da capacitação de seus funcionários e favorecer condições para que possamos avançar.

Ao Prof. Leir Miranda Esteves, pela revisão textual.

Ao Túlio de Cesar Matos, Cláudia Regina Correa de Matos e Marina Matos, pela diagramação e impressão deste trabalho.

A todos, e não menos importantes, que contribuíram para concretização desta tese. 


\section{RESUMO}

Pereira MSS. Resposta celular e molecular do tecido conjuntivo de camundongos a medicações intracanal [Tese]. Ribeirão Preto: Faculdade de Odontologia de Ribeirão Preto da Universidade de São Paulo; 2012.

Substâncias contendo clorexidina (CHX) ou associação de antibióticos têm sido pesquisadas como medicações intracanal. Os objetivos do presente estudo foram: Capítulo 1Caracterizar a resposta do tecido conjuntivo subcutâneo de camundongos à pasta triantibiótica (Trimix), por microscopia óptica convencional e por RT-PCR em tempo real; e Capítulo 2 Comparar a resposta do tecido conjuntivo subcutâneo de camundongos a medicações intracanal contendo $\mathrm{CHX}$ por microscopia óptica convencional. No Capítulo 1, a resposta do tecido conjuntivo subcutâneo de camundongos foi avaliada por meio da implantação de tubos de polietilieno vazios ou contendo uma das substâncias avaliadas: Trimix ou Calen. Como controle adicional, foram utilizados animais que não receberam a implantação dos tubos. Para a avaliação histopatológica, decorridos os períodos experimentais de 7, 21 e 63 dias, os implantes $(n=10)$ contendo Trimix ou Calen foram removidos juntamente com o tecido conjuntivo subcutâneo e a pele adjacente e submetidos ao processamento histotécnico, sendo os cortes corados pelo método de hematoxilina e eosina e picrosírius vermelho. Foram efetuadas análises qualitativa, determinando os parâmetros de resposta biológica e quantitativa, onde foram avaliados o número de células inflamatórias e de vasos, a área e a densidade vascular, além do percentual relativo de colágeno. As reações de RT-PCR em tempo real foram realizadas nos grupos tubo vazio, pasta Calen, Trimix e controle adicional nos períodos experimentais de 7 e 21 dias. Foi realizada a deteç̧ão e quantificação das citocinas pró-inflamatórias (IL-1ß, TNF-a e IL17) e anti-inflamatória (TGF- $\beta$ ), fator crescimento endotelial vascular (VEGF), fator induzido por hipóxia (HIF-1a), metaloproteinases (MMP-2 e -9) e inibidores de metaloproteinases (TIMP-1 e 2). Os resultados foram comparados empregando teste t de Student e ANOVA, seguida do pósteste de Tukey. No Capítulo 2, foi efetuada a comparação da resposta do tecido conjuntivo subcutâneo de camundongos às pastas Calen+CHX a 0,5\%, Calen+CHX a 2,0\%, ao gel de $\mathrm{CHX}$ a $2,0 \%$ e à pasta Calen (controle) utilizando metodologia semelhante à empregada para avaliação histopatológica no Capítulo 1. Os resultados obtidos foram analisados por meio da ANOVA, seguida do pós-teste de Tukey. O nível de significancia adotado em todas as análises estatísticas foi de 5\%. Com base nos resultados obtidos, pôde-se concluir que: 1) A resposta do tecido conjuntivo subcutâneo de camundongos à pasta Trimix caracterizou-se por reação inflamatória aguda persistente e ausência de reparo no período estudado de 63 dias, o que foi suportado pela maior expressão gênica dos biomarcadores relacionados à resposta inflamatória e angiogênica, comparado à pasta Calen; 2) Quando comparadas as medicações contendo CHX, os resultados evidenciaram que a Calen $+\mathrm{CHX}$ a $0,5 \%$ exibiu resposta tecidual reparativa, em contraste com a Calen+CHX a 2,0\% e o gel de $\mathrm{CHX}$ a 2,0\% que propiciaram resposta inflamatória persistente, apontando para agressividade destes materiais. Considerando a Calen+CHX a 2,0\% e o gel de $\mathrm{CHX}$ a 2,0\%, este apresentou resposta inflamatória de maior intensidade. Desse modo, o presente estudo fornece indícios que as pastas Trimix, Calen+CHX a $2,0 \%$ e o gel de $\mathrm{CHX}$ a 2,0\% não deveriam ser empregadas como medicação intracanal.

Palavras-Chave: compatibilidade biológica, hidróxido de cálcio, clorexidina, pasta triantibiótica, RT-qPCR. 


\section{ABSTRACT}

Pereira, MSS. Cellular and molecular response of mice connective tissue to intracanal dressings [Thesis]. Ribeirão Preto: Faculdade de Odontologia de Ribeirão Preto da Universidade de São Paulo; 2012.

Substances containing chlorhexidine $(\mathrm{CHX})$ or combination of antibiotics have been investigated as intracanal dressings. The aim of this study were: Chapter 1 - To characterize the response of mice subcutaneous connective tissue to triantibiotic paste (Trimix), by conventional optical microscopy and real-time RT-PCR; and Chapter 2 - Compare the response of mice subcutaneous connective tissue to intracanal dressings containing $\mathrm{CHX}$ by conventional optical microscopy. In Chapter 1, the response of mice subcutaneous connective tissue was assessed by implantation of polyethylene tubes empty or containing one of the substances evaluated: Trimix or Calen. As additional control, animals that not received implantation of the tubes were used. For histopathological evaluation, after the experimental periods of 7, 21 and 63 days, the implants $(n=10)$ containing Trimix or Calen were removed along with the subcutaneous connective tissue and adjacent skin and subjected to processing histotechnical, and the sections were stained with hematoxylin and eosin or picrosirius red. It was carried out a qualitative analysis, determining the biological parameters and a quantitative response, assessing the number of inflammatory cells and vessels, the area and vascular density, and the relative percentage of collagen. The real-time RT-PCR reactions were performed in the empty tube group, pastes Calen, Trimix and additional control at the experimental periods of 7 and 21 days. The detection and quantification of proinflammatory (IL-1 $\beta$, TNF-a and IL-17) and antiinflammatory cytokines (TGF- $\beta$ ), vascular endothelial growth factor (VEGF), hypoxia-induced factor (HIF-1a), metalloproteinases (MMP-2 and -9) and metalloproteinases inhibitors (TIMP-1 and -2 ) were performed. The results were compared using Student's t test and ANOVA followed by Tukey test. In Chapter 2, it was compared the response of mice subcutaneous connective tissue to Calen $+0.5 \% \mathrm{CHX}$, Calen+2.0\% CHX, 2.0\% CHX gel and paste Calen (control) using methodology similar to that one used for histopathologic evaluation in Chapter 1 . The results were analyzed by ANOVA followed by Tukey test. The significance level for all statistical analysis was $5 \%$. It was concluded: 1 ) The response of mice subcutaneous connective tissue to Trimix paste was characterized by persistent acute inflammatory reaction with no repair during the studied period of 63 days, which was supported by the higher gene expression of biomarkers related to inflammation and angiogenesis, compared to Calen paste; 2) The Calen $+0.5 \% \mathrm{CHX}$ showed reparative tissue response, in contrast to Calen $+2.0 \% \mathrm{CHX}$ and $2.0 \% \mathrm{CHX}$ gel that have led to persistent inflammatory response, indicating aggressiveness of these materials. Considering the Calen+2.0\% $\mathrm{CHX}$ and $\mathrm{CHX} 2.0 \%$ gel, this induced more intense inflammatory response. Thus, this study provides evidence that the pastes Trimix, Calen+2.0\% CHX and $2.0 \%$ $\mathrm{CHX}$ gel should not be used as intracanal dressing.

Key-Words: biocompatibility, calcium hydroxide, chlorhexidine, triantibiotic paste, RT-qPCR. 


\section{SUMÁRIO}

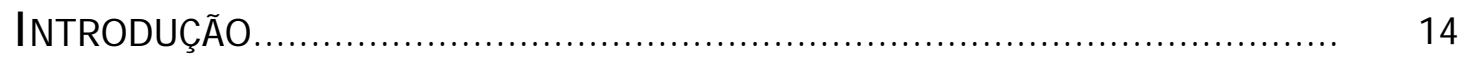

CAPÍTULO 1 - Avaliação da pasta triantibiótica................................................ 19

CAPÍTULO 2 - Avaliação de medicações intracanal contendo clorexidina............ 49

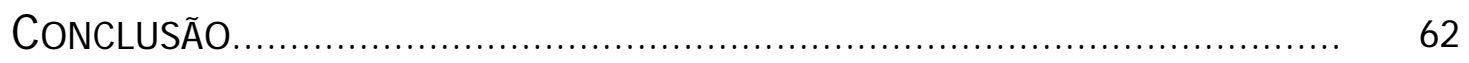

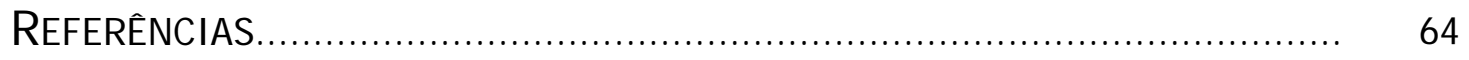

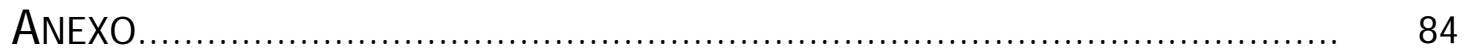




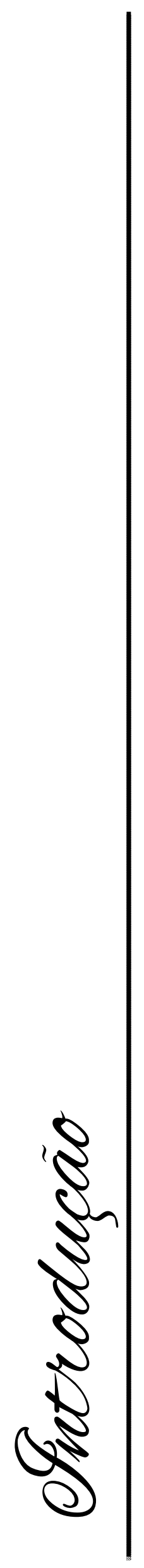




\section{NTRODUÇÃO}

Micro-organismos e seus produtos são considerados essenciais na etiologia das patologias pulpares e perirradiculares. Deste modo, o principal objetivo do tratamento endodôntico de dentes com necrose pulpar e lesão periapical é a redução ou eliminação da infecção microbiana no sistema de canais radiculares (Evans et al., 2003; Wuerch et al., 2004; Kanisavaran, 2008; Mohammadi e Abbott, 2009b; Kawashima et al., 2009). O preparo biomecânico, empregando instrumentos manuais ou rotatórios, associado a soluções irrigadoras, visa, dentre outras finalidades, ao combate à infecção (Leonardo, 2005; Soares et al., 2007; Young et al., 2007). Entretanto, como os micro-organismos não se encontram localizados somente na luz do canal radicular principal (Leonardo et al., 2002; Leonardo, 2005), o preparo biomecânico, isoladamente, não é eficaz na sua eliminação (Leonardo et al., 1994; Basrani et al., 2003; Faria et al., 2005; El Karin et al., 2007; Paula-Silva et al., 2010). Assim, devem ser empregadas substâncias para combater não somente a infecção remanescente na luz e paredes do canal radicular, mas principalmente aquela situada em áreas profundas e difusas da estrutura do dente, tais como istmos, ramificações, deltas, irregularidades e túbulos dentinários, áreas estas inacessíveis ao preparo biomecânico e ao sistema de defesa do organismo (Shuping et al., 2000; Faria et al., 2005; Leonardo et al., 2006; Soares et al., 2006b; El Karin et al., 2007; Lee et al., 2008). Além disto, estas substâncias devem ser capazes de promover a detoxicação da endotoxina bacteriana - LPS (Buck et al., 2001; Silva et al., 2002; Gomes et al., 2009a). Com estes propósitos e também visando a prevenir a reinfecção do sistema de canais radiculares, diferentes substâncias antimicrobianas têm sido utilizadas como medicação intracanal entre sessões, em dentes com necrose pulpar e lesão periapical (Barbosa et al., 1997; Silva et al., 2002; De Rossi et al., 2005; Leonardo, 2005; Soares et al., 2006a; Kanisavaran, 2008; Mohammadi e Abbott, 2009b).

Do ponto de vista clínico, a medicação intracanal ideal para dentes com necrose pulpar e lesão periapical deve apresentar amplo espectro antimicrobiano, tempo de ação suficiente para eliminar bactérias, possuir propriedades físico-químicas que permitam sua difusão através dos túbulos dentinários e ramificações laterais do sistema de canais radiculares e ser biocompatível, a fim de favorecer o reparo e não provocar irritação adicional aos tecidos periapicais (Silva et al., 2008).

Atualmente, o hidróxido de cálcio $\left[\mathrm{Ca}(\mathrm{OH})_{2}\right]$ é considerado a medicação intracanal de 
escolha (Siqueira Jr e Lopes, 1999; Almyroudi et al., 2002; Gomes et al., 2002; Carrote, 2004; Soares et al., 2006a; Silva et al., 2008; Kawashima et al., 2009; Gangwar, 2011; Madhubala et al., 2011; I waya et al., 2011). O Ca(OH) 2 possui pH alcalino (aproximadamente 12,5 a 12,8), sendo quimicamente classificado como uma base forte. Suas principais ações ocorrem por meio de sua dissociação iônica, promovendo atividade antibacteriana e indução da deposição de tecido mineralizado (Mohammadi e Dummer, 2011).

No entanto, sua eficácia como medicação intracanal tem sido questionada, sendo vários mecanismos sugeridos para explicar suas limitações, incluindo a capacidade tampão da dentina, sua neutralização por produtos microbianos, localização dos micro-organismos em áreas inacessíveis no sistema de canais radiculares, resistência bacteriana intrínseca ou alteração da expressão do gene bacteriano, permitindo sobrevivência frente a mudanças ambientais (Nerwich et al., 1993; Siqueira Jr e Lopes, 1999; Portenier et al., 2001; Nakajo et al., 2004; Nair et al., 2005; Mohammadi e Dummer, 2011). Assim, várias substâncias estão sendo pesquisadas na busca de medicações intracanal que possuam equilíbrio entre as propriedades antimicrobianas e compatibilidade biológica.

Entre as substâncias, destaca-se a clorexidina ( $\mathrm{CHX}$ ), que é uma bisbiguanida catiônica, de grande interesse por seu amplo espectro antimicrobiano. Sua atividade antimicrobiana é desencadeada por meio da interação iônica com a superfície celular carregada negativamente dos micro-organismos, causando dano à membrana celular, inibição enzimática e perda irreversível do conteúdo citoplasmático (Shen et al., 2011). A principal vantagem da CHX é a substantividade, que permite efeito residual prolongado e não promove resistência microbiana (Komorowski et al., 2000; Roshental et al., 2004; Anthanassiadis et al., 2007; Neelakantan et al., 2007). A CHX, na forma de gel ou associada ao $\mathrm{Ca}(\mathrm{OH})_{2}$, tem sido investigada como medicação intracanal em estudos in vitro (Lenet et al., 2000; Lima et al. 2001; Barthel et al., 2002; Basrani et al., 2003; Evans et al., 2003; Haenni et al., 2003; Gomes et al., 2003; Basrani et al., 2004; Rosenthal et al., 2004; Schäfer e Bössmann, 2005; Gomes et al., 2006; Ercan et al., 2006; Ballal et al., 2007; Krithikadatta et al., 2007; Neelakantan et al., 2007; Souza-Filho et al., 2008; Delgado et al., 2010; Kandaswamy et al., 2010; Lima et al., 2011; Vaghela et al., 2011) e in vivo (Wuerch et al., 2004; Dammaschke et al., 2005; De Rossi et al., 2005; Soares et al., 2006a; Manzur et al., 2007; Vianna et al., 2007; Wang et al., 2007; Semenoff et al., 2008; Silva et al., 2009; Gondim et al., 2011; Martinho et al., 2011), sendo escassas e controversas as análises da reação tecidual a estas medicações (Dammaschke et al., 2005; De Rossi et al., 
2005; Gomes-Filho et al., 2008; Semenoff et al., 2008; Silva et al., 2009).

0 uso de antibióticos como medicação intracanal possui relação histórica com 0 tratamento endodôntico. Durante a década de 50, uma pasta poliantibiótica, com a seguinte composição: penicilina, para atuar contra micro-organismos Gram-positivos; bacitracina, para atuar contra cepas resistentes à penicilina; estreptomicina, visando Gram-negativos; caprilato de sódio, um fungicida, foi preconizada para uso como medicação intracanal (Grossman, 1951). No entanto, esta e outras associações de antibióticos tiveram seu uso limitado como medicação intracanal, em decorrência do espectro de ação insatisfatório juntamente com o potencial risco de efeitos adversos, tais como a possibilidade de ocorrência de hipersensibilidade, toxicidade, desenvolvimento de resistência microbiana, crescimento de fungos, entre outros (Marrie et al., 1981; Longman et al., 2000; El Karin et al., 2007; Mohammadi, 2009).

Mesmo assim, recentemente tem ressurgido o interesse pelas pastas poliantibióticas para serem usadas como medicação intracanal (Mohammadi e Abbott, 2009a; Ferreira et al., 2010; Barnes e Patel 2011; Jungermann et al., 2011). A associação de antibióticos é justificada pela natureza polimicrobiana da infecção pulpar e perirradicular e também visando evitar a ocorrência de resistência microbiana (Mohammadi e Abbott, 2009a; Jungermann et al., 2011). Neste contexto, estudos têm relatado a eficácia da pasta triantibiótica (Trimix), composta de ciprofloxacino, metronidazol e minociclina, contra micro-organismos encontrados nos sistema de canais radiculares (Hoshino et al., 1996; Sato et al., 1996; Windley et al., 2005; Madhubala et al., 2011). O uso/indicação da Trimix está baseado essencialmente em relatos de casos clínicos de dentes com necrose pulpar e rizogênese incompleta (Banchs e Trope, 2004; Jung et al., 2008; Akgun et al., 2009; Bose et al., 2009; Ding et al., 2009; Leung, 2010; Petrino et al., 2010; Thomson e Kahler, 2010; Nosrat et al., 2011; Torabinejad e Turman, 2011) e de dentes decíduos com necrose pulpar (Takushige et al., 2004; Prabhakar et al., 2008; Nakornchai et al., 2010; Pinky et al., 2011; Trairatvorakul e Detsomboonrat, 2011). Além disso, há relatos de indicação desta pasta em casos de insucesso após o uso de medicação intracanal convencional no tratamento de dentes com necrose pulpar e extensa lesão periapical (Er et al., 2007; Kusgoz et al., 2007; 2009; Taneja et al., 2010). Contudo, apesar desses relatos de sucessos clínicos e radiográficos acerca do uso da Trimix, não existem evidências científicas suficientes para sua indicação e poucos descreveram sobre a reação tecidual frente a esta pasta em diferentes períodos de tempo (Scarparo et al., 2011; Gomes-Filho et al., 2012).

Deve-se ressaltar que a caracterização da reação tecidual a materiais endodônticos por 
meio de modelos experimentais pré-clínicos é fundamental antes de sua aplicação clínica (Reyes-Carmona et al., 2011). Assim, pesquisas adicionais são necessárias para explorar e melhor definir a resposta tecidual de substâncias indicadas como medicações intracanal alternativas. Pelo exposto, os objetivos do presente estudo foram:

1) Caracterizar a resposta do tecido conjuntivo subcutâneo de camundongos à Trimix por microscopia óptica convencional e por RT-PCR em tempo real (Capítulo 1);

2) Comparar a resposta do tecido conjuntivo subcutâneo de camundongos a medicações intracanal contendo CHX por microscopia óptica convencional (Capítulo 2). 


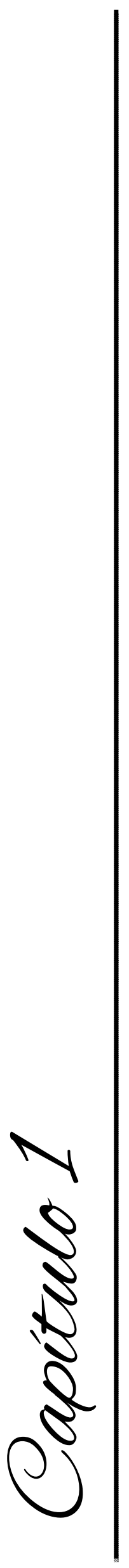




\section{CAPÍtULO 1}

\section{AVALIAÇÃO DA PASTA TRIANTIBIÓTICA}

\section{INTRODUÇÃO}

A ocorrência de necrose pulpar em dentes com rizogênese incompleta promove a descontinuidade do desenvolvimento radicular (Cvek, 1992). Tradicionalmente, para estes casos, o hidróxido de cálcio $\left[\mathrm{Ca}(\mathrm{OH})_{2}\right]$ é usado como medicação intracanal para induzir o desenvolvimento de uma barreira apical de tecido calcificado, que serve como matriz contra a qual o material obturador é compactado (Selden, 2002; Hargreaves et al., 2008; Mohammadi e Dummer, 2011). Embora ocorra fechamento apical por esta barreira calcificada, as paredes radiculares continuam finas, curtas e frágeis, consequentemente com maior suscetibilidade à fratura (Selden, 2002; Ding et al., 2009; Lovelace et al., 2011). Outras desvantagens dessa técnica são o elevado número de consultas exigidas, o período prolongado e a grande variabilidade do tempo de tratamento e consequentemente dificuldade de monitoramento dos pacientes. Para evitar estes inconvenientes, uma opção de tratamento seria a utilização de uma barreira apical artificial de agregado de trióxido mineral, o MTA, possibilitando a conclusão imediata do tratamento endodôntico, porém também sem favorecer o aumento do comprimento e da espessura das paredes radiculares (Rafter, 2005; Marchesan et al., 2008; Parirokh e Torabinejad, 2010).

Recentemente, uma abordagem clínica diferente tem sido preconizada para induzir a revascularização de dentes com necrose pulpar e rizogênese incompleta, possibilitando o fechamento apical "espontâneo" (Huang, 2008; Lovelace et al., 2011). De acordo com esta abordagem, realiza-se a desinfecção do canal radicular, empregando irrigação com hipoclorito de sódio, seguida da aplicação de uma pasta triantibiótica (Trimix), composta de ciprofloxacino, metronidazol e minociclina (Hoshino et al., 1996; Sato et al., 1996; Windley et al., 2005; Murray et al., 2007; Reynolds et al., 2009; Cohenca et al., 2010; Silva et al., 2010; Wang et al., 2010; Barnes e Patel, 2011; Lin e Rosenberg, 2011; Lovelace et al., 2011; Nosrat et al., 2011). Esta pasta permanece no canal radicular por períodos que variam de dias a meses de acordo com os diferentes trabalhos (Banchs e Trope, 2004; Windley et al., 2005; Thibodeau e Trope, 2007; Ding et al., 2009; Akgun et al., 2009; Kim et al., 2010; Petrino et al., 2010; Lovelace et al., 2011). Após a remoção da pasta, efetua-se ou não a indução de sangramento para preencher o 
canal radicular, promovendo a formação de coágulo sanguíneo abaixo da junção amelocementária. Uma camada de MTA é inserida sobre o coágulo sanguíneo e efetua-se o selamento coronário (Banchs e Trope, 2004; Hargreaves et al., 2008; Jung et al., 2008; Reynolds et al., 2009; Cohenca et al., 2010; Silva et al., 2010; Yamauchi et al., 2011). 0 objetivo desta técnica é permitir a revascularização do canal radicular e a continuidade da formação radicular, por meio do desenvolvimento normal da espessura das paredes dentinárias, do comprimento da raiz e da morfologia apical (Thibodeau et al., 2007; Huang, 2008; Jung et al., 2008; Trope, 2008; Lovelace et al., 2011; Nosrat et al., 2011).

Em relação à pasta Trimix, estudo in vitro, avaliando a eficácia antibacteriana dos componentes desta medicação isoladamente ou em combinação frente às bactérias de dentina e polpa infectadas e também presentes em lesão periapical, mostrou que nenhum deles sozinho eliminou todas as bactérias, mas, quando utilizados em associação, eliminaram as bactérias de todas as amostras (Hoshino et al., 1996). A associação destes medicamentos também foi efetiva em eliminar bactérias de camadas profundas da dentina radicular (Sato et al., 1996).

A indicação da Trimix está baseada essencialmente em relatos de casos clínicos de sucesso na revascularização de dentes, apresentando necrose pulpar, com ou sem lesão periapical e com rizogênese incompleta (Banchs e Trope, 2004; Jung et al., 2008; Akgun et al., 2009; Bose et al., 2009; Ding et al., 2009; Leung, 2010; Petrino et al., 2010; Nosrat et al., 2011; Torabinejad e Turman, 2011). Até o momento, são escassos os estudos que avaliaram a compatibilidade biológica desta pasta em diferentes períodos de tempo (Scarparo et al., 2011; Gomes-Filho et al., 2012), tendo sido especulado que a pasta Trimix seria tóxica aos tecidos (Wang et al., 2010), promovendo lesão tecidual e retardo no reparo (Silva et al., 2010).

Diante de lesão tecidual, múltiplos sinais químicos são ativados para desencadear uma resposta imuno-inflamatória do hospedeiro, visando ao reparo do tecido lesado (Coussens e Werb, 2002; Bilate, 2007). Inicialmente, a inflamação induz uma resposta angiogênica, produzindo tecido de granulação que pode ter destinos diferentes: (1) a neoformação vascular fornece oxigênio, nutrientes e leucócitos para a área lesada, favorecendo a reparação tecidual seguida da regressão vascular ou (2) leucócitos ativados liberam citocinas e enzimas proteolíticas, levando à persistência da reposta inflamatória e à excessiva angiogênese (Arroyo e Iruela-Arispe, 2010).

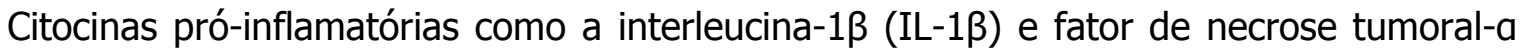
(TNF-a) são consideradas mediadores clássicos da inflamação e também se comportam como 
reguladores da angiogênese. Já a interleucina-17 (IL-17) atua por meio da ativação celular para produção de mais citocinas pró-inflamatórias. Por outro lado, o fator de crescimento transformador- $\beta$ (TGF- $\beta$ ) atua principalmente como inibidor do processo inflamatório e agente fibrinogênico (Beklen et al., 2007; Bilate, 2007; Abbas et al., 2008; Fukushima et al., 2010).

Diante da baixa tensão de oxigênio gerada pelo processo inflamatório, o fator induzido pela hipóxia (HIF-1a) promove a expressão de citocinas pró-inflamatórias e pró-angiogênicas por células do infiltrado inflamatório (Carmi et al., 2009; Semenza, 2009; Imtiyaz e Simon, 2011). Em contrapartida, em condições de tensão normal de oxigênio, citocinas, como IL-1- $\beta$ e TGF- $\beta$, são capazes de induzir a produção de HIF-1a (Thornton et al., 2000; McMahon et al., 2006).

O fator de crescimento endotelial vascular (VEGF), o principal estimulador da angiogênese, é induzido pelo HIF-1a ou por citocinas e fatores de crescimento como IL-1 $\beta$, IL17, TNF-a e TGF- $\beta$. O VEGF está envolvido em vários estágios do desenvolvimento vascular, devido à sua habilidade em induzir respostas das células endoteliais, incluindo proliferação, migração, especialização e sobrevivência (Zachary e Gliki, 2001; Ferrara et al., 2003). Adicionalmente, o VEGF possui efeito pró-inflamatório (Moromizato et al., 2000; Sakurai et al., 2003; Usui et al., 2004), aumentando a permeabilidade do endotélio vascular (Bates et al., 2002), promovendo a vasodilatação (Hood et al., 1998; Kroll e Waltenberger, 1999) e estimulando o recrutamento de células inflamatórias e expressão das metaloproteinases da matriz, as MMPs (Pepper et al., 1991; Unemori et al., 1992; Mandriota et al., 1995).

As MMPs constituem um grupo de enzimas responsáveis pela degradação dos componentes da matriz extracelular e da membrana basal (Navarro et al., 2006), sendo induzidas via fatores de crescimento e citocinas, tais como IL-1 $\beta$, TNF-a, TGF- $\beta$ e VEGF (Birkedal-Hansen, 1993). Ao mesmo tempo em que favorece os processos de remodelação e reparo tecidual, o excesso da atividade das MMPs nos tecidos pode provocar debilidade no reparo da matriz extracelular. Dentre estas proteases, as MMPs -2 e -9 são conhecidas por degradar o colágeno nativo e o desnaturado, portanto apresentando importante papel na inflamação e angiogênese (Visse e Nagase, 2003).

A atividade das MMPs é controlada por meio dos inibidores endógenos específicos das metaloproteinases, os TIMPs (Leung et al., 1989; Howard et al., 1991; Ferrara et al., 1998; Lamoreaux et al., 1998; Sternlicht e Werb, 2001; Hiratsuka et al., 2002; Accorsi-Mendonça et al., 2005; Stetler-Stevenson e Seo, 2005). Estes inibidores são proteínas pequenas e 
multifuncionais que regulam o nível de ativação das MMPs e sua habilidade de hidrolisar um determinado substrato (Birkedal-Hansen, 1993; Souza e Line, 2002). Desta forma, o equilíbrio entre a produção de MMPs e a de TIMPs representa o ponto principal para a homeostase da matriz extracelular (Navarro et al., 2006; Piotrowski et al., 2009).

Assim, uma vez que o uso/indicação da pasta Trimix está baseado essencialmente em relatos de casos clínicos de dentes com necrose pulpar e rizogênese incompleta (Banchs e Trope, 2004; Jung et al., 2008; Akgun et al., 2009; Bose et al., 2009; Ding et al., 2009; Kim et al., 2010; Leung, 2010; Petrino et al., 2010; Thomson e Kahler, 2010; Nosrat et al., 2011; Torabinejad e Turman, 2011) sem comprovações científicas do seu papel na biologia tecidual, os objetivos do presente estudo foram:

1) Caracterizar a resposta do tecido conjuntivo subcutâneo de camundongos à pasta Trimix por microscopia óptica convencional;

2) Avaliar a expressão gênica local de citocinas pró e anti-inflamatórias, do HIF-1a, VEGF, MMPs e TIMPs induzida pela Trimix.

\section{MATERIAL e MÉtodos}

O presente estudo foi analisado e aprovado pela Comissão de Ética em Experimentação Animal da Faculdade de Medicina de Ribeirão Preto da Universidade de São Paulo, protocolo $\mathrm{n}^{\circ}$ 185/2009 (Anexo A). Os experimentos com animais realizados neste trabalho foram conduzidos de acordo com as recomendações desta Comissão.

Foram utilizados 70 camundongos isogênicos da linhagem BALB/C, machos, com 6 a 7 semanas de idade, pesando de 20 a 25 gramas, distribuídos em 4 grupos. Cada animal recebeu dois implantes dorsais compostos de tubos de polietileno vazios ou contendo uma das substâncias avaliadas: pasta Trimix ou pasta de $\mathrm{Ca}(\mathrm{OH})_{2}$ (Calen - S.S.White Artigos Dentários Ltda., Rio de Janeiro, RJ, Brasil), que foi empregada como controle. A pasta Trimix foi preparada imediatamente antes de ser implantada no tecido subcutâneo, manipulando-se partes iguais de ciprofloxacino, metronidazol e minociclina, nas concentrações de $200 \mathrm{mg}$ cada uma (Bioquant Ribeirão Preto, SP, Brasil) com água destilada esterilizada, obtendo-se uma pasta de consistência cremosa (Reynolds et al., 2009). Como controle adicional, foram utilizados animais que não receberam a implantação dos tubos. 


\section{Preparo dos tubos de polietileno}

Foram utilizados tubos de polietileno (Embramed, São Paulo, SP, Brasil) de 1,5mm de diâmetro interno e $10 \mathrm{~mm}$ de comprimento, os quais tiveram uma extremidade fechada com o auxílio de uma pinça clínica aquecida. Após terem sido esterilizados por óxido de etileno, os tubos foram preenchidos com as pastas avaliadas, sob condições de assepsia (fluxo laminar), imediatamente antes de sua implantação.

\section{Procedimento operatório}

Para o procedimento cirúrgico, os animais foram anestesiados pela associação de cloridrato de quetamina (Dopalen, Agribrands, Saúde Animal, Paulínia, SP, Brasil) - 1mL/Kg e xilazina (Rompun, Bayer, Saúde Animal, São Paulo, SP, Brasil) - 0,5mL/Kg, administrada via intramuscular. Em seguida, foi realizada a tricotomia da região dorsal e antissepsia com solução de clorexidina a 2,0\% (Bioquant).

O procedimento cirúrgico consistiu de duas incisões de $0,5 \mathrm{~cm}$, efetuadas com tesoura cirúrgica, nas regiões escapulares do dorso de cada animal, seguidas de divulsão com tesoura de ponta romba, formando duas bolsas no tecido subcutâneo com bases a $20 \mathrm{~mm}$ das linhas de incisão. Em cada bolsa, foi implantado um tubo de polietileno com a medicação, tomando-se o cuidado de se colocarem os tubos não paralelos à linha de incisão para evitar sua expulsão e mobilidade. Em cada animal, os dois tubos implantados continham a mesma substância.

Após a sutura, com fio de seda 4-0 (Ethicon Johnson \& Johnson, São Paulo, SP, Brasil), os animais foram mantidos em gaiolas individuais no biotério do Departamento de Patologia da Faculdade de Medicina de Ribeirão Preto - USP e alimentados com dieta padrão de laboratório e livre acesso à água.

\section{Avaliação histopatológica}

A avaliação histopatológica foi efetuada nos grupos das pastas Trimix e Calen, que foi empregada como controle. O quadro 1 apresenta a distribuição dos grupos. 
Quadro 1 - Divisão dos grupos, substâncias empregadas, número de animais e períodos experimentais.

\begin{tabular}{|ccc|}
\hline & \multicolumn{2}{c|}{ Substâncias } \\
\cline { 2 - 3 } Períodos & Calen (controle) & Trimix \\
\hline \multirow{2}{*}{$\mathbf{7}$ dias } & $\mathbf{5}$ animais & $\mathbf{5}$ animais \\
& $(10$ tubos $)$ & $(10$ tubos $)$ \\
\hline \multirow{2}{*}{$\mathbf{2 1}$ dias } & $\mathbf{5}$ animais & $\mathbf{5}$ animais \\
& $(10$ tubos $)$ & $(10$ tubos $)$ \\
\hline \multirow{2}{*}{$\mathbf{6 3}$ dias } & $\mathbf{5}$ animais & $\mathbf{5}$ animais \\
& $(10$ tubos $)$ & $(10$ tubos $)$ \\
\hline
\end{tabular}

Decorridos os períodos experimentais de 7, 21 e 63 dias, 5 camundongos do grupo Calen e do grupo Trimix, escolhidos ao acaso, foram anestesiados, a tricotomia dorsal foi realizada e os implantes foram removidos juntamente com o tecido conjuntivo subcutâneo e a pele adjacente ( $n=10$ implantes por grupo em cada período). Em seguida, os animais foram eutanizados por sobredose anestésica. Os tecidos foram fixados em formol tamponado a $10 \%$ por 24 horas e submetidos ao processamento histotécnico.

Os espécimes foram desidratados em soluções crescentes de álcool etílico (80\%, 95\%, 30 minutos cada um e 100\%, 4 trocas de 1 hora cada uma). Após o último álcool, foram efetuados três banhos de xilol (30 minutos cada um), dois banhos de parafina (2 horas cada um) e inclusão dos espécimes em parafina, que foram orientados de maneira a permitir cortes histológicos do implante em seu sentido longitudinal. Cortes semi-seriados foram obtidos com $6 \mu \mathrm{m}$ e com $7 \mu \mathrm{m}$ de espessura da região correspondente à parte central do tubo e corados com hematoxilina e eosina e com picrosírius vermelho, respectivamente.

\section{Picrosírius vermelho}

Os cortes foram desparafinizados, hidratados em série decrescente de alcoóis, lavados em água corrente, deixados em solução de ácido fosfomolibdico a $2 \%$ por 2 minutos e lavados em água. Em seguida, os cortes foram deixados em solução vermelho da síria a 0,1\% por 90

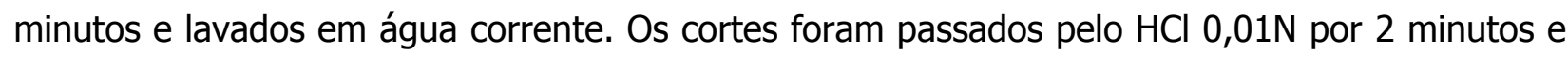
lavados em água corrente. Por último, foram desidratados, diafanizados, e as lâminas foram montadas.

As análises qualitativa e quantitativa, foram efetuadas em microscópio de luz convencional Leica (Leica DMR; Leica Microsystems GmbH, Wetzlar, Alemanha), examinando a extremidade do implante em que as pastas Calen e Trimix ficaram em contato com tecido 
subcutâneo. Foram avaliados três cortes de cada implante, mantendo-se um intervalo mínimo de $50 \mu \mathrm{m}$ entre os cortes (Bortolo, 2009).

$\mathrm{Na}$ análise qualitativa, foram analisados os parâmetros de resposta biológica, incluindo a presença e extensão da cápsula fibrosa, do infiltrado inflamatório, de necrose, ocorrência de fibroblastos e vascularização.

Para a análise quantitativa, foi utilizado o programa Leica QWin v3 (Leica Imaging Systems Ltd; Cambridge, Inglaterra) em conjunto com uma videocâmera (Leica DFC 300FX; Leica Microsystems AG, Heerbrugg, Suíça) acoplada ao microscópio e um computador on-line. Foram avaliados:

- O número de células inflamatórias presentes em quatro campos histológicos de $100 \mu m^{2}$ cada um;

- O número de vasos, suas áreas em $\mu \mathrm{m}^{2}$ e a densidade vascular em quatro campos histológicos de $100 \mu m^{2}$ cada um. Os vasos sanguíneos foram definidos como estruturas com luz e com presença ou não de hemácias, sendo delineados manualmente, contados e a área delimitada por cada vaso calculada pelo programa Leica QWin (Kyriakides et al., 2001; Ho et al., 2004). A densidade vascular foi obtida por meio da relação entre área e número de vasos por campo histológico (Prado et al., 2000; Kyriakides et al., 2001); e

- O percentual relativo de colágeno, expresso em porcentagem (\%) de colágeno por área, de quatro campos histológicos dos cortes corados com picrosírius vermelho (Campos et al., 2011).

As análises foram realizadas às cegas por um único avaliador calibrado. Todos os procedimentos laboratoriais foram realizados no Laboratório de Cardiologia Celular e Molecular da Faculdade de Medicina de Ribeirão Preto - USP.

\section{RT-PCR em tempo real (RT-qPCR)}

As reações de RT-qPCR foram realizadas nos grupos que portavam tubo vazio, pastas Calen e Trimix, nos períodos experimentais de 7 e 21 dias utilizando 5 animais de cada grupo. Também foram usados animais que não receberam os tubos (controle adicional). 0 quadro 2 apresenta a distribuição dos grupos. 
Quadro 2 - Divisão dos grupos, substâncias empregadas, número de animais e períodos experimentais.

\begin{tabular}{|ccccc|}
\hline \multirow{2}{*}{ Períodos } & \multicolumn{4}{c|}{ Substâncias } \\
\cline { 2 - 5 } & Vazio & Calen & Trimix & Sem implante \\
\hline \multirow{2}{*}{$\mathbf{7}$ dias } & $\mathbf{5}$ animais & $\mathbf{5}$ animais & $\mathbf{5}$ animais & $\mathbf{5}$ animais \\
& $(10$ tubos $)$ & $(10$ tubos $)$ & $(10$ tubos $)$ & \\
\hline \multirow{2}{*}{$\mathbf{2 1}$ dias } & $\mathbf{5}$ animais & $\mathbf{5}$ animais & $\mathbf{5}$ animais & $\mathbf{5}$ animais \\
& $(10$ tubos $)$ & $(10$ tubos $)$ & $(10$ tubos $)$ & \\
\hline
\end{tabular}

Foram realizadas anestesia, tricotomia, antissepsia, incisão, divulsão e cuidadosa remoção da "cápsula" de tecido conjuntivo subcutâneo presente na extremidade aberta de cada um dos dois tubos de polietileno implantados em cada animal. Em seguida, as duas "cápsulas" retiradas foram colocadas em miniplaca RNase e DNase-free, a qual estava sobre o gelo. Os resíduos de pasta junto às "capsulas" foram removidos com irrigação usando soro fisiológico gelado. As duas "cápsulas" foram maceradas, usando-se lâmina de bisturi $\mathrm{n}^{\circ} 15$ e inseridas em

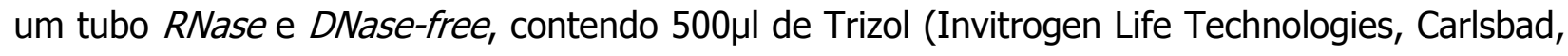
CA, EUA). Nos animais que não receberam os implantes, foi efetuada a remoção do tecido conjuntivo subcutâneo na região dorsal, usando-se pinça e tesoura cirúrgica. As amostras foram congeladas a $-80^{\circ} \mathrm{C}$ até o momento da extração do RNA.

\section{Extração do RNA total e confeç̧ão do DNA complementar (CDNA)}

Para extração do RNA, foi utilizado o método que combina o uso do Trizol seguido da utilização parcial do Kit de extração Illustra' ${ }^{\text {TM }}$ RNAspin Mini (GE Healthcare, Alemanha). Inicialmente os espécimes foram descongelados e permaneceram em temperatura ambiente para a extração do RNA. Acrescentaram-se 200 $\mu \mathrm{L}$ de clorofórmio (Merck, Frankfurt, Alemanha), e o macerado foi misturado por agitação manual durante 15 segundos e centrifugado a 12.000xg, por 15 minutos a $4^{\circ} \mathrm{C}$, com o objetivo de separar a solução em 3 fases distintas: fase aquosa superior (RNA), fase intermediária (restos de células e proteínas desnaturadas) e fase inferior (Trizol e clorofórmio). A fase aquosa superior foi processada, usando-se o Kit de extração RNAspin Mini, e o RNA foi isolado de acordo com as normas do fabricante. Após a extração, foram determinadas quantidade, pureza e qualidade do RNA, usando-se um espectrofotômetro (Thermo Scientific NanoDrop ${ }^{T M}$ 1000, Wilmington, DE, EUA).

O RNA purificado foi submetido à confecção do cDNA com a enzima Transcriptase Reversa SuperScript ${ }^{\top M}$ III (Invitrogen Life Technologies). Foram adicionados $1 \mu \mathrm{L}(500 \mu \mathrm{g} / \mathrm{mL}) \mathrm{de}$ 
Oligo $(\mathrm{dT})_{12-18}, 1 \mu \mathrm{L}$ de mix dNTP $10 \mathrm{mM}, 1 \mu \mathrm{g}$ do RNA extraído e água destilada para $14 \mu \mathrm{L}$ de volume final para cada reação. A reação foi incubada a $65^{\circ} \mathrm{C}$ por 5 minutos em termociclador PTC-100 (MJ Research, Watertown, EUA), seguida de incubação no gelo por 5 minutos. A seguir, foram adicionados à reação, o mix contendo $4 \mu \mathrm{L}$ de tampão, $1 \mu \mathrm{L}$ de DTT $0,1 \mathrm{mM}$ e $1 \mu \mathrm{L}$ de enzima Transcriptase Reversa SuperScript ${ }^{\mathrm{TM}}(200 \mathrm{U} / \mu \mathrm{L})$, totalizando $20 \mu \mathrm{L}$ de volume final de reação, conforme recomendações do fabricante (Invitrogen Life Technologies). A reação foi então prosseguida com incubação a $50^{\circ} \mathrm{C}$ por 60 minutos e inativação a $70^{\circ} \mathrm{C}$ por 15 minutos. $\mathrm{O}$ cDNA confeccionado foi diluído 4 vezes, adicionando-se $60 \mu \mathrm{L}$ de água destilada esterilizada ao volume final após a reação.

Deteç̧ão e quantificação das citocinas pró-inflamatórias (IL-1ß, TNF-a e IL-17) e antiinflamatória (TGF- $\beta$ ), VEGF, HIF-1a, MMP-2 e -9 e TIMP-1 e -2

A análise de transcritos de genes de citocinas (IL-1 $\beta$, TNF- $a$, IL-17 e TGF- $\beta$ ), VEGF, HIF-1a, metaloproteinases (MMP-2 e -9) e seus inibidores (TIMP-1 e -2) foi realizada com cDNA confeccionado a partir do RNA extraído das "cápsulas" de tecido conjuntivo subcutâneo dos camundongos. A reação RT-qPCR foi realizada com 6,5 $\mathrm{L}$ de SYBR Green Mix (Invitrogen Life Technologies), 0,5 $\mathrm{L}$ de cada primer (senso e antisenso) a 10 $\mu \mathrm{M}, 5 \mu \mathrm{L}$ do cDNA sintetizado a partir de $1 \mu \mathrm{g}$ de RNA extraído e $\mathrm{H}_{2} \mathrm{O}$ destilada esterilizada suficiente para volume final de $15 \mu \mathrm{L}$. A reação foi submetida ao aparelho Step One Plus (Applied Biosystems, Foster City, CA, EUA) e compreendeu de 2 minutos a $50^{\circ} \mathrm{C}, 2$ minutos a $95^{\circ} \mathrm{C}$, e quarenta ciclos de 15 segundos a $95^{\circ} \mathrm{C}, 30$ segundos a $58^{\circ} \mathrm{C}$ e 30 segundos a $72^{\circ} \mathrm{C}$. Nas reações SYBR Green, um ciclo final de 20 minutos com temperatura crescente de 60 a $95^{\circ} \mathrm{C}$ foi empregado para a obtenção de uma curva de dissociação dos produtos da reação, utilizada para análise da especificidade de amplificação. Os resultados foram normalizados com $\beta$-actina e analisados com base no valor de Ct (cycle threshold) ou linha de corte. O resultado foi calculado com a fórmula $\Delta \mathrm{Ct}=\mathrm{Ct}$ gene estudado - Ct $\beta$-actina; $\Delta \Delta \mathrm{Ct}=\Delta \mathrm{Ct}$ amostra $-\Delta \mathrm{Ct}$ amostra calibradora, sendo que esta foi definida como a média de $\Delta$ Ct de cinco amostras sem implante. O número de vezes de expressão diferencial no mRNA comparado com o controle foi definido pela fórmula $2^{-\Delta \Delta c t}$, de acordo com o "User's Bulletin \#2 (P/N 4303859)" da empresa fabricante do aparelho (Applied Biosystem).

Como controle adicional das reações de RT-qPCR, foram utilizadas amostras cujo cDNA foi confeccionado na ausência de Transcriptase Reversa SuperScript ${ }^{\mathrm{TM}}$ (falso cDNA), com a finalidade de averiguar se não poderia estar ocorrendo amplificação de DNA genômico nas 
amostras "reais" ao invés da expressão gênica em decorrência dos estímulos estudados.

Os primers e sequências utilizados durante a reação RT-qPCR foram desenhados usando o PrimerExpress software (Applied Biosystems, Warrington, UK), com sequência de nucleotídeos presentes no banco de dados GenBank e estão descritos no Quadro 3.

Quadro 3 - Relação dos primers e sequências utilizadas.

\begin{tabular}{|c|c|c|}
\hline Gene & Senso & Antisenso \\
\hline$\beta$-ACTINA & 5'- AGT GCT TCT AGG CGG ACT GTT - 3' & 5'- GCC ATG CCA ATG TTG TCT CT - 3' \\
\hline IL-1及 & 5'- TAG CAG TGA TGA GAA TGA CCT GTT C - 3' & 5'- TTG GAA GCA GCC CTT CAT CT - 3' \\
\hline IL-17 & 5'- TCT GTG CCA TCT CTG ATG CTG TTG GCT - $3^{\prime}$ & 5'-TCG CTG CTG CCT TAC CTG TA - 3' \\
\hline TGF- $\beta$ & 5'- TGA ACC AAG GAG ACG GAA TAC A - 3' & 5'- GGA GTT TGT TAT CTT TGC TGT CAC A - 3' \\
\hline TNF- $\alpha$ & 5'- TGT GCT CAG AGC TTT CAA CAA - 3' & 5'- CTT GAT GGT GGT GCA TGA GA - 3' \\
\hline HIF-1 $\alpha$ & $5^{\prime}$-TCAAGTCAGCAACGTGGAAG-3' & 5'-TATCGAGGCTGTGTCGACTG-3' \\
\hline VEGF & 5'- TTA CTG CTG TAC CTC CAC C - $3^{\prime}$ & 5'- ACA GGA CGG CTT GAA GAT G - 3' \\
\hline MMP-2 & 5'- CTG ATG GCA CCC ATT TAC ACC T - 3' & 5'-GAT CTG AGC GAT GCC ATC AAA - 3' \\
\hline MMP-9 & 5'- AGA GAT GCG TGG AGA GTC GAA - 3' & 5'- AAG GTT TGG AAT CTG CCC AGG - 3' \\
\hline TIMP-1 & 5'- CTA TCC CTT GCA AAC TGG AGA - 3' & 5'- ACC TGA TCC GTC CAC AAA CA - 3' \\
\hline TIMP-2 & 5'- CAA GTT CTT CGC CTG CAT CAA - 3' & 5'- TCG AAA CCC TTG GAG GCT T - 3' \\
\hline
\end{tabular}

\section{Análise estatística}

Os dados da foram analisados por meio do programa estatístico Graph Pad Prism 5.01 (Graph Pad Software In., San Diego, CA, EUA). Para os resultados da avaliação histopatológica foi empregado teste $t$ de Student. Os resultados do RT-qPCR foram analisados por meio da ANOVA, seguida do pós-teste de Tukey. Os dados foram apresentados como a média e erropadrão da média. O nível de significância adotado foi de $5 \%$. 


\section{RESULTADOS}

\section{Da avaliação histopatológica}

A pasta Trimix induziu a formação de tecido reacional espesso com resposta inflamatória exuberante, formação de tecido de granulação apresentando densa rede de vasos sanguíneos congestos e grande quantidade de células inflamatórias, com predomínio de neutrófilos polimorfonucleares em todos os períodos. O grupo Calen (controle), aos 7 dias, apresentou tecido reacional moderadamente espesso, com predomínio de células inflamatórias do tipo leucócitos polimorfonucleares. Aos 21 e 63 dias, foram observadas poucas células inflamatórias do tipo linfomononucleares, presença de fibroblastos dispostos entremeados por numerosas fibras colágenas, que se apresentavam de forma organizada, indicando reparo (Figura 1).

Em relação ao número de células inflamatórias (Figura 2), houve diferença estatisticamente significante entre os grupos Trimix e Calen aos 7, 21 e 63 dias, com o grupo Trimix apresentando maior número de células inflamatórias em todos os períodos $(p<0,05)$. 0 número de células inflamatórias no grupo Calen diminuiu com o tempo $(p<0,05)$, o que não ocorreu com o grupo Trimix ( $p>0,05)$.

Considerando o número de vasos sanguíneos (Figura 3), não houve diferença entre os grupos Trimix e Calen nos 3 períodos experimentais $(p>0,05)$. Quando analisada a área dos vasos sanguíneos, houve diferença entre os grupos Trimix e Calen $(p<0,05)$ nos períodos de 7 , 21 e 63 dias, havendo a presença de vasos mais calibrosos no grupo Trimix (Figura 4) e consequentemente maior densidade vascular $(p<0,05)$ como mostrado na Figura 5.

Foi também realizada a avaliação do diâmetro e perímetro dos vasos a partir dos resultados da área vascular, obtendo-se as mesmas diferenças encontradas na comparação da área e densidade vascular (dados não mostrados). 


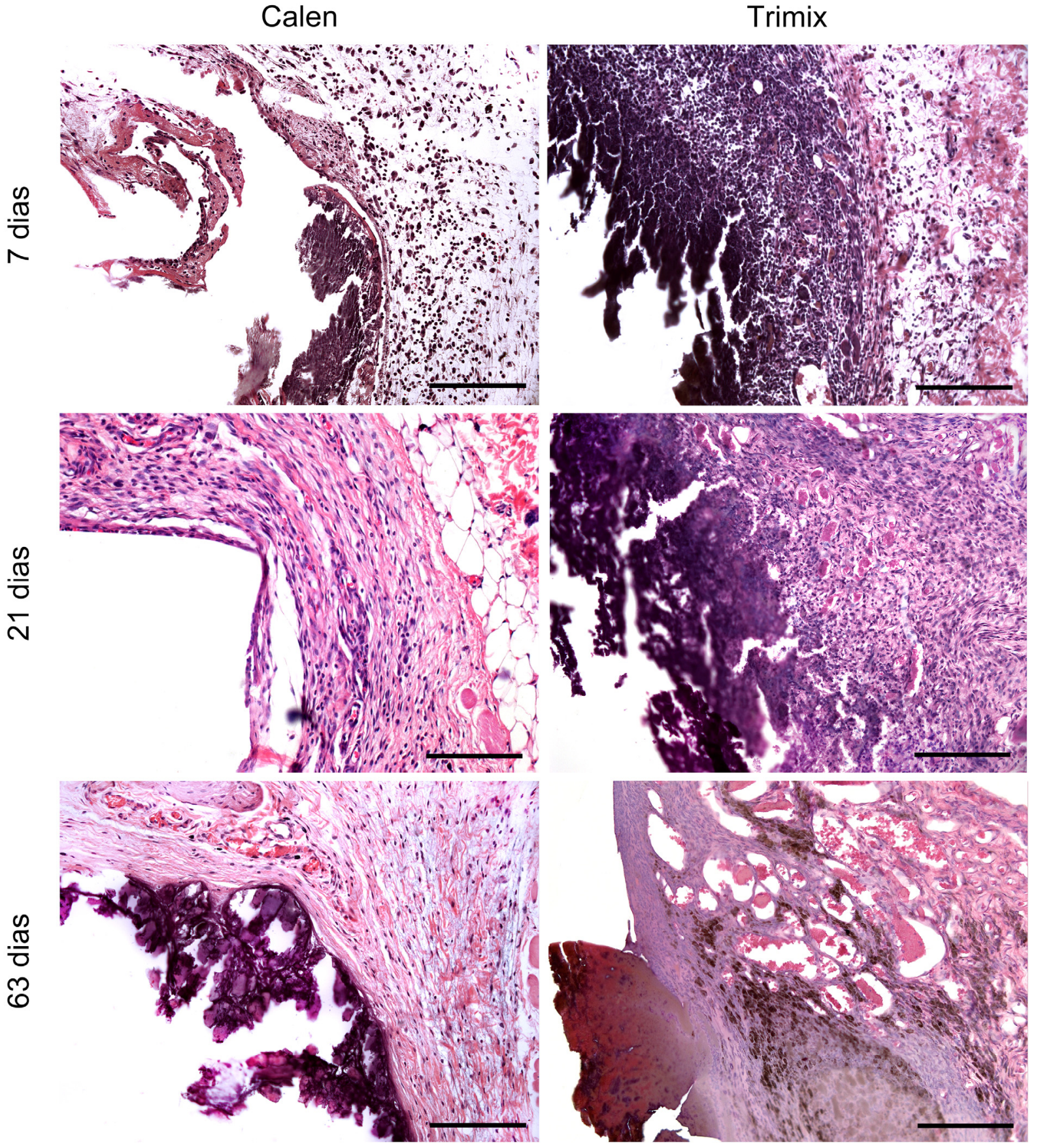

Figura 1 - Aspectos microscópicos da resposta do tecido conjuntivo subcutâneo de camundongos às pastas Calen e Trimix nos períodos de 7, 21 e 63 dias. (Hematoxilina e eosina; barra =

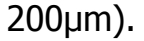




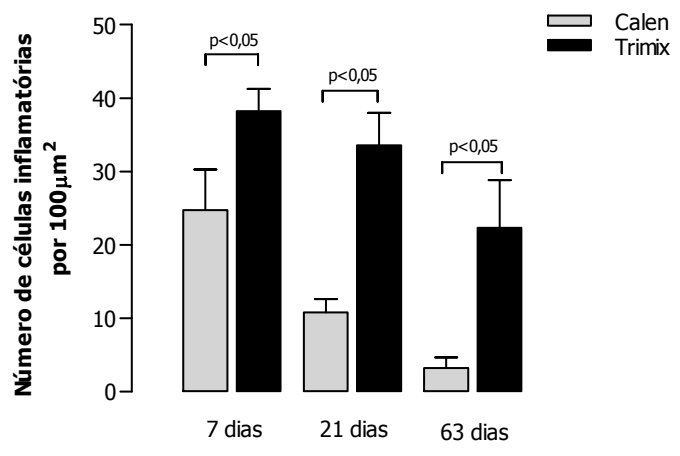

Figura 2 - Comparação do número de células inflamatórias 7, 21 e 63 dias após a implantação dos tubos nos grupos Calen e Trimix.

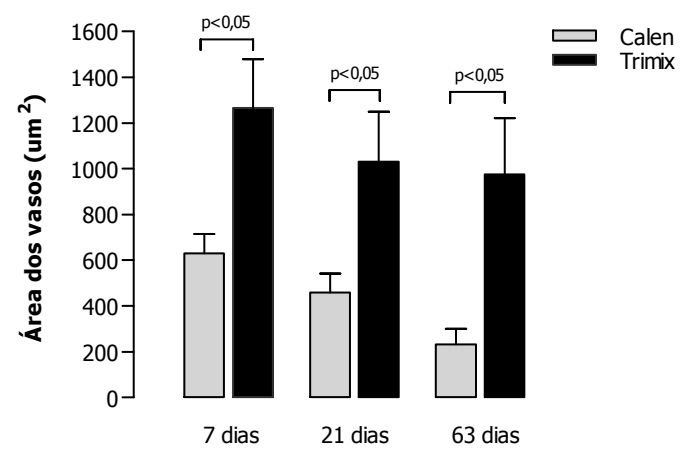

Figura 4 - Comparação da área dos vasos 7, 21 e 63 dias após a implantação dos tubos nos grupos Calen e Trimix.

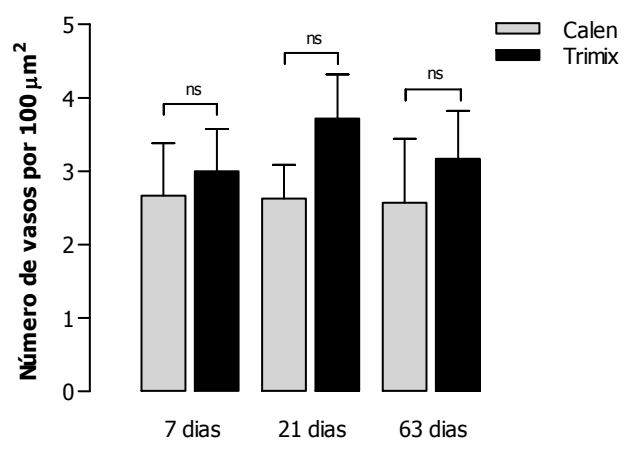

Figura 3 - Comparação do número de vasos 7, 21 e 63 dias após a implantação dos tubos nos grupos Calen e Trimix. ns = não significante.

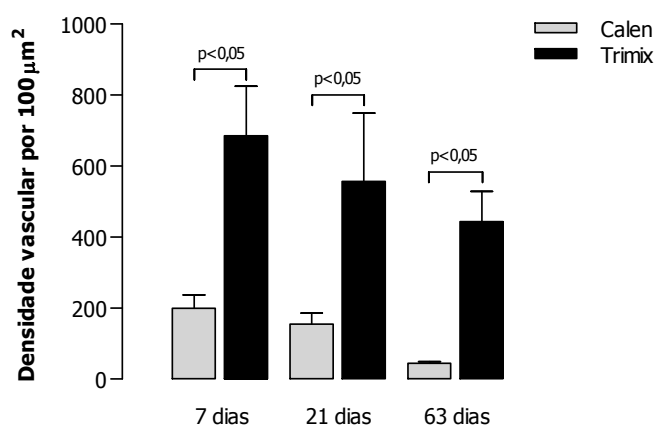

Figura 5 - Comparação da densidade vascular 7, 21 e 63 dias após a implantação dos tubos nos grupos Calen e Trimix.

Em relação ao colágeno, aos 7 dias o grupo Trimix apresentou maior percentual relativo de colágeno por área comparado ao grupo Calen $(p<0,05)$. Aos 21 e 63 dias, o grupo Trimix apresentou menor quantidade de colágeno que o grupo Calen $(p<0,05$ e $p<0,0001$, respectivamente). Houve aumento da colagenização de forma estatisticamente significativa e progressiva no grupo Calen a partir de 21 dias $(p<0,05)$, por meio da deposição de colágeno fino do tipo III, seguido de colágeno denso do tipo I. Contrariamente, a porcentagem de colágeno por área diminuiu no grupo Trimix do período de 7 para 21 dias $(p<0,05)$, como mostrado na Figura 6. 


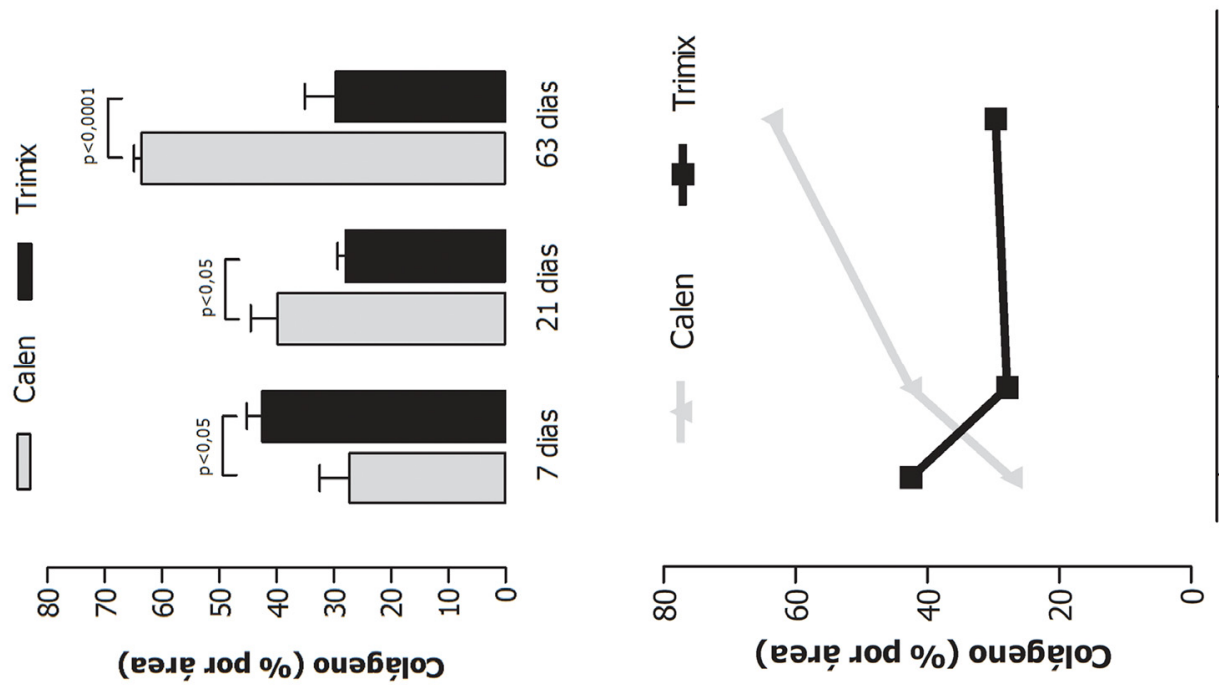

ำ ำ

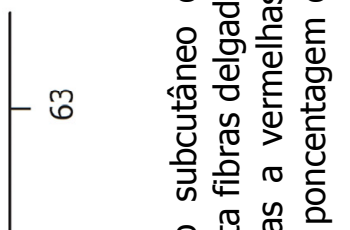

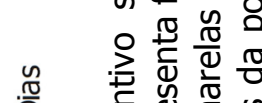

西

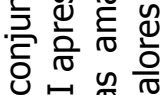

记 蚝

은 은 눙 음

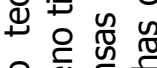

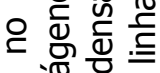

중 $\frac{\pi}{8}$ ต

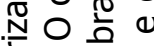

䒕 0 는

즘 웜

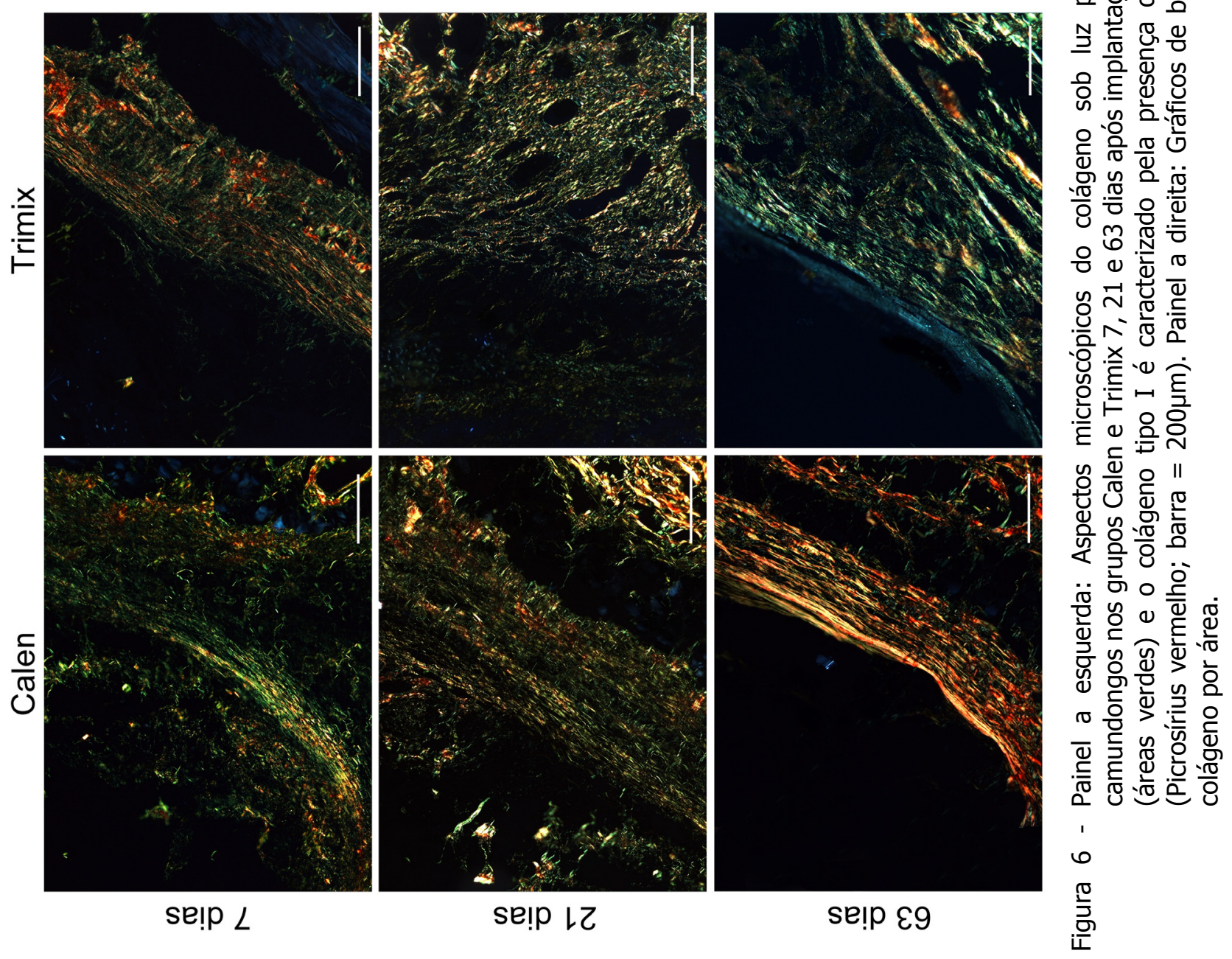




\section{Do RT-qPCR}

Os resultados da análise da expressão de RNAm dos genes relacionados à resposta imuno-inflamatória e angiogênese por meio do RT-qPCR (Figuras 7 e 8) revelaram que, nos dois períodos estudados, todos os genes foram expressos similarmente nos grupos tubo vazio e Calen ( $p>0,05)$, com exceção da MMP-2 aos 7 dias e MMP-9 aos 21 dias $(p<0,05)$.

Aos 7 dias, houve maior expressão dos genes IL-1 $\beta$, TNF-a, IL-17, TGF- $\beta$, HIF-1a, VEGF e TIMP-1 no grupo Trimix $(p<0,05)$ em comparação aos grupos que receberam tubos contendo Calen ou tubo vazio. Neste período não houve diferença na expressão do gene MMP-9 entre os grupos Calen e Trimix ( $p>0,05)$, mas no grupo Trimix a expressão foi superior comparado ao grupo tubo vazio $(p<0,05)$. A expressão de MMP-2 foi superior no grupo Calen comparado ao Trimix e ao tubo vazio $(p<0,05)$, enquanto que TIMP-2 apresentou expressão superior no grupo Calen em comparação ao Trimix, o qual não apresentou diferença do grupo tubo vazio $(p>0,05)$.

Aos 21 dias, a expressão de IL-1ß, IL-17, HIF-1a e MMP-2 foi estatisticamente maior no grupo Trimix em relação a pasta Calen e àqueles animais que receberam o tubo vazio $(p<0,05)$. Contrariamente MMP-9 apresentou expressão superior no grupo Calen comparado à pasta Trimix e tubo vazio $(p<0,05)$. O gene TIMP-1 foi expresso sem diferença nos grupos Calen e Timix $(p>0,05)$ e de forma inferior em relação ao grupo que recebeu tubo vazio comparado ao grupo Trimix $(p<0,05)$. Com relação aos genes VEGF, TNF-a, TGF- $\beta$ e TIMP-2, não houve diferença da expressão nos animais que receberam quaisquer intervenções $(p>0,05)$.

Considerando apenas o grupo Calen, os genes IL-1 $\beta$, TGF- $\beta$, HIF-1a e TIMP-2 foram expressos sem diferença estatisticamente significante nos dois períodos avaliados $(p>0,05)$. No período de 21 dias, observou-se aumento na expressão dos genes IL-17, VEGF e MMP-9 $(p<0,05, p<0,05$ e $p<0,0001$, respectivamente). Por outro lado, houve redução da expressão de TNF-a, MMP-2 e TIMP-1 aos 21 dias $(p<0,05)$.

No grupo Trimix, houve manutenção de elevada expressão dos genes IL-1 $\beta$ e TGF- $\beta$ entre os dias 7 e 21 ( $p>0,05$ ). Os genes TNF-a, HIF-1a e TIMP-1 apresentaram diminuição de sua expressão aos 21 dias ( $p<0,0001, p<0,0001$ e $p<0,05$, respectivamente); enquanto IL-17, VEGF, MMP-9, MMP-2 e TIMP-2, contrariamente, tiveram expressão aumentada no decorrer dos períodos experimentais ( $p<0,0001, p<0,05, p<0,0001, p<0,0001$ e $p<0,05$, respectivamente). 
IL1- $\beta$

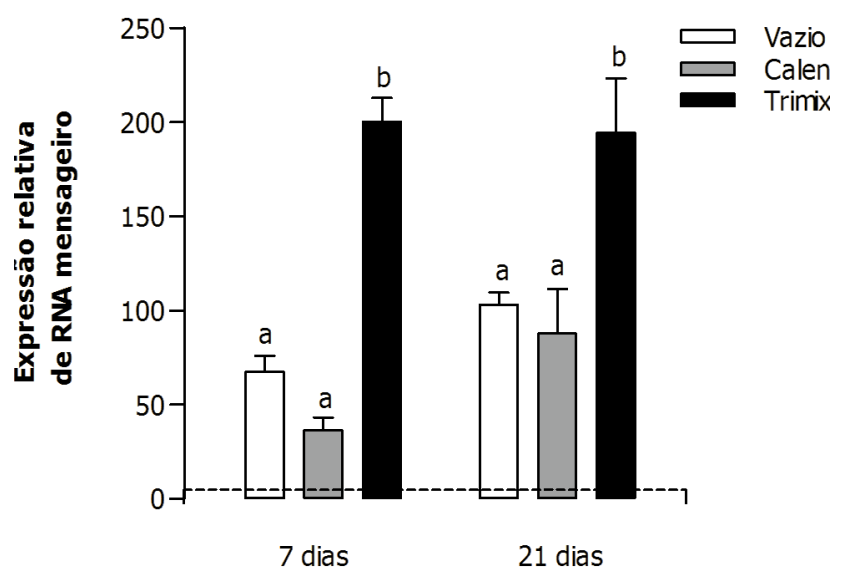

IL-17

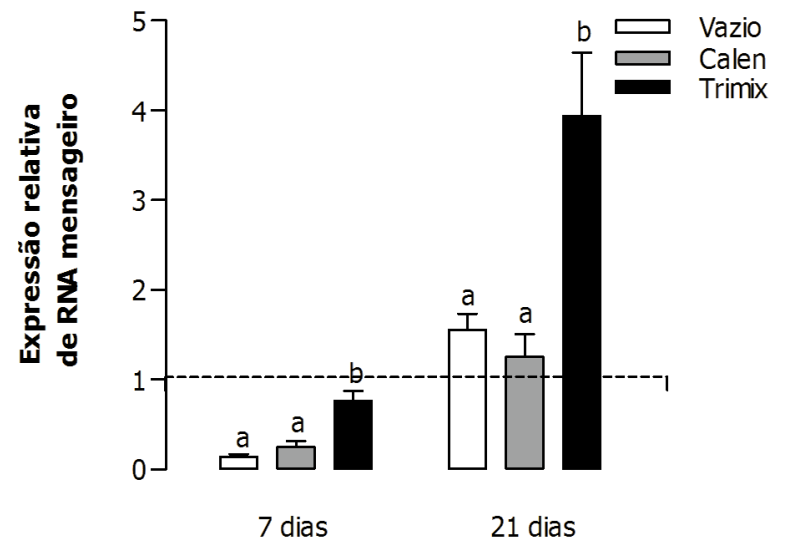

HIF-1 $\alpha$

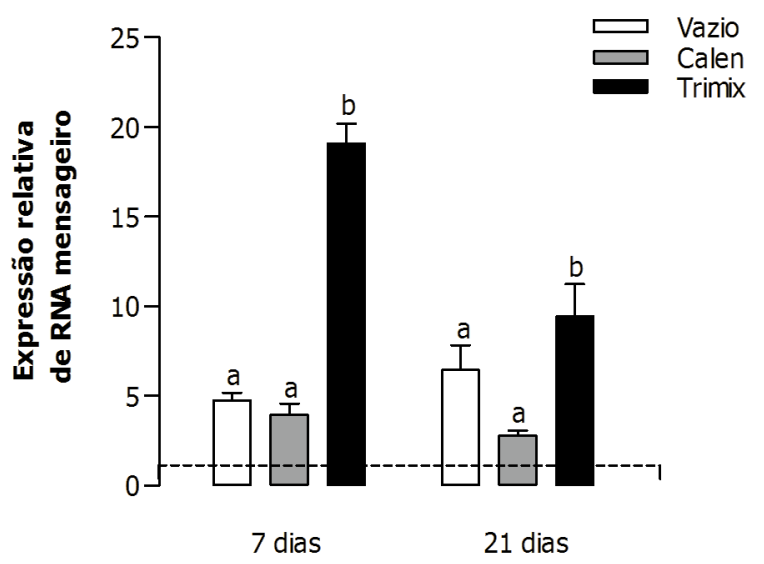

TNF- $\alpha$

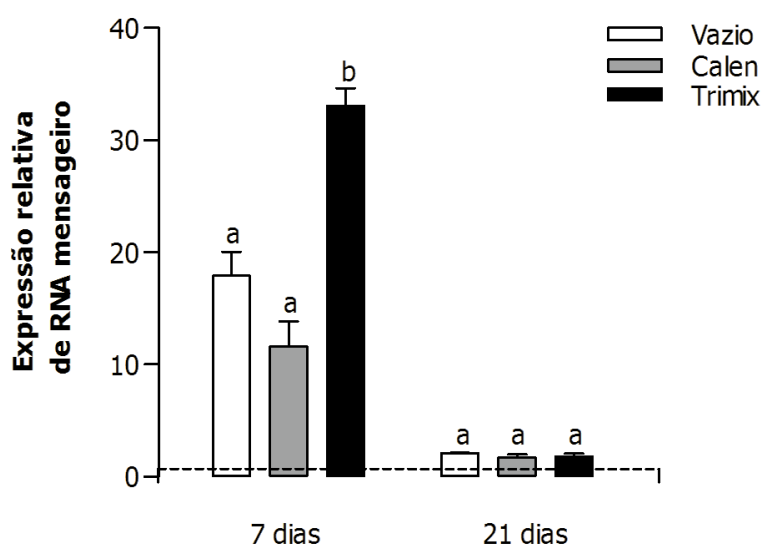

TGF- $\beta$

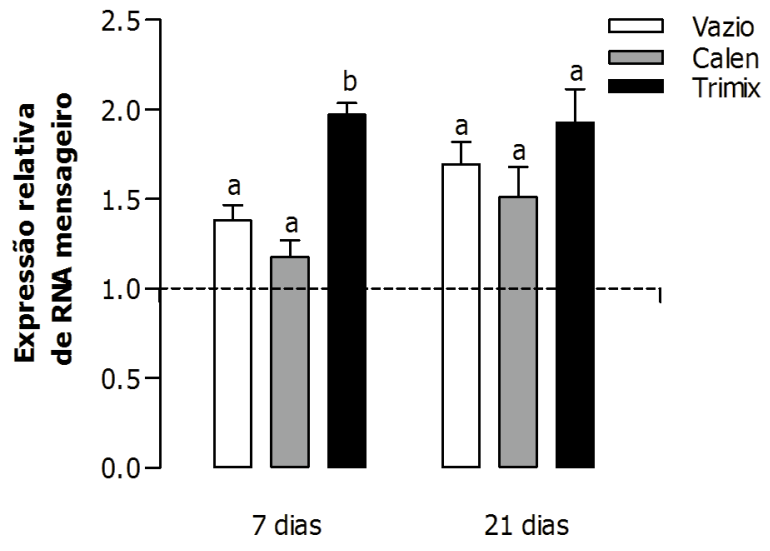

VEGF

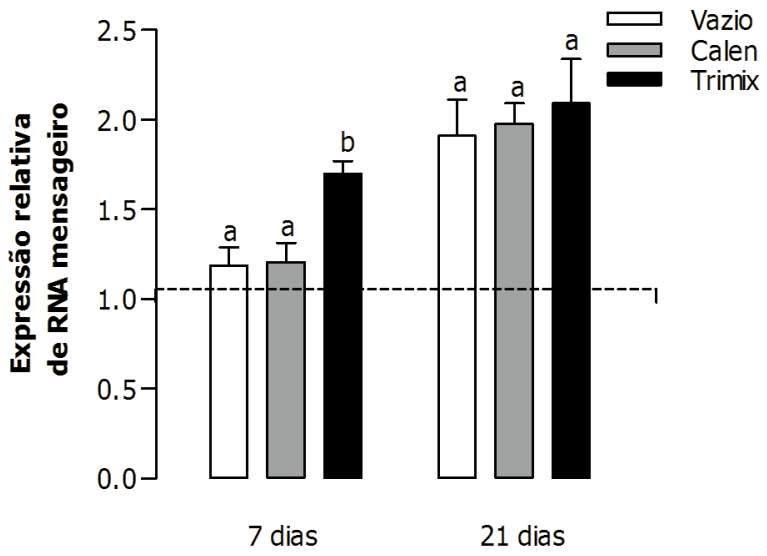

Figura 7 - Comparação da expressão de genes envolvidos na resposta tecidual frente ao tubo vazio, à pasta Calen e à Trimix nos períodos de 7 e 21 dias. Dentro de cada período, diferenças estatísticas foram representadas por letras diferentes. A linha tracejada corresponde à média da expressão gênica do controle adicional (sem implante) nos períodos avaliados. 
MMP-2

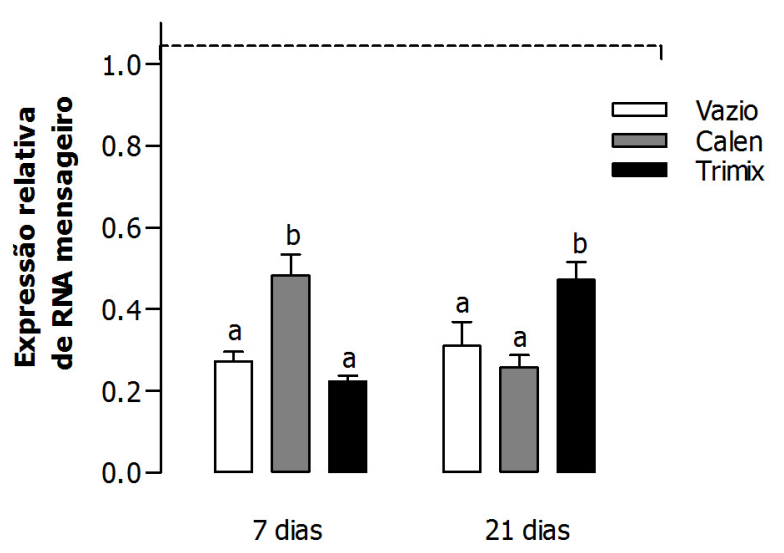

TIMP-1

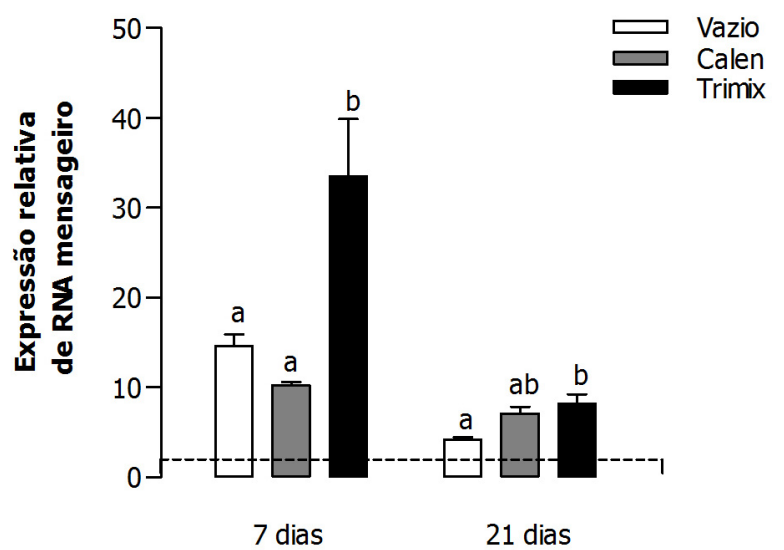

MMP-9

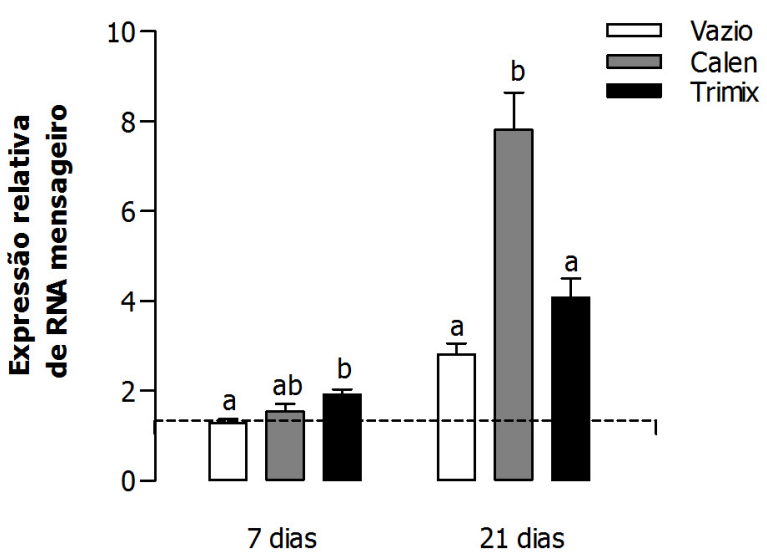

TIMP-2

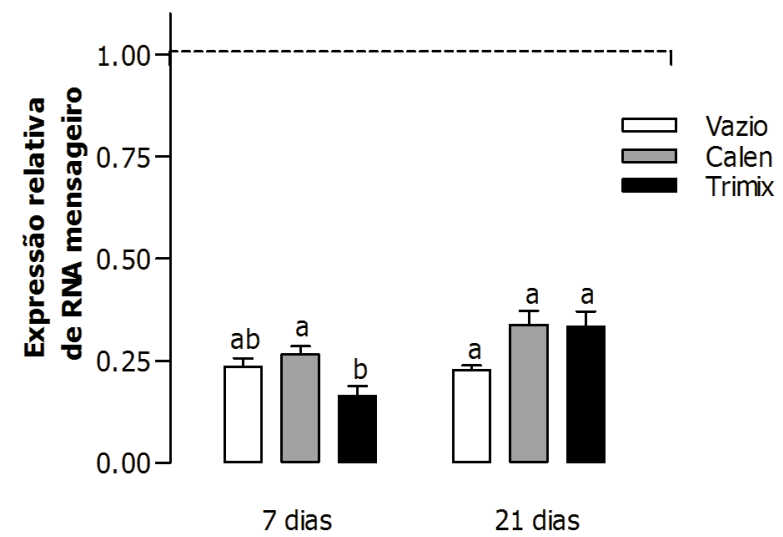

Figura 8 - Comparação da expressão de genes envolvidos na resposta tecidual frente ao tubo vazio, à pasta Calen e à Trimix nos períodos de 7 e 21 dias. Dentro de cada período, diferenças estatísticas foram representadas por letras diferentes. A linha tracejada corresponde à média da expressão gênica do controle adicional (sem implante) nos períodos avaliados.

Analisando a relação MMP-2 e TIMP-2, nos dois períodos avaliados, os resultados monstraram que no grupo Calen houve redução progressiva de MMP-2 $(p<0,05)$, ao passo que a expressão de TIMP-2 sofreu aumento, embora não estatisticamente significante. No grupo Trimix, percebeu-se um aumento progressivo tanto da expressão MMP-2 quanto de TIMP-2 com o decorrer do tempo $(p<0,05)$. Quando analisada a expressão de MMP-9 e TIMP-1, os resultados determinaram relação inversamente proporcional das expressões destes genes nos grupos Calen e Trimix, ou seja, houve aumento progressivo de MMP-9 ( $<<0,0001)$ e redução de TIMP $1(p<0,05)$ com o tempo. Estes resultados podem ser mais bem observados nas Figuras 912. 
Calen

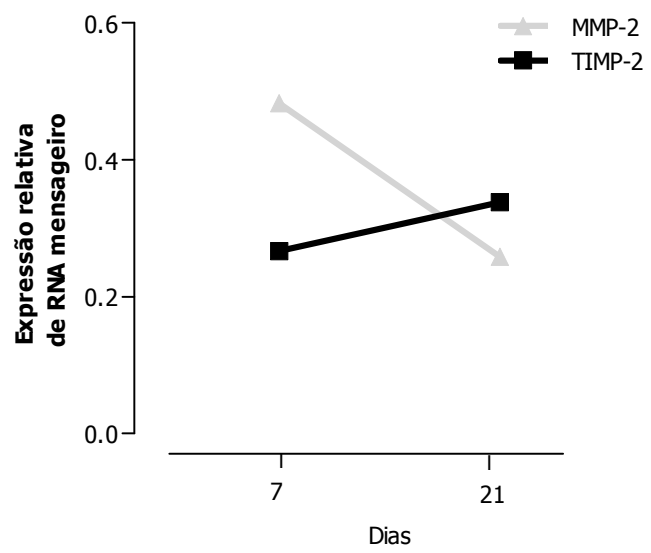

Figura 9 - Relação da expressão de MMP-2 e TIMP-2 frente à pasta Calen nos períodos de $7 \mathrm{e}$ 21 dias.

Trimix

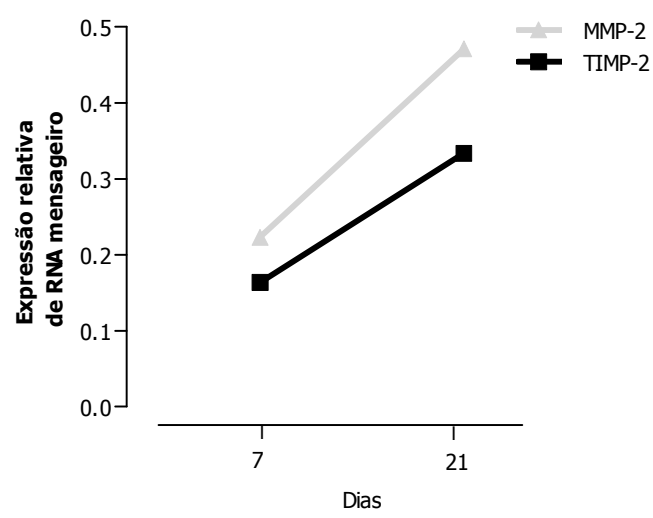

Figura 11- Relação da expressão de MMP-2 e TIMP-2 frente à pasta Trimix nos períodos de $7 \mathrm{e}$ 21 dias.

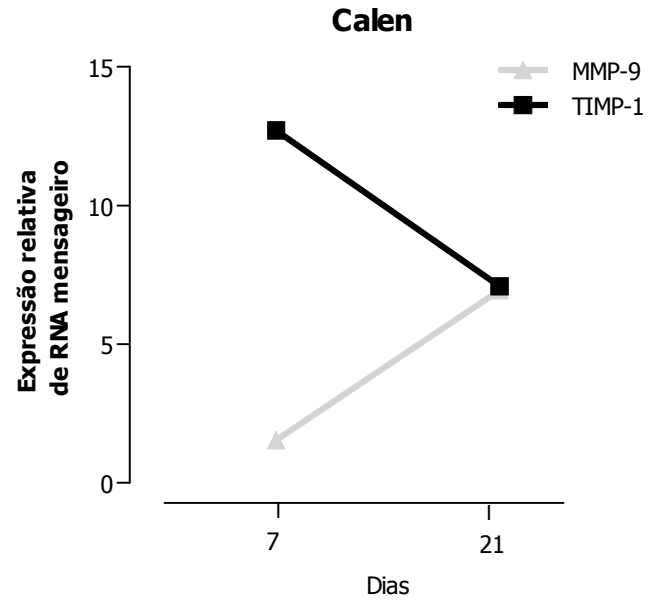

Figura 10 - Relação da expressão de MMP-9 e TIMP-1 frente à pasta Calen nos períodos de $7 \mathrm{e}$ 21 dias.

Trimix

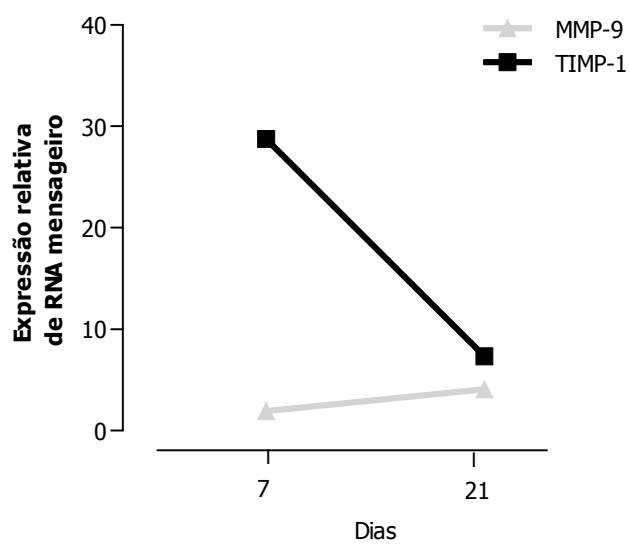

Figura 12 - Relação da expressão de MMP-9 e TIMP-1 frente à pasta Trimix nos períodos de $7 \mathrm{e}$ 21 dias.

\section{DISCUSSÃo}

\section{Do modelo experimental utilizado}

Este estudo foi realizado com base na norma ISO 10993-6 (2007) que descreve o método para comparação da resposta biológica de substâncias implantadas no tecido subcutâneo de animais, com o objetivo de caracterizar a evolução da resposta tecidual frente aos materiais avaliados. Os efeitos locais são avaliados por meio da comparação da resposta tecidual induzida pelo material-teste e pelo material-controle, que por sua vez deve apresentar biocompatibilidade e aceitabilidade clínica. Deste modo, os efeitos locais desencadeados pelos 
espécimes teste, neste trabalho representado pela pasta Trimix, foram comparados à resposta tecidual induzida pelos espécimes controle, a pasta Calen, a qual possui características de biocompatibilidade bem estabelecidas (Leonardo et al., 1993; Nelson-Filho et al., 1999; Delgado, 2002), além de aceitabilidade clínica (Faria et al., 2004; Faria et al., 2005; Leonardo, 2005; Nelson-Filho et al., 2006).

O método de implantação de materiais no tecido subcutâneo de animais é classificado como teste secundário para avaliação da resposta tecidual de materiais endodônticos, sendo largamente utilizado e aceito (Olsson et al., 1981). No presente estudo, optou-se por este tipo de avaliação devido à escassez de estudos avaliando a resposta biológica da pasta Trimix em diferentes períodos de tempo (Scarparo et al., 2011; Gomes-Filho et al., 2012) e, também, devido ao seu uso clínico como medicação intracanal estar baseado essencialmente em relatos de sucesso de casos clínicos (Banchs e Trope, 2004; Jung et al., 2008; Akgun et al., 2009; Bose et al., 2009; Ding et al., 2009; Leung, 2010; Petrino et al., 2010; Nosrat et al., 2011; Torabinejad e Turman, 2011), sem comprovações científicas do seu papel na biologia tecidual.

Animais de diversas espécies podem ser utilizados nestes testes, como cão, coelho, rato e camundongo, entre outros. Porém, o camundongo é o mais utilizado e o mais conhecido cientificamente (Chorilli et al., 2007), devido principalmente ao fato de ser mamífero, pequeno, muito prolífero, ter período de gestação curto, ser de fácil domesticação e manutenção (Santos, 2002), além de apresentar os mesmos sistemas e órgãos que os humanos (Willis-Owen e Flint, 2006). Do mesmo modo que Silva et al. (2009) e Queiroz et al. (2011), no presente trabalho foram utilizados camundongos isogênicos machos, devido ao ciclo hormonal das fêmeas que poderia interferir nos resultados. Ademais, os animais tiveram a mesma origem e padrões de idade, peso e saúde semelhantes, possibilitando resposta biológica homogênea ao mesmo estímulo.

Para acondicionamento das pastas avaliadas, optou-se pelo tubo cilíndrico de polietileno, baseado na literatura que mostra biocompatibilidade deste material (Torneck, 1966; 1967; Olsson et al., 1981; Garcia et al., 2008; Silva et al., 2009; Queiroz et al., 2011; GomesFilho et al., 2012), sendo, portanto, largamente empregado e aceito em protocolos para testes de resposta biológica em tecido subcutâneo de camundongos. Os tubos utilizados possuíam $10 \mathrm{~mm}$ de comprimento por $1,5 \mathrm{~mm}$ de diâmetro interno e apenas uma das extremidades abertas, com o objetivo de simular as condições do canal radicular e permitir o contato do material testado com o tecido conjuntivo subcutâneo. Desta forma, foi possível estabelecer a 
quantidade do material a ser implantada e, ao mesmo tempo, limitar e padronizar a área para análise da resposta biológica, favorecendo condições similares para comparação (Cintra et al., 2010).

Os períodos avaliados neste estudo foram de 7, 21 e 63 dias (Silva et al., 2009; Queiroz et al., 2011). Conforme a norma ISO 10993-6 (2007), para teste de implantação de curta duração, os períodos testes devem ser determinados de acordo com o tempo de exposição clínica, variando de 1 até 4 semanas, e ser continuados até alcançado um estado de equilíbrio no que diz respeito à resposta biológica, aproximadamente por volta de 9 semanas. Assim, no presente estudo, foram determinados os períodos de 7 e 21 dias por serem mais comumente encontrados na literatura para o tempo de permanência da pasta Trimix nos canais radiculares (Jung et al., 2008; Ding et al., 2009; Petrino et al., 2010; Nosrat et al, 2011), sendo continuado até ser alcançado um estado de equilíbrio da população celular, aos 63 dias.

\section{Da avaliação histopatológica}

O objetivo inicial do presente estudo foi caracterizar a resposta do tecido conjuntivo subcutâneo de camundongos frente à pasta Trimix. Observou-se que a pasta Trimix ocasionou em todos os períodos avaliados resposta inflamatória de grande intensidade, caracterizada por grande infiltrado inflamatório composto principalmente de neutrófilos e células linfomononucleares, resposta angiogênica exacerbada e deposição insatisfatória de colágeno, denotando agressão tecidual mesmo aos 63 dias. Apesar de ter apresentado número de vasos sanguíneos semelhante ao grupo Calen $(p>0,05)$, as áreas vasculares e, consequentemente, a densidade vascular apresentaram-se maiores no grupo Trimix $(p<0,05)$. Paralelamente, enquanto no grupo Trimix as áreas dos vasos e densidade vasculares permaneceram semelhantes nos três períodos avaliados neste estudo ( $p>0,05)$; no grupo Calen, houve diminuição progressiva das áreas vasculares e da densidade vascular $(p<0,05)$. Estes resultados direcionam para o fato de que, nos períodos iniciais, a inflamação induz resposta angiogênica, produzindo tecido de granulação que pode ter evolução diferente: (1) no caso da pasta Calen, acredita-se que a neoformação vascular forneceu oxigênio, nutrientes e leucócitos para a área lesada, favorecendo a reparação tecidual e posteriormente ocorreu a regressão vascular; (2) em contrapartida, frente à continuidade da irritação tecidual provocada pela Trimix, provavelmente houve manutenção da ativação leucocitária e liberação contínua de citocinas e enzimas proteolíticas, levando à persistência da reposta inflamatória e à excessiva angiogênese (Arroyo e Iruela-Arispe, 2010). 
Também foi evidenciada a diminuição da quantidade de colágeno no grupo Trimix do período de 7 para 21 dias $(p<0,05)$. Contrariamente, foi evidenciada a deposição de colágeno a partir dos 21 dias no grupo Calen $(p<0,05)$. Sabe-se que a deposição do colágeno após uma lesão é um marco do reparo tecidual. Tem sido demonstrado que as fibras que compõem a área reparada são inicialmente compostas de colágeno do tipo III (fibras finas), sendo substituído por colágeno tipo I, composto por fibras densas (Junqueira et al., 1973; Vaz et al., 2009). Os dois padrões distintos de colágeno foram visualizados, sendo que as fibras se tornaram espessadas, mudando de verde (Tipo III) para amarelo/vermelho (tipo I) com o decorrer do tempo, mostrando a evolução do reparo tecidual no grupo Calen, mas não no grupo Trimix.

Estes achados mostram persistência de irritação tecidual que pode ter culminado em reação inflamatória persistente e retardo no processo do reparo em função do tempo em comparação à pasta Calen.

Os resultados do presente trabalho confirmam especulações de que a Trimix seria tóxica aos tecidos, uma vez que dentes de cães com rizogênese incompleta e lesão periapical, tratados com a Trimix não apresentaram revascularização do canal radicular (Wang et al., 2010) e mostraram infiltrado inflamatório mais intenso e retardo no reparo quando comparado com o grupo sem o uso da Trimix (Silva et al., 2010).

Em estudo radiográfico e histológico em dentes de ratos com rizogênese incompleta e lesão periapical no qual foi usada a Trimix como medicação intracanal, foi observada redução significante da lesão periapical, aumento do comprimento da raiz e da espessura das paredes radiculares. Entretanto, a avaliação histológica mostrou reposta inflamatória variável frente à pasta Trimix, mesmo após 6 semanas. Em alguns espécimes, houve formação parcial de tecido conjuntivo e tecido semelhante ao cemento na porção radicular apical e superfície externa da raiz. Outros apresentaram infiltrados inflamatórios leves e ausência de formação de tecido mineralizado no ápice radicular. Paralelamente, alguns animais apresentaram formação de cemento somente sobre a superfície radicular externa e distante da abertura apical e intenso infiltrado inflamatório (Scarparo et al., 2011), como evidenciado no presente estudo.

Contrariamente aos nossos resultados, estudo recente (Gomes-Filho et al., 2012), mostrou no tecido conjuntivo subcutâneo de ratos que a Trimix, proporcionou nos períodos de 7 e 15 dias, moderada infiltração de células inflamatórias crônicas, linfócitos e macrófagos, presentes em uma cápsula fibrosa. A resposta tecidual da Trimix ocorreu de forma semelhante 
à pasta de $\mathrm{Ca}(\mathrm{OH})_{2}$ e ao controle (tubo vazio). Nos períodos de 30, 60 e 90 dias, houve redução da intensidade da inflamação, com presença de cápsula fibrosa fina e raras células inflamatórias para o grupo Trimix, pasta de $\mathrm{Ca}(\mathrm{OH})_{2}$ e controle. Estes autores concluíram que a Trimix foi biocompatível nos diferentes períodos avaliados.

A divergência de resultados talvez se deva a diferentes concentrações dos antibióticos e aos veículos utilizados na pasta Trimix. Isto porque Gomes-Filho et al. (2012) utilizaram quantidades iguais de ciprofloxacino $200 \mathrm{mg}$, metronidazol 500mg e minociclina $100 \mathrm{mg}$, juntamente com macrogol e propilenoglicol (Trope, 2008). No presente estudo, a pasta Trimix consistiu na mistura de partes iguais de ciprofloxacino, metronidazol e minociclina, nas concentrações de 200mg cada um, com água destilada esterilizada (Reynolds et al., 2009; Cohenca et al., 2010; Silva et al., 2010). Considerando que a citotoxidade destes antibióticos é dose-dependente (Ferreira et al., 2010) e que apenas a minociclina apresenta maior concentração no presente estudo, é no mínimo intrigante a diferença dos resultados. A princípio, estes dados geram a suposição de que talvez a minociclina seria a responsável pela agressividade tecidual evidenciada no presente estudo. No entanto, esta suposição não é amparada pela literatura, pois tem sido demonstrado que além da ação antimicrobiana, a minociclina apresenta atividade anti-inflamatória por meio da inibição de MMPs e também efeito antiapoptótico (Soory, 2008).

Outra consideração seria em relação aos veículos utilizados. Enquanto os veículos viscosos, macrogol (nomenclatura internacional do polietileno glicol) e proprilenoglicol, foram utilizados por Gomes-Filho et al. (2012), no presente estudo, foi utilizada a água destilada esterilizada, ou seja, veículo aquoso. Sabe-se que o veículo pode interferir na resposta tecidual das pastas endodônticas, como ocorre na própria pasta Calen, em que a resposta tecidual satisfatória pode ser atribuída pelo menos em parte ao seu veículo, o polietileno glicol 400, o qual libera íns de hodrogênio $\left(\mathrm{H}^{+}\right)$que interagem com grupo hidroxila $\left(\mathrm{OH}^{-}\right)$do $\mathrm{Ca}(\mathrm{OH})_{2}$, reduzindo a área de necrose superficial decorrente de sua alcalinidade (Nelson-Filho et al., 1999). Desta forma, a diferença dos veículos utilizados poderia ser o motivo para os resultados.

A importância em se conhecer a compatibilidade biológica de materiais endodônticos se deve do fato de que, se estes materiais forem demasiadamente irritantes aos tecidos, causarem inflamação de maior porte ou promoverem necrose tecidual de maior extensão, todo o tratamento endodôntico será prejudicado e, como consequência, a capacidade de reparação tecidual sofrerá interferências significativas (Nassri et al., 2003). 
Desta forma, pelo exposto, os resultados do presente estudo mostraram resposta biológica insatisfatória da pasta Trimix comparada à pasta Calen. Ademais, apesar de a associação de antibióticos diminuir a ocorrência do desenvolvimento de cepas bacterianas resistentes (Ding et al., 2009), a possibilidade de ocorrer resistência bacteriana foi relatada (Greenstein e Polson, 1998). Além disso, os componentes da pasta Trimix podem desencadear reação alérgica (Bhalla et al., 2007), e a minociclina está relacionada à descoloração da coroa dentária (Windley et al., 2005; Reynolds et al., 2009; Kim et al., 2010). Estes efeitos colaterais biológicos e clínicos, associados aos resultados do presente estudo, que monstraram a ocorrência de resposta inflamatória aguda e persistente, fornecem indícios de que a pasta Trimix não deveria ser empregada como medicação intracanal.

\section{Do RT-qPCR}

É possível que a manutenção da ativação leucócitária no local da implantação dos tubos com pasta Trimix tenha levado à liberação crônica de citocinas e enzimas proteolíticas (Arroyo e Iruela-Arispe, 2010), perpetuando assim o dano tecidual em detrimento ao reparo.

Em função disso, o presente estudo objetivou complementar os resultados da avaliação histopatológica nos períodos de 7 e 21 dias, que correspondem aos tempos mais indicados para permanência clínica da pasta Trimix nos canais radiculares como medicação (Jung et al., 2008; Ding et al., 2009; Petrino et al., 2010; Nosrat et al., 2011). Por meio do RT-qPCR, foram determinadas in vivo as expressões relativas de RNA mensageiro dos biomarcadores relacionados ao processo inflamatório e à angiogênese promovidos pela interação do hospedeiro com as pastas Calen e Trimix.

No presente estudo, não houve diferença entre os grupos tubo vazio e Calen na expressão de todos os genes avaliados nos dois períodos estudados, exceto para MMP-2 aos 7 dias e MMP-9 aos 21 dias. Conhecendo, por meio de estudos prévios, a compatibilidade biológica do tubo de polietileno (Torneck, 1966; 1967; Olsson et al., 1981; Garcia et al., 2008; Semenoff et al., 2008; Silva et al., 2009; Danesh et al., 2010; Queiroz et al., 2011; Gomes-Filho et al., 2012) e da pasta Calen (Leonardo et al., 1993; Nelson-Filho et al., 1999; Delgado, 2002), esta última confirmada pela avaliação histopatológica no presente estudo, acredita-se que o padrão de respostas moleculares observado no grupo Calen seja o ideal e necessário para direcionar a ocorrência do reparo.

Comparando com o grupo Calen, a pasta Trimix induziu maior expressão de IL-1ß aos 7 e 21 dias. A intensa e estável expressão de IL-1ß pelo grupo Trimix corrobora com os achados 
histopatológicos que monstraram reação inflamatória grave e persistente, acompanhada por resposta angiogênica exuberante. A IL-1ß é considerada uma das principais citocinas próinflamatórias e pró-angiogênica. Sua função principal é mediar a resposta inflamatória frente a diferentes estímulos (Thornton et al., 2000; Naldine e Carraro, 2005; Abbas et al., 2008; Carmi et al., 2009). Assim, o estímulo químico, representado neste estudo pela pasta Trimix, desencadeou uma superexpressão de IL-1ß e, subsequentemente, indução de uma rede de citocinas, quimiocinas e de mediadores inflamatórios. A principal fonte celular de IL-1 $\beta$ são fagócitos mononucleares ativados. Entretanto, a IL-1 $1 \beta$ também é produzida por muitos tipos celulares que não os macrófagos, tais como neutrófilos, células epiteliais e endoteliais (Dinarello, 1996; Naldini e Carraro, 2005; Apte et al., 2006; Abbas et al., 2008; Dinarello, 2009). Assim, supõe-se que a manutenção de expressão aumentada no grupo Trimix pode ter sido ocasionada pela grande quantidade de neutrófilos observada mesmo no período de 21 dias, além de células linfomononucleares e endoteliais.

Ademais, a IL-1 $1 \beta$ se comporta como um regulador da angiogênese por meio de efeitos diretos (aumentando a proliferação) e indiretos (aumentando a liberação de fatores próangiogênicos por células inflamatórias), principalmente sobre as células endoteliais (Naldini e Carraro, 2005). A maior densidade vascular frente à pasta Trimix pode estar relacionada, pelo menos em parte, à expressão elevada de IL-1ß. Este fato é suportado por estudo prévio que determinou o papel da IL-1 $\beta$ na indução e manutenção da angiogênese, evidenciando que esta citocina desempenha ação essencial na iniciação e propagação angiogênica. Isso porque sua neutralização promoveu redução no recrutamento celular e na angiogênese, bem como ausência da indução de respostas angiogênicas por macrófagos derivados de ratos knockout para IL-1 $\beta$ (Carmi et al., 2009).

O TNF-a também é considerado um importante mediador pró-inflamatório, podendo agir em conjunto com a IL-1 $\beta$ (Wajant et al., 2003; Abbas et al., 2008) e é possível que sua expressão elevada também tenha contribuído para a intensidade da resposta inflamatória frente à pasta Trimix aos 7 dias. A principal fonte celular de TNF-a são os fagócitos mononucleares ativados, e sua ação ocorre por meio de estímulo ao recrutamento e ativação de neutrófilos e monócitos. Estes efeitos são mediados por ações sobre as células do endotélio vascular e leucócitos (Abbas et al., 2008). Relatos prévios sugeriram que o TNF-a está relacionado à angiogênese (Naldini e Carraro, 2005; Sethi et al., 2008). Sua atuação seria pela inibição direta da proliferação de células endoteliais, mas indiretamente aumentaria a angiogênese por meio 
do recrutamento e ativação de macrófagos (Naldini e Carraro, 2005). Entretanto, foi demonstrado que diferentemente da $\mathrm{IL}-1 \beta$, sua neutralização não alterou o processo de angiogênese (Carmi et al., 2009), o que corrobora com a manutenção de maior área e densidade vascular no grupo Trimix aos 21 dias, mesmo com a redução significativa da expressão de TNF-a.

Assim, a intensa expressão de IL-1ß, no grupo Trimix, nos dois períodos avaliados e de TNF-a aos 7 dias, suportam a ocorrência da iniciação e perpetuação de processo inflamatório grave e angiogênese exuberante.

Recentemente, a IL-17 tem sido intensamente pesquisada, principalmente pelo fato de potencializar o dano tecidual (Abbas et al., 2008; Liang et al., 2010; Schenkein et al., 2010). No presente estudo, pode-se observar expressão tardia (21 dias) de IL-17 no grupo Trimix, o que indica que sua produção provavelmente foi originada de células T CD4+ efetoras, uma vez que células da imunidade inata também são importantes fontes de IL-17 (Liang et al., 2007; Peck e Mellins, 2009; Pelletier et al., 2010; Schenkein et al., 2010). A ação da IL-17 ocorre por meio da ativação de células endoteliais e macrófagos para produção de mais citocinas pró-inflamatórias, como a IL-1 $\beta$, além de várias quimiocinas, as quais promovem recrutamento de neutrófilos (Beklen et al., 2007; Bilate, 2007; Abbas et al., 2008; Fukushima et al., 2010). Dessa forma, a manutenção da expressão de IL-1 $\beta$ aos 21 dias no grupo Trimix pode estar relacionada à ação da IL-17. A IL-17 também induz a produção de citocinas hematopoiéticas, as quais estimulam a produção de neutrófilos pela medula óssea (Abbas et al., 2008), favorecendo a persistência deste tipo celular como evidenciado na análise histopatológica do grupo Trimix. Ainda, é possível que outras citocinas ou quimiocinas relacionadas ao recrutamento de neutrófilos (Bilate, 2007; Abbas et al., 2008) estejam sendo produzidas no local da inflamação, favorecendo o acúmulo inicial dessas células no local de inserção dos tubos com Trimix, anteriormente ao $21^{0}$ dia experimental. A ausência de reparo frente à pasta Trimix pode ter sido influenciada pela expressão tardia de IL-17, pois sua produção por células T favorece a inflamação destrutiva (Abbas et al., 2008).

Frente à lesão tecidual ocorre queda dos níveis de oxigênio - hipóxia (Fraisl et al., 2009; Semenza, 2009). Nesta condição de hipóxia, o HIF-1a regula a expressão de genes envolvidos na glicólise, eritopoiese, angiogênese, proliferação e função celular. Deste modo, visando a homeostase de oxigênio - normóxia, o HIF-1a induz a expressão de citocinas pró-inflamatórias e pró-angiogênicas por células do infiltrado inflamatório (Carmi et al, 2009; Dehne e Brüne, 
2009; Semenza, 2009; Imtiyaz e Simon, 2011). Diante da normóxia, o HIF-1a sofre degradação por meio de hidroxilação dependente de oxigênio (Cramer et al., 2003). De acordo com os resultados obtidos no presente estudo, a agressividade tecidual provocada pela pasta Trimix, aos 7 dias, pode ter influenciado a maior expressão de HIF-1a, o qual, por sua vez, estaria relacionado ao aumento da expressão de IL-1- $\beta$, TNF-a e VEGF. Aos 21 dias, a significante redução do HIF-1a no grupo Trimix pode ser explicada pela maior densidade vascular e consequente homeostase de oxigênio. Por outro lado, a maior expressão de HIF-1a frente à pasta Trimix, mesmo diante da rica área vascular observada na avaliação histopatológica, provavelmente se deve ao fato de que, além da hipóxia, outros estímulos produzidos por citocinas, como IL-1- $\beta$ e TGF- $\beta$, são capazes de induzir acúmulo e transcrição de HIF-1a em normóxia (Thornton et al., 2000; McMahon et al., 2006). Assim, recentemente, tem-se sugerido que o HIF-1a possui um importante e adicional papel na inflamação. Em macrófagos, o HIF-1a não somente regula a geração de energia glicolítica, mas também otimiza a imunidade inata, controla a expressão de genes pró-inflamatórios e influencia a migração celular. Em neutrófilos, o HIF-1a promove sua sobrevivênvia em condições de hipóxia e medeia saída de células inflamatórias dos vasos sanguíneos (Imtiyaz e Simon, 2011).

Em geral, a hipóxia gera sinal inicial para indução de TGF- $\beta$ (Ambalavanan et al., 2008), o que provavelmente contribuiu para sua maior expressão aos 7 dias no grupo Trimix. O TGF- $\beta$ é sintetizado e secretado por células $T$ estimuladas, fagócitos mononucleares ativados, entre outros tipos de células. Sua principal ação é inibir a proliferação e a função efetora de células $T$ e a ativação de macrófagos. Atua também em neutrófilos e células endoteliais, em grande parte para contrapor-se aos efeitos das citocinas pró-inflamatórias. Desta forma, após as repostas imunes e inflamatórias regredirem, o TGF- $\beta$ regula a reparação tecidual, por ações sobre a sístese de colágeno, proteoglicanos e fibronectina e produção de MMPs pelos macrófagos e fibroblastos (Roberts et al., 1992; Abbas et al., 2008). Esta atuação do TGF- $\beta$ foi evidenciada no grupo Calen no qual ocorreu um aumento progressivo de colágeno a partir de 21 dias favorecendo o reparo tecidual.

Entretanto, além de efeitos anti-inflamatórios, o TGF- $\beta$ é capaz de exercer ação próinflamatória. Em combinação com citocinas evocadas durante respostas imunes naturais, como IL-6, IL-1 e IL-23, o TGF- $\beta$ pode promover a diferenciação de um subconjunto pró-inflamatório de células $\mathrm{T} \mathrm{CD4}^{+}$que secretam IL-17. Assim, o TGF- $\beta$ exerce efeitos complexos sobre respostas imunes mediadas por células $T$ (Veldhoen et al., 2006; Dwivedi et al., 2011), os quais 
podem estar relacionados com a reação frente à pasta Trimix, uma vez que a manutenção da lesão tecidual pode ter impedido as ações do TGF- $\beta$ sobre a sístese de colágeno e provavelmente favorecido seu efeito pró-inflamatório.

O VEGF é uma citocina pró-angiogênica que age induzindo a proliferação, diferenciação e migração de células endoteliais. Adicionalmente, induz o aumento da permeabilidade vascular (Ferrara e Davis-Smyt, 1997; Byrne et al., 2005; Takahashi e Shibuya, 2005; Damico, 2007). É expresso por neutrófilos, macrófagos e fibroblastos (Reyes-Carmona et al., 2011) por meio de mecanismo dependente do HIF-1a ou quando estimulado por citocinas e fatores de crescimento, tais como a IL-1 $\beta$, IL-17, TNF-a e TGF- $\beta$. A análise dos dados deste trabalho forneceu evidência de relação positiva entre a expressão de VEGF aos 7 dias no grupo Trimix e estes genes, uma vez que todos apresentaram maior expressão em comparação ao grupo Calen. O VEGF possui efeito pró-inflamatório (Moromizato et al., 2000; Sakurai et al., 2003; Usui et al., 2004), neuroprotetor (Storkebaum e Carmeliet, 2004) e é um fator importante na estabilização e remodelação vascular (Benjamin et al., 1998). Desta forma, sugere-se que a maior expressão de VEGF observada durante a fase inicial da inflamação no grupo Trimix esteja relacionada à gravidade da resposta inflamatória, gerando maior aumento da permeabilidade vascular e da indução de angiogênese. Por outro lado, o aumento progressivo da expressão observada aos 21 dias pode estar relacionado à estabilização e remodelação vascular (Benjamin et al., 1998). 0 VEGF também aumenta a expressão celular de MMPs, que degradam a matriz extracelular e facilitam a penetração dos neovasos no tecido, ao mesmo tempo em que diminui a expressão endotelial dos TIMPs (Leung et al., 1989; Ferrara et al., 1998; Lamoreaux et al., 1998; Hiratsuka et al., 2002). Esta relação pode ser observada aos 21 dias, quando houve relação positiva entre expressão de VEGF e MMP-2, MMP-9 e TIMP-1.

As MMPs são uma família de endopeptidades zinco-dependentes envolvidas no processo de degradação da matriz extracelular (Sternlicht e Werb, 2001; Navarro et al., 2006; Araújo et al., 2011). São estimuladas durante o processo inflamatório podendo atuar como mediadoras da remodelação e reparo tecidual ou provocar debilidade no reparo e dano à matriz extracelular (Curran e Murray, 2000; Sternlicht e Werb, 2001; Accorsi-Mendonça et al., 2008; Kim et al., 2011). São expressas por fibroblastos, neutrófilos e macrófagos, entre outras células (Sternlicht e Werb, 2001; Accorsi-Mendonça et al., 2005), sendo subdivididas de acordo com seu substrato. As MMPs -2 e -9, as quais foram avaliadas no presente estudo, são conhecidas como gelatinases por degradar gelatina, ou seja, o colágeno nativo e o colágeno desnaturado, portanto 
apresentando importante papel na inflamação e angiogênese (Visse e Nagase, 2003). No presente estudo, a expressão de MMP-2 no grupo Calen decresceu com o tempo. Contrariamente, no grupo Trimix, houve aumento de MMP-2 aos 21 dias. Considerando a MMP9, os resultados obtidos determinaram uma expressão tardia desta protease frente às duas pastas avaliadas, sendo esta expressão superior no gupo Calen. Estudo prévio mostrou que a pasta Calen, utilizada como curativo de demora por 15 dias em dentes de cães com necrose pulpar e lesão periapical, promoveu redução da síntese de MMP -2 e -9 (Paula-Silva et al., 2010). Esta ação inibitória do meio rico em cálcio sobre a indução de MMPs foi observada no presente trabalho apenas para a MMP-2 aos 21 dias. Contudo, a maior expressão de MMP-9 frente à pasta Calen observada neste estudo não está associada ao dano tecidual. Sugere-se estar relacionada ao processo de remodelamento e reparo tecidual, caracterizado pelo entrelaçamento e organização da nova matriz colagenosa (Araújo et al., 2011). Porém, deve-se ressaltar que no presente estudo foi avaliada a expressão de RNAm de MMPs e não sua atividade propriamente dita, sendo que estudos posteriores ainda são necessários para confirmar a atividade dessas enzimas no modelo estudado. A menor expressão de MMP-9 pela pasta Trimix também pode estar relacionada à minociclina presente nesta pasta poliantibiótica, uma vez que estudo mostrou que a minociclina pode inibir a expressão de mRNA da MMP-9, mas não da MMP-2 (Yao et al., 2007).

As MMPs são reguladas em vários níveis incluindo transcrição, secreção, ativação e inibição via inibidores teciduais endógenos, os TIMPs (Kim et al., 2011). A expressão destes inibidores é observada durante a remodelação tecidual, sendo que o equilíbrio entre a produção de MMPs e TIMPs representa um ponto crítico na manutenção da homeostasia da matriz extracelular (Navarro et al., 2006; Piotrowski et al., 2009). São expressos por muitos tipos celulares, incluindo fibroblastos, neutrófilos polimorfonucleares, macrófagos e células endoteliais (Howard et al., 1991; Stemankovic, 2003), possuindo atividade mitogênica para vários tipos celulares (Gomez, 1997). Os TIMPs dos tipos 1 (TIMP-1) e 2 (TIMP-2) apresentam atividade frente a todas formas ativas de MMPs (Folgueras, 2004). Tadavia, o TIMP-1 forma preferencialmente complexo com a MMP-9, enquanto o TIMP-2 atua sobre a MMP-2 (Goldberg et al., 1992).

Entretanto a ausência de relação significativa entre TIMP-1 e MMP-9, bem como entre TIMP-2 e MMP-2, parece indicar que mecanismos subjacentes e ainda não conhecidos possam influenciar a expressão das MMPs (Ribeiro et al., 2008). A intensidade da expressão de MMP- 
2, avaliada em relação ao TIMP-2, determina que, no grupo Calen, houve uma redução progressiva de MMP-2, ao passo que a expressão de TIMP-2 sofreu um aumento, embora não estatisticamente significante. Esta relação permite inferir que, aos 7 dias, houve maior atividade de MMP-2, o que pode estar associado ao seu papel central na degradação da matriz extracelular, permitindo a invasão de células endoteliais, facilitando a angiogênese e o remodelamento tecidual (Araújo et al., 2011). Contrariamente, maior expressão do TIMP-2 foi observada aos 21 dias, justificando a inibição da degradação tecidual e o reparo tecidual. Por outro lado, no grupo Trimix percebeu-se um aumento progressivo tanto da expressão MMP-2 quanto de TIMP-2 com o tempo, mas com maior intensidade para a MMP-2, o que pode justificar a maior densidade vascular neste grupo. Considerando MMP-9 e TIMP-1, os resultados mostraram relação inversamente proporcional das expressões destes genes nos grupos Calen e Trimix, caracterizada por aumento progressivo de MMP-9 e redução de TIMP 1 com o tempo. Entretanto, observando a intensidade da expressão, percebe-se uma tendência para o equilíbrio, principalmente no grupo Calen aos 21 dias. É possível que esse equilíbrio tenha importância no reparo tecidual observado frente à pasta Calen.

No presente estudo, com exceção dos genes VEGF e MMP-9 aos 7 dias, houve diferença na expressão de todos os genes avaliados, entre os grupos sem inserção de tubo e tubo vazio nos dois períodos avaliados, mostrando que o fato de fazer um procedimento cirúrgico ou uma pequena incompatibilidade do material já pode induzir alterações na expressão gênica local.

Os resultados obtidos no presente foram analisados por meio das respostas integradas dos genes avaliados com base em suas respectivas ações (Reyes-Carmona et al., 2011). Em função da ausência de estudos prévios avaliando a expressão de genes relacionados à resposta inflamatória e angiogênica frente às pastas avaliadas, uma real comparação dos resultados do presente estudo torna-se impossibilitada.

Com base nas metodologias empregadas e nos resultados obtidos por este estudo, concluiu-se que:

1) A resposta do tecido conjuntivo subcutâneo de camundongos à pasta Trimix caracterizou-se por reação inflamatória aguda persistente com ausência de reparo no período de 63 dias;

2) A pasta Trimix promoveu maior expressão gênica dos biomarcadores relacionados à resposta inflamatória e angiogênica.

Desse modo, os resultados do presente estudo contraindicariam o uso da pasta Trimix como medicação intracanal. 


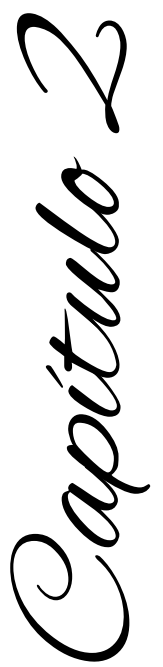




\section{CAPÍtUlo 2}

\section{AvaliaÇÃO DE MEDICAÇÕES INTRACANAL CONTENDO ClOREXIDINA}

\section{INTRODUÇÃO}

O uso da medicação intracanal em dentes com necrose pulpar e lesão periapical visível radiograficamente, visando à redução e/ou à eliminação dos micro-organismos é justificada devido à presença destes micro-organismos por todo o sistema de canais radiculares (Takahashi, 1998; Leonardo et al., 2000; McGurkin-Smith et al., 2005; Sathorn et al., 2009). Tradicionalmente, o hidróxido de cálcio $\left[\mathrm{Ca}(\mathrm{OH})_{2}\right]$ é considerado a medicação intracanal de escolha para esses casos (Heithersay 1975; Foreman e Barnes, 1990; Siqueira Jr e Lopes, 1999; Almyroudi et al., 2002; Gomes et al., 2002; Carrote, 2004; Soares et al., 2006a; Paquette et al., 2007; Silva et al., 2008; Gangwar, 2011; Silveira et al., 2011). Em virtude de sua dissociação em íons $\mathrm{Ca}^{2+}$ e $\mathrm{OH}^{-}, \mathrm{O} \mathrm{Ca}(\mathrm{OH})_{2}$ exerce atividade contra a maioria dos micro-ogranismos presentes na infecção endodôntica (Byström et al., 1985), promove a inativação da endotoxina bacteriana LPS (Safavi e Nichols, 1993; Nelson-Filho et al., 2002) e ativa, na região periapical, mecanismos celulares e moleculares da regeneração tecidual (Leonardo et al., 1994; Siqueira Jr e Lopes 1999; Mohammadi e Abbott, 2009b).

Todavia, tem sido demonstrado reduzida atividade antimicrobiana do $\mathrm{Ca}(\mathrm{OH})_{2}$ contra importantes micro-organismos relacionados à infecção pulpar e perirradicular, tais como o Enterococcus faecalis e Candida spp (Ørstavik e Haapasalo, 1990; Barbosa et al., 1997; Waltimo et al., 1999; Komorowski et al., 2000; Gomes et al., 2002; Basrani et al., 2003; Evans et al., 2003; Gomes et al., 2003; Haenni et al., 2003; Lin et al., 2003; Ercan et al., 2006; Lana et al., 2009; Delgado et al., 2010; Gangwar, 2011). Estes micro-organismos são ocasionalmente detectados em infecções endodônticas primárias (Lana et al., 2001; Siqueira Jr et al., 2002), mas são os mais frequentemente isolados nas infecções secundárias ou persistentes (Sirén et al., 1997; Waltimo et al., 1997; D'Arcangelo et al., 1999; Siqueira Jr e Rôças, 2004; Stuart et al., 2006; Krithikadatta et al., 2007), sendo, portanto, intimamente relacionados a falhas no tratamento endodôntico (Williams et al., 2006; Ballal et al., 2007; Krithikadatta et al., 2007).

Isso porque o $E$. faecalis apresenta resistência a uma ampla variedade de agentes antimicrobianos, devido a diversos mecanismos de defesa (Love, 2001; Distel et al., 2002; Evans et al., 2002; Figdor et al., 2003). Por sua vez, a C. albicans, além de possuir capacidade 
de sobreviver frente a altos níveis de $\mathrm{pH}$, utiliza os íons $\mathrm{Ca}^{2+}$, fornecidos pelo $\mathrm{Ca}(\mathrm{OH})_{2}$, para favorecer seu crescimento e morfogênese (Siqueira Jr e Sen, 2004).

Assim, têm sido pesquisadas várias substâncias para serem utilizadas como medicação intracanal alternativa ao $\mathrm{Ca}(\mathrm{OH})_{2}$. Dentre elas, destaca-se a clorexidina $(\mathrm{CHX})$, a qual apresenta alta eficácia contra micro-organismos Gram-positivos, Gram-negativos, aeróbios, anaeróbios facultativos, leveduras e vírus, apresentando ação bactericida em alta concentração e bacteriostática em baixa concentração (Michelotto et al., 2008; Mohammadi e Abbott, 2009b; Shen et al., 2011). Outra favorável e importante característica da CHX é sua adsorção a tecidos mineralizados e liberação gradual (substantividade), o que prolonga seu período de atividade antimicrobiana (Komorowski et al., 2000; Almyroudi et al., 2002; Dametto et al., 2005; Michelotto et al., 2008). Devido a estas propriedades, a CHX tem sido recomendada como medicação intracanal (Barbosa et al., 1997; Lindskog et al., 1998; Almyroudi et al., 2002; Basrani et al., 2002; Basrani et al., 2003; Lynne et al., 2003; Gomes et al., 2003; Zamany et al., 2003; Siqueira Jr et al., 2003; Wuerch et al., 2004; Onçag et al., 2006; Manzur et al., 2007; Malkhassian et al., 2009), sendo mais efetiva do que o $\mathrm{Ca}(\mathrm{OH})_{2}$ na eliminação dos $E$. faecalis e de C. albicans (Heling et al., 1992; Almyroudi et al., 2002; Basrani et al., 2003; Haenni et al., 2003; Lin et al., 2003; Krithikadatta et al., 2007; Neelakantan et al., 2007; Kandaswamy et al., 2010; Vaghela et al., 2011) presentes nos túbulos dentinários.

Com o objetivo de potencializar o efeito antimicrobiano do $\mathrm{Ca}(\mathrm{OH})_{2}$, tem sido proposta, como medicação intracanal, a utilização da pasta de $\mathrm{Ca}(\mathrm{OH})_{2}$ associada à $\mathrm{CHX}$ em concentrações de 0,12\% a 2\% (Evans et al., 2003; Sirén et al., 2004; Ercan et al., 2006; Soares et al., 2006a; Soares et al., 2007; Onçag et al., 2006; Manzur et al., 2007; Al-Nazhan e Al-Obaidae, 2008; Gomes et al., 2009b; Silva et al., 2009; Valera et al., 2009; 2010; Delgado et al., 2010; Gondim et al, 2011; Lima et al., 2011). Essa associação resulta em um efeito antimicrobiano sinérgico (Evans et al., 2003; Podbielski et al., 2003; Zehnder et al., 2003; Zarella et al., 2005; Soares et al., 2007; Souza-Filho et al., 2008; Lima et al., 2011), sem alteração da solubilidade, alcalinidade ou atividade de ambas as substâncias (Podbielski et al., 2003; Basrani et al., 2003; Sirén et al., 2004; Signoretti et al., 2011). No entanto, não há consenso na literatura se a adição da $\mathrm{CHX}$ ao $\mathrm{Ca}(\mathrm{OH})_{2}$ prejudica/altera a reação do tecido conjuntivo (Semenoff et al., 2008; Silva et al., 2009).

Outra forma de utilização da CHX, como medicação intracanal, é o gel a 2,0\% (Lenet et al., 2000; Basrani et al., 2002; Basrani et al., 2003; Wuerch et al., 2004; Manzur et al., 2007; 
Krithikadatta et al., 2007; Neelakantan et al., 2007; Gomes et al., 2009b; Malkhassian et al., 2009; Valera et al., 2010), o qual apresenta propriedade antimicrobiana satisfatória (Wang et al., 2007; Delgado et al., 2010; Kandaswamy et al., 2010; Martinho et al., 2011; Vaghela et al., 2011) e substantividade (Ferraz et al., 2001; Neelakantan et al., 2007). Sua viscosidade favorece bom contato com as paredes do canal radicular e atividade residual por até 2 semanas (Barthel et al., 2002). No entanto, são escassos estudos, avaliando sua compatibilidade biológica em diferentes períodos de tempo (Gomes-Filho et al., 2008).

Desta forma, diante da escassez de estudos e de resultados controversos, o objetivo deste estudo foi caracterizar a resposta do tecido conjuntivo subcutâneo de camundongos a medicações contendo $\mathrm{CHX}$ : associações de $\mathrm{Ca}(\mathrm{OH})_{2}$ com $\mathrm{CHX}$ a 0,5 e a 2,0\% e o gel de $\mathrm{CHX}$ a 2,0\% por microscopia óptica convencional.

\section{MATERIAl e Métodos}

O presente projeto de pesquisa foi avaliado e aprovado pela Comissão de Ética em Experimentação Animal da Faculdade de Medicina de Ribeirão Preto da Universidade de São Paulo, protocolo $n^{\circ}$ 185/2009 (Anexo A). Os experimentos com animais realizados no presente estudo foram conduzidos de acordo com as recomendações desta Comissão.

Foram utilizados 60 camundongos isogênicos da linhagem BALB/C, machos, com 6 a 7 semanas de idade, pesando de 20 a 25 gramas. Os camundongos foram divididos em 4 grupos para cada período experimental de 7, 21 e 63 dias. Cada animal recebeu dois implantes dorsais compostos de tubos de polietileno contendo uma das substâncias avaliadas: pasta à base de $\mathrm{Ca}(\mathrm{OH})_{2}$ (Calen, S.S.White Artigos Dentários Ltda., Rio de Janeiro, RJ, Brasil; composição: 2,5g $\mathrm{Ca}(\mathrm{OH})_{2}, 0,5 \mathrm{~g}$ óxido de zinco, 0,05g colofônia e 1,75mL polietilenoglicol 400) que foi empregada como controle; pasta Calen associada à $\mathrm{CHX}$ (Bioquant, Ribeirão Preto, SP, Brasil) na concentração final de 0,5\%; pasta Calen associada à $\mathrm{CHX}$ (Bioquant) na concentração final de 2,0\%; ou gel de $\mathrm{CHX}$ a 2,0\% (composição: $1 \%$ natrosol e gluconato de $\mathrm{CHX}$ a 2,0\% em pH 7; Bioquant, Ribeirão Preto, SP, Brasil). O quadro 1 apresenta a distribuição dos grupos.

\section{Preparo dos tubos de polietileno}

Foram utilizados tubos de polietileno (Embramed, São Paulo, SP, Brasil) de 1,5mm de diâmetro interno e $10 \mathrm{~mm}$ de comprimento, os quais tiveram uma extremidade fechada com o auxílio de uma pinça clínica aquecida. Após terem sido esterilizados por óxido de etileno, os 
tubos foram preenchidos com os materiais a serem avaliados, sob condições de assepsia (fluxo laminar), imediatamente antes de sua implantação.

Quadro 1 - Divisão dos grupos: substâncias empregadas, períodos experimentais e número de animais.

\begin{tabular}{|ccccc|}
\hline \multirow{2}{*}{ Períodos } & \multicolumn{5}{c|}{ Substâncias } \\
\cline { 2 - 5 } & $\begin{array}{c}\text { Calen } \\
\text { (controle) }\end{array}$ & Calen+CHX a 0,5\% & Calen+CHX a 2,0\% & Gel de CHX a 2,0\% \\
\hline \multirow{2}{*}{$\mathbf{7}$ dias } & $\mathbf{5}$ animais & $\mathbf{5}$ animais & $\mathbf{5}$ animais & $\mathbf{5}$ animais \\
& $(10$ tubos $)$ & $(10$ tubos $)$ & $(10$ tubos $)$ & (10 tubos) \\
\hline \multirow{2}{*}{$\mathbf{2 1}$ dias } & $\mathbf{5}$ animais & $\mathbf{5}$ animais & $\mathbf{5}$ animais & $\mathbf{5}$ animais \\
& $(10$ tubos $)$ & $(10$ tubos $)$ & $(10$ tubos $)$ & (10 tubos) \\
\hline \multirow{2}{*}{$\mathbf{6 3}$ dias } & $\mathbf{5}$ animais & $\mathbf{5}$ animais & $\mathbf{5}$ animais & $\mathbf{5}$ animais \\
& $(10$ tubos $)$ & $(10$ tubos $)$ & $(10$ tubos $)$ & (10 tubos) \\
\hline
\end{tabular}

\section{Procedimento operatório}

Para o procedimento cirúrgico, os animais foram anestesiados pela associação de cloridrato de quetamina (Dopalen, Agribrands, Saúde Animal, Paulínia, SP, Brasil) - 1mL/Kg e xilazina (Rompun, Bayer, Saúde Animal, São Paulo, SP, Brasil) - 0,5mL/Kg administrada via intramuscular. Em seguida, foi realizada a tricotomia da região dorsal e antissepsia com solução de clorexidina a 2,0\% (Bioquant).

O procedimento cirúrgico consistiu de duas incisões de 0,5cm, efetuadas com tesoura cirúrgica, nas regiões escapulares do dorso de cada animal, seguidas de divulsão com tesoura de ponta romba, formando duas bolsas no tecido subcutâneo com bases a $20 \mathrm{~mm}$ das linhas de incisão. Em cada bolsa, foi implantado um tubo de polietileno com a medicação, tomando-se o cuidado de se colocarem os tubos não paralelos à linha de incisão para evitar sua expulsão e mobilidade. Em cada animal, os dois tubos implantados continham a mesma substância.

Após a sutura com fio de seda 4-0 (Ethicon Johnson \& Johnson, São Paulo, SP, Brasil), os animais foram mantidos em gaiolas individuais no biotério do Departamento de Patologia da Faculdade de Medicina de Ribeirão Preto - USP e alimentados com dieta padrão de laboratório e livre acesso à água.

Decorridos os períodos experimentais de 7, 21 e 63 dias, 5 camundongos de cada grupo, escolhidos ao acaso, foram anestesiados, a tricotomia dorsal foi realizada, e os implantes foram removidos juntamente com o tecido conjuntivo subcutâneo e a pele adjacente $(n=10$ implantes por grupo em cada período). Em seguida, os animais foram eutanizados por sobredose 
anestésica. Os tecidos foram fixados em formol tamponado a $10 \%$ por 24 horas e submetidos ao processamento histotécnico.

\section{Avaliação histopatológica}

No processamento histotécnico, os espécimes foram desidratados em soluções crescentes de álcool etílico (80\%, 95\%, 30 minutos cada e 100\%, 4 trocas de 1 hora cada). Após o último álcool, foram efetuados três banhos de xilol (30 minutos cada), dois banhos de parafina (2 horas cada) e inclusão em parafina, sendo os espécimes orientados de maneira a permitir cortes histológicos do implante em seu sentido longitudinal. Cortes semi-seriados foram obtidos com $6 \mu \mathrm{m}$ de espessura da região correspondente à parte central do tubo e corados com hematoxilina e eosina (HE).

As análises qualitativa e quantitativa dos cortes corados com HE foram efetuadas em microscópio de luz convencional Leica (Leica DMR; Leica Microsystems GmbH, Wetzlar, Alemanha), examinando-se a extremidade do implante em que as substâncias ficaram em contato com tecido subcutâneo. Foram avaliados três cortes de cada implante, mantendo-se um intervalo mínimo de 50 $\mu$ m entre os cortes (Bortolo, 2009).

$\mathrm{Na}$ análise qualitativa, foram verificados os parâmetros de resposta biológica, incluindo a presença e extensão da cápsula fibrosa, do infiltrado inflamatório, de necrose, ocorrência de fibroblastos e vascularização. Para a análise quantitativa, foi utilizado o programa Leica QWin v3 (Leica Imaging Systems Ltd; Cambridge, Inglaterra), em conjunto com uma videocâmera (Leica DFC 300FX; Leica Microsystems AG, Heerbrugg, Suíça) acoplada ao microscópio e um computador on-line. Foram avaliados:

- O número de células inflamatórias presentes em quatro campos histológicos de $100 \mu m^{2}$ cada um;

- O número de vasos e suas áreas $\left(\mu \mathrm{m}^{2}\right)$ em quatro campos histológicos de $100 \mu \mathrm{m}^{2}$ cada um.

Os vasos sanguíneos foram definidos como estruturas com luz e com presença ou não de hemácias, sendo delineados manualmente e contados. A área delimitada por cada vaso foi calculada pelo programa Leica QWin (Kyriakides et al., 2001; Ho et al., 2004).

As análises foram realizadas às cegas por um único avaliador calibrado. Todos os procedimentos laboratoriais foram realizados no Laboratório de Cardiologia Celular e Molecular da Faculdade de Medicina de Ribeirão Preto - USP. 


\section{Análise estatística}

Os resultados obtidos foram analisados por meio do programa estatístico Graph Pad Prism 5.01 (Graph Pad Software In., San Diego, CA, EUA). Foi empregada a análise de variância (ANOVA), seguida do pós-teste de Tukey. Os dados foram apresentados como a média e erropadrão da média por um campo de $100 \mu m^{2}$. O nível de significância adotado foi de $5 \%$.

\section{RESULTADOS}

\section{Da avaliação histopatológica}

\section{Calen (controle)}

Aos 7 dias, o grupo Calen apresentou tecido reacional moderadamente espesso com infiltrado inflamatório predominantemente neutrofílico e vasos sanguíneos de pequeno calibre. Aos 21 e 63 dias, foram observadas poucas células inflamatórias do tipo linfomononucleares, presença de fibroblastos entremeados por numerosas fibras colágenas, que se apresentavam de forma organizada, indicando reparo (Figura 1).

\section{Calen $+\mathrm{CH}$ × a $0,5 \%$}

Aos 7 dias, observou-se camada espessa de tecido reacional com presença de infiltrado inflamatório neutrofílico, necrose do tecido circunjacente com sinais de reparo no tecido muscular e pequena quantidade de vasos. Aos 21 e 63 dias, a camada de tecido reacional apresentou-se delgada e bem organizada, semelhante a um tecido conjuntivo fibroso, porém com persistência, em menor grau, da necrose do tecido circunjacente e sinais de reparo no tecido muscular, caracterizado pela presença de células satélites (Figura 1).

\section{Calen $+\mathrm{CHX}$ a $2,0 \%$}

Aos 7 e 21 dias, observou-se camada espessa de tecido reacional com presença de infiltrado inflamatório neutrofílico, necrose do tecido circunjacente com sinais de reparo no tecido muscular e rede de vasos sanguíneos de pequeno calibre. Já, aos 63 dias, a camada de tecido reacional apresentou-se delgada e mais organizada, porém com persistência, em menor grau, da necrose do tecido circunjacente e sinais de reparo no tecido muscular (Figura 1).

\section{Gel de CHX a 2,0\%}

O gel de $\mathrm{CHX}$ a 2,0\% induziu reação tecidual severa, caracterizada por espessa camada de tecido reacional e intenso infiltrado inflamatório com predomínio de neutrófilos, além de 
células linfomononucleares, o qual persistiu mesmo aos 63 dias indicando agressividade residual. Presença de necrose do tecido circunjacente e sinais de reparo no tecido muscular e de vasos sanguíneos de pequeno calibre também foram observados (Figura 1).

Aos 7 dias, o gel de $\mathrm{CHX}$ a 2,0\% apresentou maior número de células inflamatórias do que os grupos Calen, Calen+CHX a 0,5\% e Calen+CHX a 2,0\% $(p<0,05)$. Nos períodos de 21 e 63 dias, os grupos Calen e Calen+CHX a 0,5\% apresentaram menor número de células inflamatórias, seguidos pelo Calen+CHX a 2,0\% e pelo gel de $\mathrm{CHX}$ a 2,0\% $(\mathrm{p}<0,05)$, que, por sua vez, apresentou o maior número de células inflamatórias (Figura 2 A).

A comparação dentro de cada grupo, nos diferentes períodos avaliados, mostrou que, no grupo Calen, houve uma diminuição progressiva do número de células inflamatórias ( $p<0,0001)$ com o passar do tempo. Nos grupos Calen+CHX a 0,5\% e Calen+CHX a 2,0\%, 0 número de células inflamatórias diminuiu aos 21 dias $(p<0,05)$, mas não aos 63 dias. No grupo gel de $\mathrm{CHX}$ a 2,0\% houve manutenção de elevado número de células inflamatórias nos três períodos estudados $(p>0,05)$.

Quanto ao número de vasos, não houve diferença estatisticamente significante entre os grupos em nenhum dos períodos avaliados (Figura 2 B). Em relação à área dos vasos, não houve diferença entre os grupos no período de 7 dias. No período de 21 dias, não houve diferença entre os grupos Calen, Calen $+\mathrm{CHX}$ a 0,5\% e Calen+CHX a 2,0\% (p>0,05), ao mesmo tempo em que os grupos Calen e Calen+CHX a 0,5\% diferenciaram estatisticamente do grupo gel de $\mathrm{CHX}$ a 2,0\% $(\mathrm{p}<0,05)$ o qual não diferiu do grupo Calen+CHX a 2,0\% ( $p>0,05)$. Aos 63 dias, os grupos Calen e Calen+CHX a 0,5\% apresentaram vasos menos calibrosos, sendo estatisticamente diferentes dos Calen+CHX a 2,0\% e gel de CHX a 2,0\%, os quais apresentaram maior área vascular $(p<0,05)$, como pode ser evidenciado na Figura 2 C.

A comparação dentro de cada grupo nos diferentes períodos, mostrou que os grupos Calen e Calen+CHX a 0,5\% apresentaram redução da área dos vasos de 7 para 63 dias $(p<0,05)$. Contrariamente, nos grupos Calen+CHX a 2,0\% e gel de $\mathrm{CHX}$ a 2,0\%, houve manutenção da área vascular no decorrer do tempo ( $p>0,05)$. 


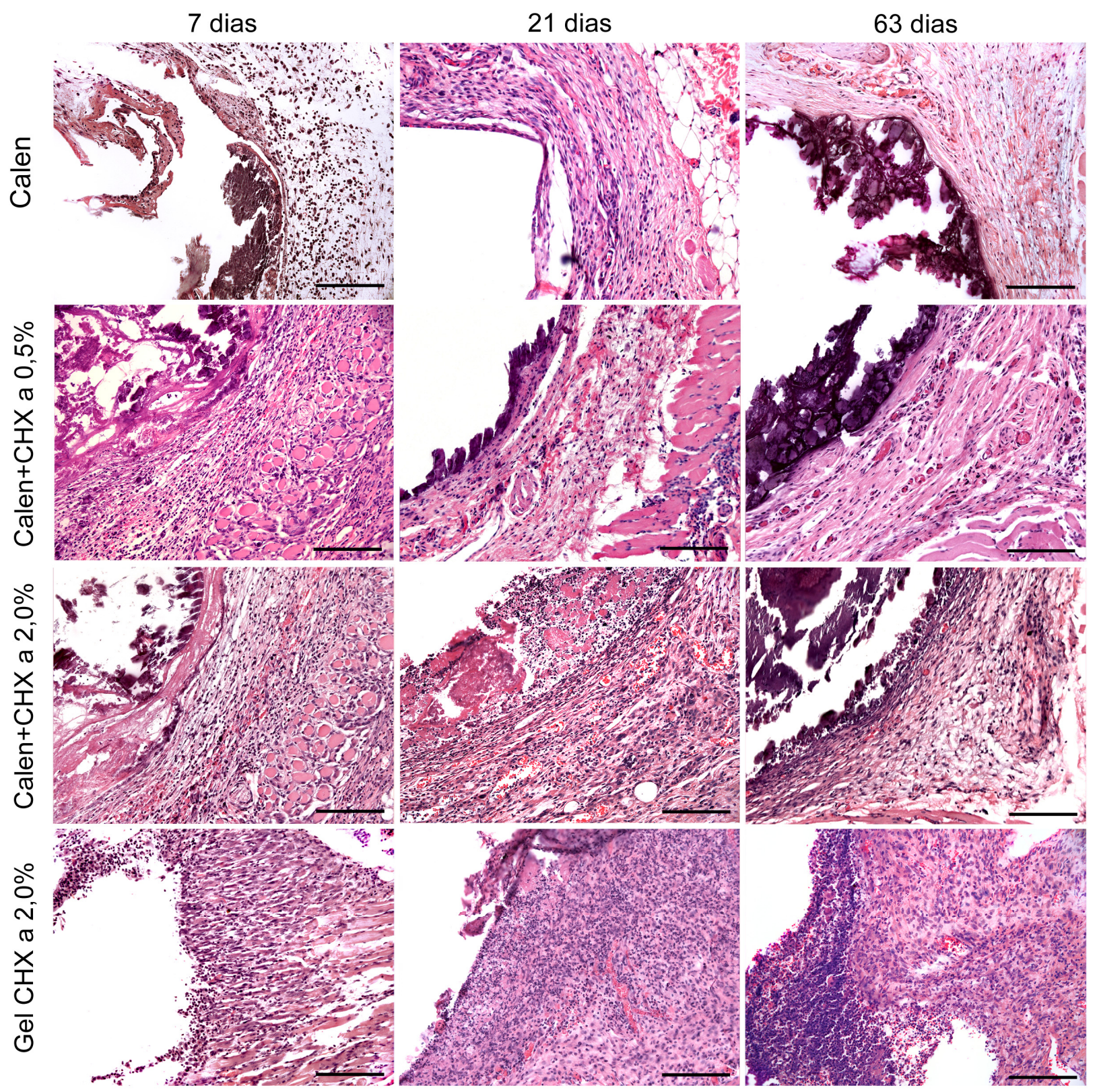

Figura 1 - Aspectos microscópicos da resposta do tecido conjuntivo subcutâneo de camundongos às pastas Calen, Calen+CHX a 0,5\%, Calen+CHX a 2,0\% e ao gel de $\mathrm{CHX}$ a 2,0\% nos períodos experimentais de 7, 21 e 63 dias. $(\mathrm{HE} ;$ barra $=200 \mu \mathrm{m})$. 

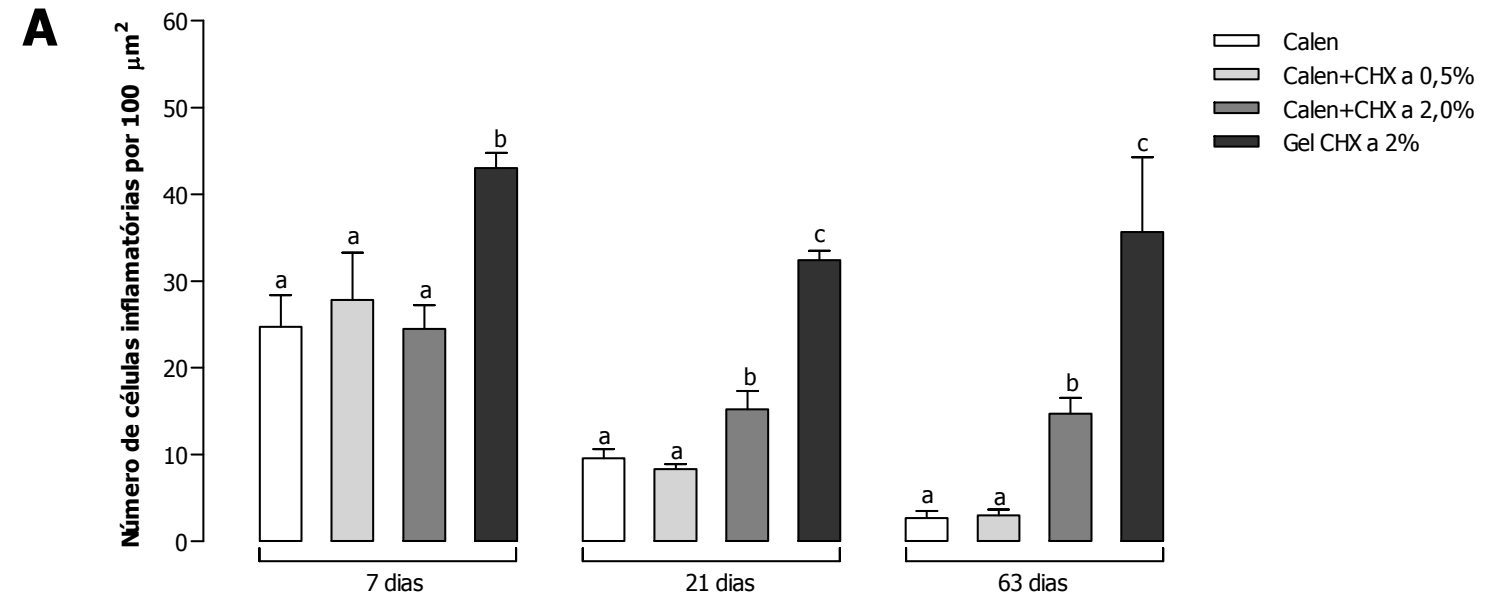

B
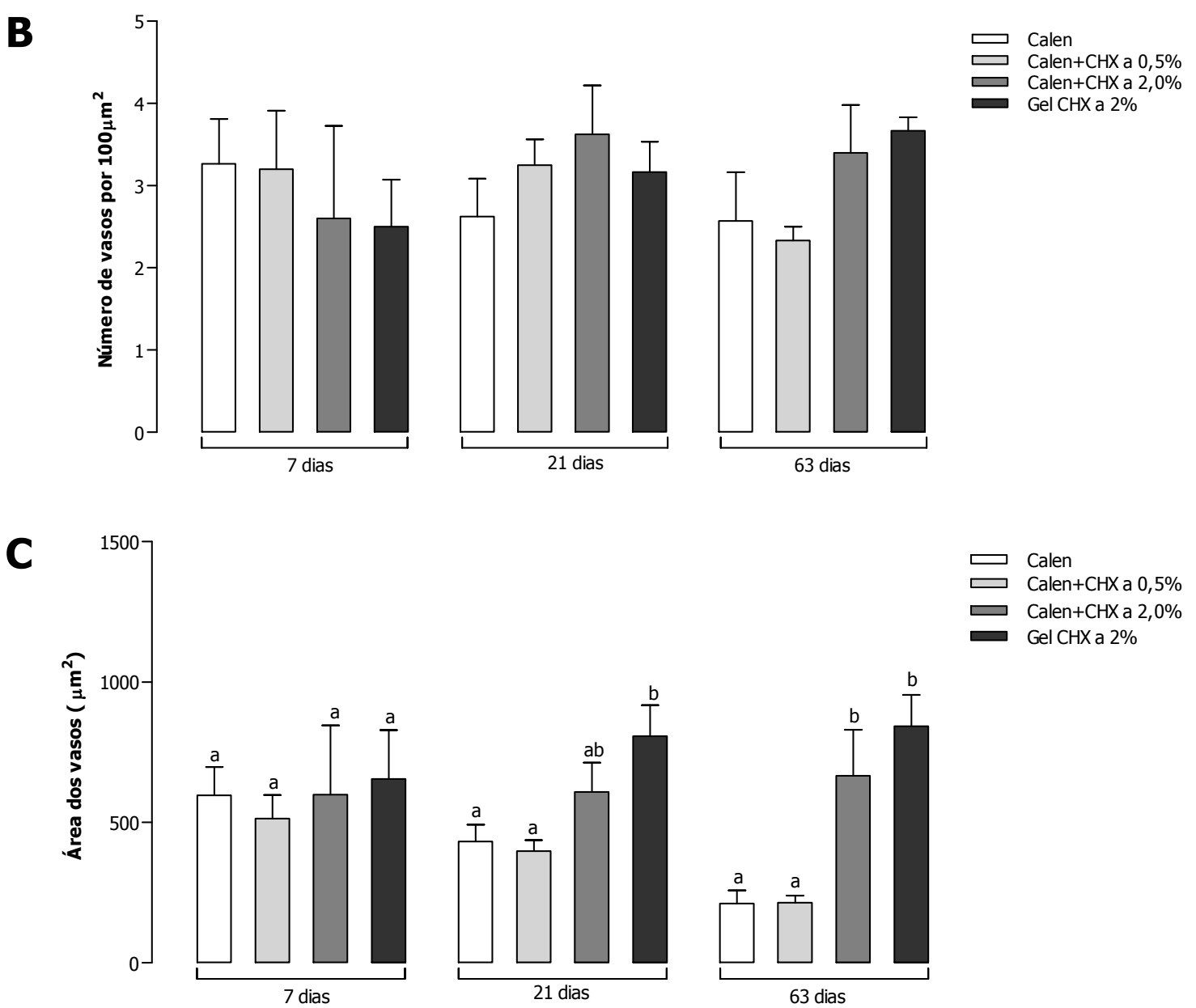

Figura 2 - Comparação do número de células inflamatórias (A), número de vasos (B) e área vascular (C) aos 7, 2163 dias após a implantação dos tubos nos grupos Calen, Calen+CHX a 0,5\%, Calen+CHX a 2,0\% e gel de $\mathrm{CHX}$ a 2,0\%. Dentro de cada período, diferenças estatísticas foram representadas por letras diferentes. Não houve diferença entre os grupos em relação ao número de vasos. 


\section{DISCUSSÃo}

Implantação no tecido subcutâneo de tubos de polietileno contendo as substâncias a serem avaliadas é um método amplamente utilizado para determinar in vivo a reação tecidual frente a materiais endodônticos (Torneck, 1966; 1967; Olsson et al., 1981; Garcia et al., 2008; Semenoff et al., 2008; Silva et al., 2009; Danesh et al., 2010; Queiroz et al., 2011; Gomes-Filho et al., 2012), representando uma fonte preliminar de informações sobre a compatibilidade do material com a atividade biológica dos tecidos circundantes (Queiroz et al., 2011). Na maioria dos estudos, após técnica de coloração com $\mathrm{HE}$, a avaliação histopatológica é realizada por meio de sistema de escores (análise semi-quantitativa). Todavia, tal análise promove uma avaliação subjetiva da reação tecidual (Yamanaka et al., 2011). No presente estudo, foi realizada análise histopatológica qualitativa e quantitativa, determinando o número de células inflamatórias e de vasos, além da área vascular. Desta forma, buscou-se complementar a leitura morfológica das reações teciduais com a morfometria, que além de conferir segurança pelas contagens em campos histológicos estratégicos, corrobora e sustenta a análise morfológica de forma bem definida e direcionada (Kyriakides et al., 2001; Ho et al., 2004; Garcia et al., 2008; Gomes-Filho et al., 2008).

Diferentes substâncias têm sido associadas ao $\mathrm{Ca}(\mathrm{OH})_{2}$ com o objetivo de melhorar suas propriedades físico-químicas, tais como radiopacidade, viscosidade, infiltração, taxa de dissociação iônica e principalmente sua atividade antimicrobiana (Basrani et al., 2004). Dentre estas substâncias, a CHX tem sido empregada para potencializar a atividade antimicrobiana do $\mathrm{Ca}(\mathrm{OH})_{2}$ contra micro-organismos resistentes a este (Basrani et al., 2004; Schäfer e Bössmann, 2005; Lima et al., 2011). Entretanto, ao selecionar uma combinação para $\circ \mathrm{Ca}(\mathrm{OH})_{2}$, além do benefício proporcionado por ela, deve-se avaliar a viabilidade das propriedades físico-químicas e biológicas desta associação (Kuga et al., 2010).

Deste modo no presente estudo, baseado na norma ISO 10993-6 (2007), as respostas do tecido conjuntivo subcutâneo de camundongos frente às medicações intracanal contendo CHX foram comparadas à pasta Calen, utilizada como controle. A escolha da pasta Calen como controle é justificada por sua biocompatibilidade (Leonardo et al., 1993; Nelson-Filho et al., 1999; Delgado, 2002; Leonardo et al., 2006), a qual está relacionada em parte, à neutralização do grupo $\mathrm{OH}^{-}$pelo $\mathrm{H}^{+}$liberado por seu veículo, o polietileno glicol 400, reduzindo assim área de necrose superficial provocada pelo $\mathrm{Ca}(\mathrm{OH})_{2}$ (Nelson-Filho et al., 1999), além de sua 
aceitabilidade clínica (Faria et al., 2004; Faria et al., 2005; Leonardo, 2005; Nelson-Filho et al., 2006).

Os resultados microscópicos do presente estudo mostraram que a pasta Calen+CHX a 0,5\% apresentou resposta tecidual semelhante à pasta Calen $(p>0,05)$, caracterizada por reação inflamatória moderada aos 7 dias. Esta reação foi progressivamente reduzida, sendo aos 63 dias evidenciado tecido conjuntivo bem organizado, com raras células inflamatórias e menor área vascular, indicando reparo tecidual. Este resultado é consistente com estudo prévio que observou a ocorrência de resposta tecidual adequada frente à associação da pasta Calen+CHX a 0,4\% (Silva et al., 2009), sendo a compatibilidade biológica da associação Calen+CHX a 0,5\% provavelmente justificada pela baixa concentração da $\mathrm{CHX}$.

Considerando a reação tecidual induzida pela associação Calen+CHX a 2,0\%, o presente estudo mostrou que apesar dos resultados aos 7 dias terem sido similares às pastas Calen e Calen+CHX a 0,5\% ( $>>0,05)$, contrariamente a estes grupos, aos 21 e 63 dias, foi determinado persistência de irritação tecidual e consequente manutenção da resposta inflamatória. Similarmente, estudo recente evidenciou que a pasta de $\mathrm{Ca}(\mathrm{OH})_{2}$ associada à $\mathrm{CHX}$ a 2,0\% (UltraCal ${ }^{\mathrm{TM}}$ ), implantada no tecido conjuntivo subcutâneo de camundongos, levou à ocorrência de resposta tecidual insatisfatória, caracterizada por infiltrado inflamatório neutrofílico associado a grande quantidade de macrófagos e vasos congestos (Silva et al., 2009). Do mesmo modo, a pasta Calen+CHX a 1,0\%, como medicação intracanal, retardou o processo de reparo de lesões periapicais de dentes de cães induzidas experimentalmente (De Rossi et al., 2005). Contrariamente, resultado de estudo anterior não observou diferença da resposta tecidual comparando o uso da associação de $\mathrm{Ca}(\mathrm{OH})_{2}$ com água destilada ou com $\mathrm{CHX}$ a 2,0\%, no tecido submucoso bucal de ratos em diferentes períodos experimentais (Semenoff et al., 2008).

Os resultados do presente estudo confirmaram que embora $\mathrm{O} C a(O H)_{2}$, mais especificamente a pasta Calen, apresente compatibilidade biológica bem estabelecida (Leonardo et al., 1993; Nelson-Filho et al., 1999; Delgado, 2002; Leonardo et al., 2006), as substâncias a ela associada visando melhorar suas propriedades antimicrobiana e clínica podem alterar significativamente a resposta tecidual deste material (Silva et al., 2009). Deste modo, a resposta tecidual distinta apresentada pelas pastas Calen+CHX a 0,5\% e Calen+CHX a 2,0\% neste estudo, deve-se provavelmente à diferença nas concentrações da $\mathrm{CHX}$, reforçando que a irritação tecidual provocada por estas associações é dose-dependente (Silva et al., 2009).

A resposta tecidual observada neste estudo frente às pastas Calen+CHX a 0,5\% e 
Calen+CHX a 2,0\% corrobora com estudos in vitro e in vivo que mostraram que a $\mathrm{CHX}$ apresenta toxicidade dose-dependente e induz a formação de amplos focos de necrose coagulativa associada com um infiltrado inflamatório, composto principalmente de neutrófilos e células mononucleares, e acentuado edema intersticial na derme e subcutâneo da pata traseira de camundongos (Faria et al., 2007; 2009).

No presente estudo, o gel de $\mathrm{CHX}$ a 2,0\% apresentou, em todos os períodos avaliados, maior número de células inflamatórias do que os demais grupos $(p<0,05)$ e manutenção de maior área vascular, indicando resposta inflamatória severa e persistente. Resultados de pesquisa anterior, pela qual a reação tecidual frente ao gel de $\mathrm{CHX}$ a 2,0\% foi determinada por meio da injeção da substância no tecido conjuntivo subcutâneo do dorso de ratos, evidenciaram leve reação inflamatória após 2 horas. No período de 48 horas, houve o pico do número de células inflamatórias que permaneceu até 14 dias. Posteriormente, aos 30 dias, significante diminuição da resposta inflamatória foi observada, direcionando para um processo de reparo no tecido conjuntivo. Sabe-se que a base viscosa utilizada no gel de $\mathrm{CHX}$ a 2,0\% tem pouca solubilidade em água. Assim, os autores sugeriram que a maior resposta inflamatória no tecido conjuntivo apresentada pelo gel, às 48 horas e aos 14 dias, seja por sua dissolução mais lenta no tecido (Gomes-Filho et al., 2008). A manutenção da resposta inflamatória observada aos 63 dias no presente trabalho, pode ser justificada pela diferença na metodologia empregada. A implantação, no tecido conjuntivo subcutâneo do material contido em tubos, é a forma determinada pela ISO 10993-6 diante de materiais não sólidos. Esta metodologia simula as condições do canal radicular e fornece as vantagens de padronizar a interface tecido/material, estabelecer a quantidade do material a ser implantada, facilitar a determinação do tecido a ser removido e ao mesmo tempo limitar e padronizar a área para análise da resposta biológica, favorecendo condições similares para comparação (Cintra et al., 2010), ao passo que, quando injetado diretamente no tecido conjuntivo subcutâneo do dorso de ratos (Gomes-Filho et al., 2008), o material pode-se espalhar ou ser reabsorvido, dificultando a análise histopatológica e interferindo nela.

Pelo exposto, os resultados do presente estudo evidenciaram que a Calen+CHX a 0,5\% levou a resposta tecidual reparativa, em contraste com a Calen+CHX a 2,0\% e o gel de $\mathrm{CHX}$ a 2,0\%, que propiciaram resposta inflamatória persistente, apontando para a agressividade desses materiais. Considerando a Calen+CHX a 2,0\% e o gel de $\mathrm{CHX}$ a 2,0\%, este apresentou resposta inflamatória de maior intensidade. 


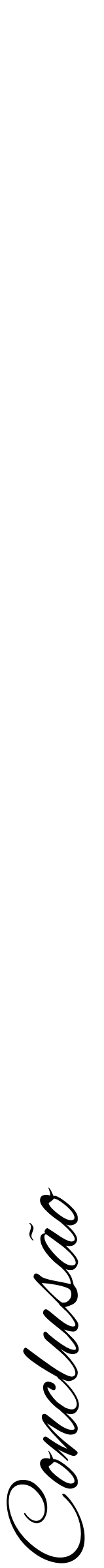




\section{CONCLUSÃo}

Considerando as condições específicas do presente estudo e com base nos resultados obtidos, pôde-se concluir que:

1) A resposta do tecido conjuntivo subcutâneo de camundongos à pasta Trimix caracterizou-se por reação inflamatória aguda persistente com ausência de reparo no período estudado de 63 dias;

2) A pasta Trimix promoveu maior expressão gênica dos biomarcadores relacionados à resposta inflamatória e angiogênica quando comparado com a pasta Calen (controle);

3) A pasta Calen $+\mathrm{CHX}$ a $0,5 \%$ levou a resposta tecidual reparativa, em contraste com a Calen+ $\mathrm{CHX}$ a 2,0\% e o gel de $\mathrm{CHX}$ a 2,0\% que propiciaram resposta inflamatória persistente;

4) Considerando a Calen+CHX a 2,0\% e o gel de $\mathrm{CHX}$ a 2,0\%, este apresentou resposta inflamatória de maior intensidade.

Desse modo, o presente estudo fornece indícios que as pastas Trimix, Calen+CHX a $2,0 \%$ e o gel de $\mathrm{CHX}$ a 2,0\% não deveriam ser empregados como medicação intracanal. 


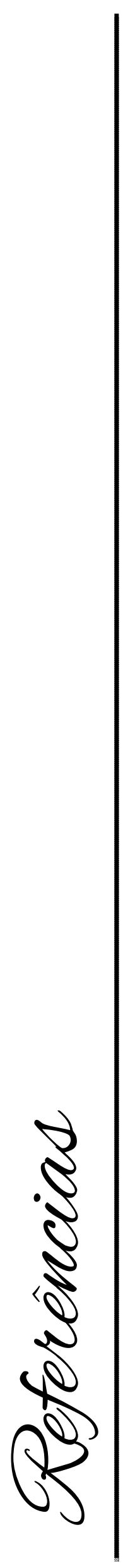




\section{REFERÊNCIAS*}

Abbas AK, Lichtman AH, Pillai S. Imunologia celular e molecular. $6^{\text {a }}$ ed. Rio de Janeiro: Elsevier; 2008.

Accorsi-Mendonça T, Paiva KB, Zambuzzi WF, Cestari TM, Lara VS, Sogayar MC. Expression of matrix metalloproteinase -2 and -9 and RECK during alveolar bone regeneration in rat. J Mol Histol 2008;39:201-8.

Akgun OM, Altun C, Guven G. Use of triple antibiotic paste as a disinfectant for a traumatized immature tooth with a periapical lesion: a case report. Oral Surg Oral Med Oral Pathol Oral Radiol Endod 2009;108:62-5.

Almyroudi A, McHugh S, Saunders WP. The effectiveness of various disinfectants used as endodontic intracanal medications: an in vitro study. J Endod 2002;28:163-7.

Al-Nazhan S, Al-Obaida M. Effectiveness of a $2 \%$ chlorhexidine solution mixed with calcium hydroxide against Candida albicans. Aust Endod J 2008;34:133-5.

Ambalavanan N, Nicola T, Hagood J, Bulger A, Serra R, Murphy-Ullrich J, Oparil S, Chen YF. Transforming growth factor-signaling mediates hypoxia-induced pulmonary arterial remodeling and inhibition of alveolar development in newborn mouse lung. Am J Physiol Lung Cell Mol Physiol 2008;295:86-95.

Anthanassiadis B, Abbott PV, Walsh $\mathrm{L}$. The use of calcium hydroxide, antibiotics and biocides as antimicrobial medicaments in endodontics. Aust Dent J 2007;52:64-82.

Apte, RN, Dotan S, Elkabets M, White MR, Reich E, Carmi Y, Song X, Dvozkin T, Krelin Y, Voronov $\mathrm{E}$. The involvement of IL-1 in tumorigenesis, tumor invasiveness, metastasis and tumor-host interactions. Cancer Metastasis Rev 2006;25:387-408.

Araújo RVS, Silva FO, Melo-Júnior MR, Porto ALF. Metaloproteinases: aspectos fisiopatológicos sistêmicos e sua importância na cicatrização. Rev Ciênc Med Biol 2011;10:82-8.

Arroyo AG, Iruela-Arispe ML. Extracellular matrix, inflammation, and the angiogenic response. Cardiovasc Res 2010;86:226-35.

Ballal V, Kundabala M, Acharya S, Ballal M. Antimicrobial action of calcium hydroxide, chlorhexidine and their combination on endodontic pathogens. Aust Dent J 2007;52:118-21.

Banchs F, Trope M. Revascularization of immature permanent teeth with apical periodontitis: new treatment protocol? J Endod 2004;30:196-200.

Normas internas do Programa de Pós-Graduação em Odontopediatria da FORP-USP (2009), de acordo com o International Comitte of Medicals Journals Editors. Uniform Requirements for manuscripts submitted to Medical Journal, 1997. Disponível em: http://www.mja.com.au/public/information/uniform.html. Acesso em setembro de 2009. 
Barbosa CAM, Goncalves RB, Siqueira Jr JF, De Uzeda M. Evaluation of the antibacterial activities of calcium hydroxide, chlorhexidine, and camphorated paramonochlorophenol as intracanal medicament. A clinical and laboratory study. J Endod 1997;23:297-300.

Barnes JJ, Patel S. Contemporary endodontics - part 1. Br Dent J 2011;211:463-8.

Barthel C, Zimmer S, Zilliges S, Schiller R, Göbel UB, Roulet JF. In situ antimicrobial effectiveness of chlorhexidine and calcium hydroxide: gel and paste versus gutta-percha points. J Endod 2002;28:427-30.

Basrani B, Ghanem A, Tjäderhane L. Physical and chemical properties of chlorhexidine and calcium hydroxide-containing medications. J Endod 2004;30:413-7.

Basrani B, Santos JM, Tjäderhane L, Grad H, Gorduysus O, Huang J, Lawrence HP, Friedman S. Substantive antimicrobial activity in chlorhexidine-treated human root dentin. Oral Surg Oral Med Oral Pathol Oral Radiol Endod 2002;94:240-5.

Basrani B, Tjäderhane L, Santos JM, Pascon E, Grad H, Lawrence HP, Friedman S. Efficacy of chlorhexidine-and calcium hydroxide-containing medicaments against Enterococcus faecalis in vitro. Oral Surg Oral Med Oral Pathol Oral Radiol Endod 2003;96:618-24.

Bates DO, Hillman NJ, Williams B, Neal CR, Pocock TM. Regulation of microvascular permeability by vascular endothelial growth factors. J Anat 2002;200:581-97.

Beklen A, Ainola M, Hukkanen M, Gürgan C, Sorsa T, Konttinen YT. MMPs, IL-1, and TNF are regulated by IL-17 in periodontitis. J Dent Res 2007;86:347-51.

Benjamin LE, Hemo I, Keshet E. A plasticity window for blood vessel remodelling is defined by pericyte coverage of the preformed endothelial network and is regulated by PDGF-B and VEGF. Development 1998;125:1591-8.

Bhalla M, Thami GP, Singh N. Ciprofloxacin-induced erythema nodosum. Clin Exp Dermatol 2007;32:115-6.

Bilate AMB. Inflamação, citocinas, proteínas de fase aguda e implicações terapêuticas. Temas de Reumatol Clin 2007;8:47-51.

Birkedal-Hansen $\mathrm{H}$. Role of matrix metalloproteinases in human periodontal diseases. J Periodontol 1993;64:474-84.

Bortolo MV. Análise comparativa da reação tecidual à implantação de tubos de polietileno, bastões de dentina e cápsulas de colágeno. Estudo microscópico em tecido subcutâneo de ratos. Avaliação de um modelo metodológico [dissertação]. Bauru: Faculdade de Odontologia de Bauru da Universidade São Paulo; 2009.

Bose R, Nummikoski P, Hargreaves K. A retrospective evaluation of radiographic outcomes in immature teeth with necrotic root canal systems treated with regenerative endodontic procedures. J Endod 2009;35:1343-9. 
Buck RA, Cai J, Eleazer PD, Staat RH, Hurst HE. Detoxification of endotoxin by endodontic irrigants and calcium hydroxide. J Endod 2001;27:325-7.

Byrne AM, Bouchier-Hayes DJ, Harmey JH. Angiogenic and cell survival functions of vascular endothelial growth factor (VEGF). J Cell Mol Med 2005;9:777-94.

Byström A, Claesson R, Sundqvist G. The antibacterial effect of camphorated paramonochlorophenol, camphorated phenol and calcium hydroxide in the treatment of infected roots canals. Endod Dent Traumatol 1985;1:170-5.

Campos EC, O'Connell JL, Malvestio LM, Romano MMD, Ramos SG, Celes MRN, Prado CM, Simões MV, Rossi MA. Calpain-mediated dystrophin disruption may be a potential structural culprit behind chronic doxorubicin-induced cardiomyopathy. Eur J Pharmacol 2011;670:541-53.

Carmi Y, Voronov E, Dotan S, Lahat N, Rahat MA, Fogel M, Huszar M, White MR, Charles A. Dinarello CA, Apte RN. The role of macrophage-derived IL-1 in induction and maintenance of angiogenesis. J Immunol 2009;183:4705-14.

Carrotte P. Endodontics: Part 9. Calcium hydroxide, root resorption, endo-perio lesions. Br Dent J 2004;197:735-43.

Chorilli M, Michelin DC, Salgado HRN. Animais de laboratório: o camundongo. Rev Ciênc Farm Básica Apl 2007;28:11-23.

Cintra LTA, Bernabé PFE, Moraes IG, Gomes-Filho JE, Okamoto T, Consolaro A, Pinheiro TN. Evaluation of subcutaneous and alveolar implantation surgical sites in the study of the biological properties of root-end filling endodontic materials. J Appl Oral Sci 2010;18:75-82.

Cohenca N, Heilborn C, Johnson JD, Flores DSH, Ito IY, Silva LAB. Apical negative pressure irrigation versus conventional irrigation plus triantibiotic intracanal dressing on root canal disinfection in dog teeth. Oral Surg Oral Med Oral Pathol Oral Radiol Endod 2010;109:42-6.

Coussens LM, Werb Z. Inflammation and cancer. Nature 2002;420:860-7.

Cramer T, Yamanishi Y, Clausen BE, Förster I, Pawlinski R, Nigel Mackman N, Haase VH, Jaenisch R, Corr M, Nizet V, Firestein GS, Gerber HP, Ferrara N, Randall S. Johnson RS. HIF-1a is essential for myeloid cell-mediated inflammation. Cell 2003;112:645-57.

Curran S, Murray GI. Matrix metalloproteinases: molecular aspects of their roles in tumour invasion and metastasis. Eur J Cancer 2000;36:1621-30.

Cvek M. Prognosis of luxated non-vital maxillary incisors treated with calcium hydroxide and filled with gutta-percha. A retrospective clinical study. Endod Dent Traumatol 1992;8:45-55.

Dametto FR, Ferraz CCR, Gomes BPFA, Zaia AA, Teixeira FB, Souza-Filho FJ. In vitro assessment of the immediate and prolonged antimicrobial action of chlorhexidine gel as an endodontic irrigamt against Enterococcus faecalis. Oral Surg Oral Med Oral Pathol 2005;99:768-72.

Damico FM. Angiogênese e doenças da retina. Arq Bras Oftalmol 2007;70:547-53. 
Dammaschke T, Schneider U, Stratmann U, Yoo JM, Schäfer E. Effect of root canal dressings on the regeneration of inflamed periapical tissue. Acta Odontol Scand 2005;63:143-52.

Danesh F, Zahra T, Jahanbani J, Rabiee M, Fazelipour S, Taghva O, Shabaninia S. Biocompatibility and mineralization activity of fresh or set white mineral trioxide aggregate, biomimetic carbonated apatite, and synthetic hydroxyapatite. J Endod 2010;36:1036-41.

D'Arcangelo C, Varvara G, De Fazio P. An evaluation of the action of different root canal irrigants on facultative aerobic-anaerobic, obligate anaerobic, and microaerophilic bacteria. J Endod 1999;25:351-3.

De Rossi A, Silva LAB, Leonardo MR, Rocha LB, Rossi MA. Effect of rotary or manual instrumentation, with or without a calcium hydroxide/ $1 \%$ chlorhexidine intracanal dressing, on the healing of experimentally induced chronic periapical lesions. Oral Surg Oral Med Oral Pathol Oral Radiol Endod 2005;99:628-36.

Dehne N, Brüne B. HIF-1 in the inflammatory microenvironment. Exp Cell Res 2009;315:1791-7.

Delgado EMS. Estudo da biocompatibilidade de uma pasta à base de hidróxido de cálcio associada à clorexidina a 1\%, no tecido conjuntivo subcutâneo da pata de ratos [dissertação]. Araraquara: Faculdade de Odontologia de Araraquara da Universidade Estadual Paulista; 2002.

Delgado RJR, Gasparoto TH, Sipert CR, Pinheiro CR, Moraes IG, Garcia RB, Bramante CM, Campanelli AP, Bernardineli N. Antimicrobial effects of calcium hydroxide and chlorhexidine on Enterococcus faecalis. J Endod 2010;36:1389-93.

Dinarello CA. Biologic basis for interleukin-1 in disease. Blood 1996;15;87:2095-147.

Dinarello CA. Immunological and inflammatory functions of the interleukin-1 family. Annu Rev Immunol 2009;27:519-50.

Ding RY, Cheung GS, Chen J, Yin XZ, Wang QQ, Zhang CF. Pulp revascularization of immature teeth with apical periodontitis: a clinical study. J Endod 2009;35:745-9.

Distel JW, Hatton JF, Gillespie MJ. Biofilm formation in medicated root canals. J Endod 2002; 28:689-93.

Dwivedi VP, Tousif S, Bhattacharya D, Kaer LV, Das J, Das G. Transforming growth factor-b inversely regulates the in vivo differentiation of $\mathrm{IL}-17$-producing $\mathrm{CD}^{+}$and $\mathrm{CD}^{+} \mathrm{T}$ cells. J Biol Chem 2011. No prelo.

El Karin I, Kennedy J, Hussey D. The antimicrobial effects of root canal irrigation and medication. Oral Surg Oral Med Oral Pathol Oral Radiol Endod 2007;103:560-9.

Er K, Kustarci A, Ozan U, Tasdemir T. Nonsurgical endodontic treatment of dens invaginatus in a mandibular premolar with large periradicular lesion: a case report. J Endod 2007;33:322-4.

Ercan E, Dalli M, Duulgergil CT, Yaman F. Effect of intracanal medication with calcium hydroxide and $1 \%$ chlorhexidine in endodontic retreatment cases with periapical lesions: an in vivo study. J 
Formos Med Assoc 2006;106:217-24.

Evans M, Davies JK, Sundqvist G, Figdor D. Mechanisms involved in the resistance of Enterococcus faecalis to calcium hydroxide. Int Endod J 2002;35:221-8.

Evans MD, Baumgartner JC, Khemaleelakul S, Xia T. Efficacy of calcium hydroxide: chlorhexidine paste as an intracanal in bovine dentin. J Endod 2003;29:338-9.

Faria G, Cardoso C, Larson R, Silva J, Rossi M. Chlorhexidine-induced apoptosis or necrosis in L929 fibroblasts: A role for endoplasmic reticulum stress. Toxicol Appl Pharmacol 2009; 234;256-65.

Faria G, Celes MRN, De Rossi A, Silva LAB, Silva JS, Rossi MA. Evaluation of chlorhexidine toxicity injected in the paw of mice and added to cultures L929 fibroblasts. J Endod 2007;33:715-22.

Faria G, Nelson-Filho P, Freitas AC, Assed S, Ito IY. Antibacterial effect of root canal preparation and calcium hydroxide paste (Calen) intracanal dressing in primary teeth with apical periodontitis. ] Appl Oral Sci 2005;13:351-5.

Faria G, Silva RAB, Fiori Júnior M, Nelson-Filho P. Re-eruption of traumatically intruded mature permanent incisor: case report. Dental Traumatology 2004;20:229-32.

Ferrara N, Davis-Smyth T. The biology of vascular endothelial growth factor. Endocr Rev 1997;18:4-24.

Ferrara N, Gerber HP, Lecouter J. The biology of VEGF and its receptors. Nat Med 2003;9:66976.

Ferrara N, Houck K, Jakeman L, Leung DW. Molecular and biological properties of the vascular endothelial growth factor family of proteins. Endocr Rev 1998;13:18-32.

Ferraz CCR, Gomes BPFA, Zaia AA, Teixeira FB, Souza-Filho FJ. In vitro assessment of the antimicrobial action and mechanical ability or chlorhexidine gel as an endodontic irrigant. J Endod 2001;27:452-5.

Ferreira MB, Myiagi S, Nogales CG, Campos MS, Lage-Marques JL. Time-and concentrationdependent cytotoxicity of antibiotics used in endodontic therapy. J Appl Oral Sci 2010;18:25963.

Figdor D, Davies JK, Sundqvist G. Starvation survival, growth and recovery of Enterococcus faecalis in human serum. Oral Microbiol Immunol 2003;18:234-9.

Folgueras AR, Pendás AM, Sánchez LM, López-Otín C. Matrix metalloproteinases in cancer: from new functions to improved inhibition strategies. Int J Dev Biol 2004;48:411-24.

Foreman PC, Barnes IE. A review of calcium hydroxide. Int Endod J 1990;23:283-97.

Fraisl P, Mazzone M, Schmidt T, Carmeliet P. Regulation of angiogenesis by oxygen and metabolism. Developmental Cell 2009;17:167-79. 
Fukushima A, Kajiya H, Izumi T, Shigeyama C, Okabe K, Anan H. Pro-inflammatory cytokines induce suppressor of cytokine signaling-3 in human periodontal ligament cells. J Endod 2010;36:1004-8.

Gangwar A. Antimicrobial effectiveness of different preparations of calcium hydroxide. Indian J Dent Res 2011;22:66-70.

Garcia LFR, Lia RCC, Lopes RA, Oliveira DA, Pires-De-Souza FCP, Santos, HSL. Análise morfológica e morfométrica do tecido subcutâneo de ratos submetidos à ação de pasta de hidróxido de cálcio e óleo de Ricinus communis. Cienc Odontol Bras 2008;11:47-54.

Goldberg GI, Strongin A, Collier IE, Genrich LT, Marmer BL. Interaction of 92-kDa type IV collagenase with the tissue inhibitor of metalloproteinases prevents dimerization, complex formation with interstitial collagenase, and activation of the proenzyme with stromelysin. J Biol Chemistr 1992;267:4583-91.

Gomes BPFA, Ferraz CCR, Vianna ME, Rosalen PL, Zaia AA, Teixeira FB, Souza-Filho FJ. In vitro antimicrobial activity of calcium hydroxide pastes and their vehicles against selected microorganisms. Braz Dent J 2002;13:155-61.

Gomes BPFA, Martinho FC, Vianna ME. Comparison of $2.5 \%$ sodium hypochlorite and $2 \%$ chlorhexidine gel on oral bacterial lipopolysaccharide reduction from primarily infected root canals. J Endod 2009a;35:1350-3.

Gomes BPFA, Montagner F, Berber VB, Zaia AA, Ferraz CCR, de Almeida JFA, Souza-Filho FJ. Antimicrobial action of intracanal medicaments on the external root surface. J Dent 2009b;37:76-81.

Gomes BPFA, Souza SFC, Ferraz CCR, Teixeira FB, Zaia AA, Valdrighi L, Souza-Filho FJ. Effectiveness of $2 \%$ chlorhexidine gel and calcium hydroxide against Enterococcus faecalis in bovine root dentine in vitro. Int Endod J 2003;36:267-75.

Gomes BPFA, Vianna ME, Sena NT, Zaia AA, Ferraz CCR, Souza-Filho FJ. In vitro evaluation of the antimicrobial activity of calcium hydroxide combined with chlorhexidine gel used as intracanal medicament. Oral Surg Oral Med Oral Pathol Oral Radiol Endod 2006;102:544-50.

Gomes-Filho JE, Aurélio KG, Costa MMTM, Bernabé PFE. Comparison of the biocompatibility of different root canal irrigants. J Appl Oral Sci 2008;16:137-44.

Gomes-Filho JE, Duarte PCT, Oliveira CB, Watanabe S, Lodi CS, Cintra LTA, Bernabé PFE. Tissue reaction to a triantibiotic paste used for endodontic tissue self-regeneration of nonvital immature permanent teeth. J Endod 2012;38:91-4.

Gomez DE. Tissue inhibitors of metalloproteinases: structure, regulation and biological functions. Eur J Cell Biol 1997;74:111-22.

Gondim JO, Avaca-Crusca JS, Valentini SR, Zanelli CF, Spolidorio DM, Giro EM. Effect of a calcium hydroxide/chlorhexidine paste as intracanal dressing in human primary teeth with necrotic pulp against Porphyromonas gingivalis and Enterococcus faecalis. Int J Paediatr Dent 
2011. No prelo.

Greenstein G, Polson A. The role of local drug delivery in the management of periodontal diseases: a comprehensive review. J Periodontol 1998;69:507-20.

Grossman LI. Polyantibiotic treatment of pulpless teeth. J Amer Dent Assoc 1951;43:265-78.

Haenni S, Schmidlin PR, Mueller B, Sener B, Zehnder M. Chemical and antimicrobial properties of calcium hydroxide mixed with irrigating solutions. Int Endod J 2003;36:100-5.

Hargreaves KM, Geisler T, Henry M, Wang Y. Regeneration potential of the young permanent tooth: what does the future hold? J Endod 2008;34:51-6.

Heithersay GS. Calcium hydroxide in the treatment of pulpless teeth with associated pathology. J Br Endod Soc 1975;8:74-93.

Heling I, Steinberg D, Kenig S, Gavrilovich I, Sela MN, Friedman M. Efficacy of a sustainedrelease device containing chlorhexidine and $\mathrm{Ca}(\mathrm{OH})_{2}$ in preventing secondary infection of dentinal tubules. Int Endod J 1992;25:20-4.

Hiratsuka S, Nakamura K, Iwai S, Murakami M, Itoh T, Kijima H, Shipley JM, Senior RM, Shibuya M. MMP 9 induction by vascular endothelial growth factor receptor-1 is involved in lung-specific metastasis. Cancer Cell 2002;2:289-300.

Ho JCK, Konerding MA, Gaumann A, Groth M, Liu WK. Fungal polysaccharopeptide inhibits tumor angiogenesis and tumor growth in mice. Life Sci 2004;75:1343-56.

Hood JD, Meininger CJ, Ziche M, Granger HJ. VEGF upregulates ecNOS message, protein, and NO production in human endothelial cells. Am J Physiol Heart Circ Physiol 1998;274:1054-8.

Hoshino E, Kurihara-Ando N, Sato I, Uematsu H, Sato M, Kota K, Iwaku M. In-vitro antibacterial susceptibility of bacteria taken from infected root dentine to a mixture of ciprofloxacin, metronidazole and minocycline. Int Endod J 1996;29:125-30.

Howard EW, Bullen EC, Banda MJ. Preferential inhibition of 72- and 92-kDa gelatinase by tissue inhibitor of metaloproteinases-2. J Biol Chem 1991;266:13070-5.

Huang GTJ. A paradigm shift in endodontic management of immature teeth: conservation of stem cells for regeneration. J Dent 2008;36:379-86.

Imtiyaz HZ, Simon MC. Hypoxia-inducible factors as essential regulators of inflammation. Curr Top Microbiol Immunol 2010;345:105-20.

ISO 10993-6: 2007, Biological evaluation of medical devices. Part 6: Tests for local effects after implantation.

Iwaya S, Motohide Ikawa M, Kubota M. Revascularization of an immature permanent tooth with periradicular abscess after luxation. Dent Traumatol 2011;27:55-8. 
Jung IY, Lee SJ, Hargreaves KM. Biologically based treatment of immature permanent teeth with pulpal necrosis: a case series. J Endod 2008;34:876-87.

Jungermann GB, Burns K, Nandakumar R, Tolba M, Venezia RA, Fouad AF. Antibiotic resistance in primary and persistent endodontic infections. J Endod 2011;37:1337-44.

Junqueira LCU, Bignolas G, Brentani RR. Picrosirius staining plus polarization microscopy, a specific method for collagen detection in tissue sections. Histochem J 1973;11:447-55.

Kandaswamy D, Venkateshbabu N, Gogulnath D, Kindo AJ. Dentinal tubule disinfection with 2\% chlorhexidine gel, propolis, morinda citrifolia juice, $2 \%$ povidone iodine, and calcium hydroxide. Int Endod J 2010;43:419-23.

Kanisavaran ZM. Chlorhexidine gluoconate in endodontics: an uptade review. Int Dent J 2008;58:247-57.

Kawashima N, Wadachi R, Suda H, Yeng T, Parashos P. Root canal medicaments. Int Dent J 2009;59:5-11.

Kim JB, Jung MH, Cho JY, Park JW, Suh JY, Lee JM. The influence of type 2 diabetes mellitus on the expression of inflammatory mediators and tissue inhibitor of metalloproteinases-2 in human chronic periodontitis. J Periodontal Implamt Sci 2011;41:109-16.

Kim JH, Kim Y, Shin SJ, Parkk JW, Jung IY. Tooth discoloration of immature permanent incisor associated with triple antibiotic therapy: a case report. J Endod 2010;36:1086-91.

Komorowski R, Grad H, Wu XY, Friedman S. Antimicrobial substantivity of chlorhexidine-treated bovine root dentin. J Endod 2000;26:315-7.

Krithikadatta J, Indira R, Dorothykalyani AL. Disinfection of dentinal tubules with $2 \%$ chlorhexidine, $2 \%$ metronidazole, bioactive glass when compared with calcium hydroxide as intracanal medicaments. J Endod 2007;33:1473-6

Kroll J, Waltenberger J. A novel function of VEGF receptor-2 (KDR): rapid release of nitric oxide in response to VEGF-A stimulation in endothelial cells. Biochem Biophys Res Commun 1999; 265:636-9.

Kuga MC, Campos EA, Resende T, Camargo MF, Sant'Anna-Filho A, Monteiro JCC. Influência da dentina na liberação de íons hidrogênio em pasta de hidróxido de cálcio associada à clorexidina. Perspect Oral Sci 2010;2:27-30.

Kusgoz A, Yildirim S, Gokalp A. Nonsurgical endodontic treatments in molar teeth with large periapical lesions in children: 2-year follow-up. Oral Surg Oral Med Oral Pathol Oral Radiol Endod 2007; 104:60-5.

Kusgoz A, Yildirim T, Er K, Arslan I. Retreatment of a resected tooth associated with a large periradicular lesion by using a triple antibiotic paste and mineral trioxide aggregate: a case report with a thirty-month follow-up. J Endod 2009;35:1603-6. 
Kyriakides TR, Zhu YH, Yang Z, Huynh G, Bornstein P. Altered extracellular matrix remodeling and angiogenesis in sponge granulomas of thrombospondin 2-null mice. Am J Pathol 2001;159:1255-62.

Lamoreaux WJ, Fitzgerald MEC, Reiner A, Hasty KA, Charles ST. Vascular endothelial growth factor increases release of gelatinase $A$ and decreases release of tissue inhibitor of metalloproteinases by microvascular endothelial cells in vitro. Microvasc Res 1998;55:29-42.

Lana MA, Ribeiro-Sobrinho AP, Stheling R, Garcia GD, Silva BTC, Hamdan S. Microorganisms isolated from root canals presenting necrotic pulp and their drug susceptibility in vitro. Oral Microbiol Immunol 2001;15:100-5.

Lana PEP, Scelza MFZ, Silva LE, Mattos-Guaraldi AL, Hirata Júnior R. Antimicrobial activity of calcium hydroxide pastes on Enterococcus faecalis cultivated in root canal systems. Braz Dent J 2009;20:32-6.

Lee $\mathrm{Y}$, Han $\mathrm{SH}$, Hong $\mathrm{SH}$, Lee $\mathrm{JK}, \mathrm{Ji} \mathrm{H}$, Kum KY. Antimicrobial efficacy of a polymeric chlorhexidine release device using in vitro model of Enterococcus faecalis dentinal tubule infection. J Endod 2008;34:855-8.

Lenet BJ, Komorowski R, Wu XY, Huang J, Grad H, Lawrence HP, Friedman S. Antimicrobial substantivity of bovine root dentin exposed to different chlorhexidine delivery vehicles. J Endod 2000;26:652-5.

Leonardo MR, Almeida WA, Ito IY, Silva LAB. Radiographic and microbiologic evaluation of posttreatment apical and periapical repair of root canals of dogs' teeth with experimentally induced chronic lesion. Oral Surg Oral Med Oral Pathol 1994;78:232-8.

Leonardo MR, Hernandez MEFT, Silva LAB, Tanomaru-Filho M. Effect of a calcium hydroxidebased root canal dressing on periapical repair in dogs: a histological study. Oral Surg Oral Med Oral Pathol Oral Radiol Endod 2006;102:680-5.

Leonardo MR, Rossi MA, Silva LA, Ito IY, Bonifacio KC. EM evaluation of bacterial biofilm and microorganisms on the apical external root surface of human teeth. J Endod 2002;28:815-8.

Leonardo MR, Silva BLA, Leonardo RT, Utrilla LS. Histological evaluation of therapy using a calcium hydroxide dressing for teeth with incompletely formed apices and periapical lesions. J Endod 1993;19:348-52.

Leonardo MR, Silva LAB, Assed S, Tanomaru-Filho M, Bonifacio KC, Ito IY. In vitro evaluation of antimicrobial activity of sealers and pastes used in endodontics. J Endod 2000;26:391-4.

Leonardo MR. Endodontia. Tratamento de canais radiculares: princípios técnicos e biológicos. São Paulo: Artes Médicas; 2005.

Leung DW, Cachianes G, Kuang WJ, Goeddel DV, Ferrara N. Vascular endothelial growth factor is a secreted angiogenic mitogen. Science 1989;246:1306-9.

Leung SF. Revascularization of immature permanent teeth with periapical lesions-report of three 
consecutive cases. Hong Kong Dent J 2010;7:31-5.

Liang SC, Hosur KB, Domon $\mathrm{H}$, Hajishengallis G. Periodontal inflammation and bone loss in aged mice. J Periodontal Res 2010;45:574-8.

Liang SC, Long AJ, Bennett F, Whitters MJ, Karim R, Collins M, Goldman SJ, DunussiJoannopoulos K, Williams CMM, Wright JF, Fouser LA. An IL-17F/A heterodimer protein is produced by mouse Th17 cells and induces airway neutrophil recruitment. J Immunol 2007;179:7791-9.

Lima KC, Fava LRG, Siqueira Jr JF, Susceptibilities of Enterococcus faecalis biofilms to some antimicrobial medications. J Endod 2001;27:616-9.

Lima RK, Guerreiro-Tanomaru JM, Faria-Júnior NB, Tanomaru-Filho M. Effectiveness of calcium hydroxide-based intracanal medicaments against Enterococcus faecalis. Int Endod J 2011. No prelo.

Lin LM, Rosenberg PA. Repair and regeneration in endodontics. Int Endod J 2011;44:889-906.

Lin Y, Mickel AK, Chogle S. Effectiveness of selected materials against Enterococcus faecalis. Part 3. The antibacterial effect of calcium hydroxide and chlorhexidine on Enterococcus faecalis. J Endod 2003;29:565-6.

Lindskog S, Pierce AM, Blomlöf L. Chlorhexidine as a root canal medicament for treating inflamatory lesions in the periodontal space. Endod Dent Traumatol 1998;14:186-90.

Longman LP, Preston AJ, Martin MV, Wilson NHF. Endodontics in the adult patient: the role of antibiotics. J Dent 2000;28:539-48.

Love RM. Enterococcus faecalis - a mechanism for its role in endodontic failure. Int Endod J 2001;34:399-405.

Lovelace TW, Henry MA, Hargreaves KM, Diogenes A. Evaluation of the delivery of mesenchymal stem cells into the root canal space of necrotic immature teeth after clinical regenerative endodontic procedure. J Endod 2011;37:133-8.

Lynne RE, Liewehr FR, West LA, Patton WR, Buxton TB, McPherson JC. In vitro antimicrobial activity of various medication preparations on $E$. faecalis in root canal dentin. J Endod 2003;29:187-90.

Madhubala MM, Srinivasan N, Ahamed S. Comparative evaluation of propolis and triantibiotic mixture as an intracanal medicament against Enterococcus faecalis. J Endod 2011;37:1287-9.

Malkhassian G, Manzur AJ, Legner M, Fillery ED, Manek S, Basrani BR, Friedman S. Antibacterial efficacy of MTAD final rinse and two percent chlorhexidine gel medication in teeth with apical periodontitis: a randomized double-blinded clinical trial. J Endod 2009;35:1483-90.

Mandriota SJ, Seghezzi G, Vassalli JD, Ferrara N, Wasi S, Mazzieri R, Mignatti P, Pepper MS. Vascular endothelial growth factor increases urokinase receptor expression in vascular 
endothelial cells. J Biol Chem 1995;270:9709-16.

Manzur A, González AM, Pozos A, Silva-Herzog D, Friedman S. Bacterial quantification in teeth with apical periodontitis related to instrumentation and different intracanal medications: a randomized clinical trial. J Endod 2007;33:114-8.

Marchesan MA, Alfredo E, Sufredini AR, Matoso FB, Vansan LP, Sousa Neto MD. Tratamento de dentes traumatizados com rizogênese incompleta - apicificação. RSBO 2008;5:58-62.

Marrie TJ, Haldane EV, Swantee CA, Kerr EA. Susceptibility of anaerobic bacteria to nine antimicrobial agents and demonstration of decreases susceptibility of Clostridium perfringes to penicilin. Antimicrob Agent Chemother 1981;19:51-5.

Martinho FC, Cintra LTA, Zaia AA, Ferraz CCR, Almeida JFA, Gomes BPFA. Efeito antimicrobiano de diferentes substâncias químicas associadas ao preparo mecânico e da medicação intracanal em dentes de cães portadores de lesões periapicais induzidas. Dental Press Endod 2011;1:3745.

McGurkin-Smith R, Trope M, Caplan D, Sigurdsson A. Reduction of intracanal bacteria using GT rotary instrumentation, $5.25 \% \mathrm{NaOCl}$, EDTA, and $\mathrm{Ca}(\mathrm{OH})_{2}$. J Endod 2005;31:359-63.

McMahon S, Charbonneau M, Grandmont S, Richard DE, Dubois CM. Transforming growth factor $\beta 1$ induces hypoxia-inducible factor-1 stabilization through selective inhibition of PHD2 expression. J Biol Chem 2006;281:24171-81.

Michelotto ALC, Andrade BM, Silva Júnior JA, Sydney GB. Clorexidina na terapia endodôntica. RSBO 2008;5:77-89.

Mohammadi Z, Abbott PV. On the local applications of antibiotics and antibiotic-based agents in endodontics and dental traumatology. Int Endod J 2009a;42:555-67.

Mohammadi Z, Abbott PV. The properties and applications of chlorhexidine in endodontics. Int Endod J 2009b;42:288-302.

Mohammadi Z, Dummer PMH. Properties and applications of calcium hydroxide in endodontics and dental traumatology. Int Endod J 2011;44:697-730.

Mohammadi Z. Antibiotics as intracanal medicaments: a review. CDA J 2009;37:99-108.

Moromizato Y, Stechschulte S, Miyamoto K, Murata T, Tsujikawa A, Joussen AM, Adamis AP. CD18 and ICAM-1-dependent corneal neovascularization and inflammation after limbal injury. Am J Pathol 2000;157:1277-81.

Murray PE, Garcia-Godoy F, Hargreaves KM. Regenerative endodontics: a review of current status and a call for action. J Endod 2007;33:377-90.

Nair PNR, Henry S, Cano V, Vera J. Microbial status of apical root canal system of human mandibular first molars with primary apical periodontitis after one-visit endodontic treatment. Oral Surg Oral Med Oral Pathol Oral Radiol Endod 2005;99:231-52. 
Nakajo K, Nakazawa F, Iwaku M, Hoshino E. Alkali-resistant bacteria in root canal systems. Oral Microbiol Immunol 2004;19:390-4.

Nakornchai S, Banditsing P, Visetratana N. Clinical evaluation of 3Mix and Vitapex ${ }^{\circledR}$ as treatment options for pulpally involved primary molars. Int J Paediat Dent 2010;20:214-21.

Naldini A, Carraro F. Role of inflammatory mediators in angiogenesis. Curr Drug Targets Inflamm Allergy 2005;4:3-8.

Nassri MRG, Lia RCC, Bombana AC. Análise da resposta tecidual de dois cimentos endodônticos. J Appl Oral Sci 2003;11:9-14.

Navarro VP, Nelson-Filho P, Silva LAB, Freitas AC. The participation of matrix metalloproteinases in the physiopathological processes of the oral cavity. Rev Odontol UNESP 2006;35:233-8.

Neelakantan P, Sanjeev K, Subbarao CV. Duration-dependent susceptibility of endodontic pathogens to calcium hydroxide and chlorhexidene gel used as intracanal medicament: an in vitro evaluation. Oral Surg Oral Med Oral Pathol Oral Radiol Endod 2007;104:138-41.

Nelson-Filho P, Faria G, Assed S, Pardini LC. Surgical repositioning of traumatically intruded permanent incisor: case report with a 10-year follow up. Dental Traumatol 2006;22;221-5.

Nelson-Filho P, Leonardo MR, Silva LAB, Assed S. Radiographic evaluation of the effect of endotoxin (LPS) plus calcium hydroxide on apical and periapical tissues of dogs. J Endod 2002; 28:694-6.

Nelson-Filho P, Silva LAB, Leonardo MR, Utrilla LS. Connective tissue responses to calcium hydroxide based root canal medicaments. Int Endod J 1999;32:303-11.

Nerwich A, Figdor D, Messer HH. pH changes in root dentin over a 4-week period following root canal dressing with calcium hydroxide. J Endod 1993;19:302-6.

Nosrat A, Seifi A, Asgary S. Regenerative endodontic treatment (revascularization) for necrotic immature permanent molars: a review and report of two cases with a new biomaterial. J Endod 2011;37:562-7.

Olsson B, Sliwkowski A, Langeland K. Subcutaneous implantation for the biological evaluation of endodontic materials. J Endod 1981;7:355-69.

Onçag O, Gogulu D, Uzel A. Efficacy of various intracanal medicaments against Enterococcus faecalis in primary teeth: an in vivo study. J Clin Pediatr Dent 2006;30:233-7.

Ørstavik D, Haapasalo M. Disinfection by endodontic irrigants and dressings of experimentally infected dentinal tubules. Endod Dent Traumatol 1990;6:142-9.

Paquette L, Legner M, Fillery ED, Friedman S. Antibacterial efficacy of chlorhexidine gluconate intracanal medication in vivo. J Endod 2007;33:788-95.

Parirokh M, Torabinejad M. Mineral trioxide aggregate: a comprehensive literature review-part III: clinical applications, drawbacks, and mechanism of action. J Endod 2010;36:400-13. 
Paula-Silva FWG, Silva LAB, Kapila YL. Matrix metalloproteinase expression in teeth with apical periodontitis is differentially modulated by the modality of root canal treatment. J Endod 2010;36:231-7.

Peck A, Mellins ED. Breaking old paradigms: Th17 cells in autoimmune arthritis. Clin Immunol 2009;132:295-304.

Pelletier M, Maggi L, Micheletti A, Lazzeri E, Tamassia N, Costantini C, Cosmi L, Lunardi C, Annunziato F, Romagnani S, Cassatella MA. Evidence for a cross-talk between human neutrophils and Th17 cells. Blood 2010;115:335-43.

Pepper MS, Ferrara N, Orci L, Montesano R. Vascular endothelial growth factor (VEGF) induces plasminogen activators and plasminogen activator inhibitor-1 in microvascular endothelial cells. Biochem Biophys Res Commun 1991;181:902-6.

Petrino JA, Boda KK, Shambarger S, Bowles WR, McClanahan SB. Challenges in regenerative endodontics: a case series. J Endod 2010;36:536-41.

Pinky C, Shashibhushan KK, Subbareddy VV. Endodontic treatment of necrosed primary teeth using two different combinations of antibacterial drugs: an in vivo study. J Indian Soc Pedod Prev Dent 2011;29:121-7.

Piotrowski WJ, Nawrocka-Kunecka A, Antczak A, Marczak J, Biernacki R, Kordek P, Kurmanowska Z, Górski P. Metalloproteinases MMP-9, MMP-2 and their tissue inhibitors TIMP-1, TIMP-2 in peripheral transbronchial lung biopsies of patients with sarcoidosis. Pol Arch Med Wewn 2009;119:628-34.

Podbielski A, Spahr A, Haller B. Additive antimicrobial activity of calcium hydroxide and chlorhexidine on common endodontic bacterial pathogens. J Endod 2003;29:340-5.

Portenier I, Haapasalo H, Rye A, Waltimo T, Ørstavik D, Haapasalo M. Inactivation of root canal medicaments by dentine, hydroxylapatite and bovine serum albumin. Int Endod J 2001;34:1848.

Prabhakar AR, Sridevi E, Raju OS, Satish V. Endodontic treatment of primary teeth using combination of antibacterial drugs: An in vivo study. J Indian Soc Pedod Prev Dent 2008;26:510 .

Prado MP, Carvalho Júnior $A E$, Fernandes TD. Estudo da densidade vascular do tendão do músculo tibial posterior em cadáveres. Rev Bras Ortop 2000;35:53-66.

Queiroz AM, Assed S, Consolaro A, Nelson-Filho P, Leonardo MR, Silva RAB, Silva LAB. Subcutaneous connective tissue response to primary root canal filling materials. Braz Dent J 2011;22:203-11.

Rafter M. Apexification: a review. Dent Traumatol 2005;21:1-8.

Reyes-Carmona JF, Santos ARS, Figueiredo CP, Felippe MS, Felippe WT, Cordeiro MM. In vivo host interactions with mineral trioxide aggregate and calcium hydroxide: inflammatory molecular 
signaling assessment. J Endod 2011. No prelo.

Reynolds K, Johnson JD, Cohenca N. Pulp revascularization of necrotic bilateral bicuspids using a modified novel technique to eliminate potential coronal discolouration: a case report. Int Endod J 2009;42:84-92.

Ribeiro RIMA, Borges Júnior PC, Cardoso SV, Candelori I, Espíndola FS, Cassali GD, Loyola AM. Expressão de metaloproteinases de matriz e de seus inibidores teciduais em carcinomas basocelulares. J Bras Patol Med Lab 2008;44:115-21.

Roberts $A B$, McCune BK, Sporn MB. TGF-beta: regulation of extracellular matrix. Kidney Int 1992;41:557-9.

Rosenthal S, Spångberg L, Safavi K. Chlorhexidine substantivity in root canal dentin. Oral Surg Oral Med Oral Pathol Oral Radiol Endod 2004;98:488-92.

Safavi KE, Nichols FC. Effect of calcium hydroxide on bacterial lipopolysaccharide. J Endod 1993;19:76-8.

Sakurai E, Anand A, Ambati BK, van Rooijen N, Ambati J. Macrophage depletion inhibits experimental choroidal neovascularization. Invest Ophthalmol Vis Sci 2003;44:3578-85.

Santos BF. Criação e manejo de camundongos. In: Andrade A, Pinto SC, Oliveira RS. Animais de laboratório: criação e experimentação. Rio de Janeiro: Fiocruz; 2002. p.115-8.

Sathorn C, Parashos P, Messer H. Australian endodontists' perceptions of single and multiple visit root canal treatment. Int Endod J 2009;42:811-8

Sato I, Ando-Kurihara N, Kota K, Iwaku M, Hoshino E. Sterilization of infected root-canal dentine by topical application of a mixture of ciprofloxacin, metronidazole and minocycline in situ. Int Endod J 1996;29:118-24.

Scarparo RK, Dondoni L, Böttcher DE, Grecca FS, Rockenbach MI, Batista EL Jr. Response to intracanal medication in immature teeth with pulp necrosis: an experimental model in rat molars. J Endod. 2011;37:1069-73.

Schäfer E, Bössmann K. Antimicrobial efficacy of chlorhexidine and two calcium hydroxide formulations against Enterococcus faecalis. J Endod 2005;31:53-6.

Schenkein HA, Koertge TE, Brooks CN, Sabatini R, Purkall DE, Tew JG. IL-17 in sera from patients with aggressive periodontitis. J Dent Res 2010;89:943-7.

Selden HS. Apexification: an interesting case. J Endod 2002;28:44-5.

Semenoff TADV, Semenoff Segundo A, Figueiredo JAP. Biocompatibility of different intracanal medications in rat buccal submucosa tissue. J Appl Oral Sci 2008;16:12-7.

Semenza GL. Regulation of oxygen homeostasis by hypoxia-inducible factor 1. Physiology 2009; 24:97-106. 
Sethi G, B Sung, Aggarwal BB. TNF: a master switch for inflammation to cancer. Front Biosci 2008;13:5094-107.

Shen Y, Stojicic S, Haapasalo M. Antimicrobial efficacy of chlorhexidine against bacteria in biofilms at different stages of development. J Endod 2011;37:657-61.

Shuping GB, Ørstavik D, Sigurdsson A, Trope M. Reduction of intracanal bacteria using nickeltitanium rotary instrumentation and various medications. J Endod 2000;26:751-5.

Signoretti FGC, Gomes BPFA, Montagner F, Tosello FB, Jacinto RC. Influence of 2\% chlorhexidine gel on calcium hydroxide ionic dissociation and its ability of reducing endotoxin. Oral Surg Oral Med Oral Pathol Oral Radiol Endod 2011;111:653-8.

Silva LAB, Nelson-Filho P, Leonardo MR, Rossi MA, Pansani CA. Effects of calcium hydroxide on bacterial endotoxin in vivo. J Endod 2002;28:94-8.

Silva LAB, Nelson-Filho P, Silva RAB, Flores DSH, Heilborn C, Johnson JD, Cohenca N. Revascularization and periapical repair after endodontic treatment using apical negative pressure irrigation versus conventional irrigation plus triantibiotic intracanal dressing in dogs' teeth with apical periodontitis. Oral Surg Oral Med Oral Pathol Oral Radiol Endod 2010;109:77987.

Silva RAB, Assed S, Nelson-Filho P, Silva LAB, Consolaro A. Subcutaneous tissue response of isogenic mice to calcium hydroxid-based pastes with chlorhexidine. Braz Dent J 2009;20:99-106.

Silva RAB, Leonardo MR, Silva LAB, Castro LMS, Rosa AL, Oliveira PT. Effects of the association between a calcium hydroxide paste and $0,4 \%$ chlorhexidine on the development of the osteogenic phenotype in vitro. J Endod 2008;34:1485-89.

Silveira CFM, Cunha RS, Fontana CE, Martina AS, Gomes BPFA, Motta RHL, Bueno CES. Assessment of the antibacterial activity of calcium hydroxide combined with chlorhexidine paste and other intracanal medications against bacterial pathogens. Eur ] Dent 2011;5:1-7.

Siqueira Jr JF, Lopes HP. Mechanisms of antimicrobial activity of calcium hydroxide: a critical review. Int Endod J 1999;32:361-9.

Siqueira Jr JF, Rôças IN, Lopes HP, Elias CN, Uzeda M. Fungal infection of the radicular dentin. J Endod 2002;28:770-3.

Siqueira Jr JF, Rôças IN, Lopes HP, Magalhães FAC, Uzeda M. Elimination of Candida albicans infection of the radicular dentin by intracanal medications. J Endod 2003;29:501-4.

Siqueira Jr JF, Rôças IN. Polymerase chain reaction-based analysis of microorganisms associated with failed endodontic treatment. Oral Surg Oral Med Oral Pathol Oral Radiol Endod 2004;97:8594.

Sirén EK, Haapasalo MP, Ranta K, Salmi P, Kerosuo EN. Microbiological findings and clinical 
treatment procedures in endodontic cases selected for microbiological investigation. Int Endod J 1997;30:91-5.

Sirén EK, Haapasalo MP, Waltimo TM, Ørstavik D. In vitro antibacterial effect of calcium hydroxide combined with chlorhexidine or iodine potassium iodile on Enterococcus faecalis. Eur J Oral Sci 2004;112:326-31.

Soares JA, Leonardo MR, Silva LAB, Tanomaru-Filho M, Ito IY. Effect of rotary instrumentation and of the association of calcium hydroxide and chlorhexidine on the antisepsis of the root canal system in dogs. Braz Oral Res 2006a;20:120-6.

Soares JA, Leonardo MR, Silva LAB, Tanomaru-Filho M, Ito IY. Histomicrobiologic aspects of the root canal system and periapical lesions in dogs'teeth after rotary instrumentation and intracanal dressing with $\mathrm{Ca}(\mathrm{OH})_{2}$ pastes. J Appl Oral Sci 2006b;14:355-64.

Soares JA, Leonardo MR, Tanomaru-Filho M, Silva LAB, Ito IY. Residual antibacterial activity of chlorhexidine digluconato and camphorated p-monochlorophenol in calcium hydroxide-based root canal dressings. Braz Dent J 2007;18:8-15.

Soory M. A Role for non-antimicrobial actions of tetracyclines in combating oxidative stress in periodontal and metabolic diseases: a literature review. Open Dent J 2008;2:5-12.

Souza AP, Line SRP. The biology of matrix metalloproteinases. Rev FOB 2002;10:1-6.

Souza-Filho FJ, Soares AJ, Vianna ME, Zaia AA, Ferraz, CCR, Gomes BPFA. Antimicrobial effect and $\mathrm{pH}$ of chlorexidine gel e calcium hydroxide alone and associated with other materials. Braz Dent J 2008;19:28-33.

Stamenkovic I. Extracellular matrix remodelling: the role of matrix metalloproteinases. J Pathol 2003;200:448-64.

Sternlicht MD, Werb Z. How matrix metalloproteinases regulate cell behavior. Annu Rev Cell Dev Biol 2001;17:463-516.

Stetler-Stevenson WG, Seo DW. TIMP-2: An endogenous inhibitor of angiogenesis. Trends Mol Med 2005;11:97-103.

Storkebaum E, Carmeliet P. VEGF: a critical player in neurodegeneration. J Clin Invest 2004;113:14-8.

Stuart CH, Schwartz SA, Beeson TJ, Owatz CB. Enterococcus faecalis. its role in root canal treatment failure and current concepts in retreatment. J Endod 2006;32:93-8.

Takahashi $H$, Shibuya M. The vascular endothelial growth factor (VEGF)/VEGF receptor system and its role under physiological and pathological conditions. Clin Sci 2005;109:227-41.

Takahashi K. Microbiological, pathological, inflammatory, immunological and molecular biological aspects of periradicular disease. Int Endod J 1998;31:311-25.

Takushige T, Cruz EV, Asgor Moral A, Hoshino E. Endodontic treatment of primary teeth using a 
combination of antibacterial drugs. Int Endod J 2004;37:132-8.

Taneja S, Kumari M, Parkash $\mathrm{H}$. Nonsurgical healing of large periradicular lesions using a triple antibiotic paste: a case series. Contemp Clin Dent 2010;1:31-5.

Thibodeau B, Teixeira F, Yamauchi M, Caplan DJ, Trope M. Pulp revascularization of immature dog teeth with apical periodontitis. J Endod 2007;33:680-9.

Thibodeau B, Trope M. Pulp revascularization of a necrotic infected immature permanent tooth: case report and review of the literature. Pediatr Dent 2007;29:47-50.

Thomson A, Kahler B. Regenerative endodontics - biologically-based treatment for immature permanent teeth: a case report and review of the literature. Aust Dent J 2010;55:446-52.

Thornton RD, Lane P, Borghaei RC, Pease EA, Caro J, Mochan E. Interleukin 1 induces hypoxiainducible factor 1 in human gingival and synovial fibroblasts. Biochem J 2000;350:307-12.

Torabinejad M, Turman M. Revitalization of tooth necrotic pulp and open apex by using plateletrich plasma: a case report. J Endod 2011;37:265-8.

Torneck CD. Reaction of rat connective tissue to polyethylene tube implants I. Oral Surg Oral Med Oral Pathol 1996;21:379-87.

Torneck CD. Reaction of rat connective tissue to polyethylene tube implants II. Oral Surg Oral Med Oral Pathol 1967;24:674-83.

Trairatvorakul C, Detsomboonrat P. Success rates of a mixture of ciprofloxacin, metronidazole, and minocycline antibiotics used in the non-instrumentation endodontic treatment of mandibular primary molars with carious pulpal involvement. Int J Paediatr Dent 2011. No prelo.

Trope M. Regenerative potential of dental pulp. Pediatr Dent 2008;30:206-10.

Unemori EN, Ferrara N, Bauer EA, Amento EP. Vascular endothelial growth factor induces interstitial collagenase expression in human endothelial cells. J Cell Physiol 1992;153:557-62.

Usui T, Ishida S, Yamashiro K, Kaji Y, Poulaki V, Moore J, Amano S, Horikawa Y, Dartt D, Golding M, Shima DT, Adamis AP. VEGF $164(165)$ as the pathological isoform: differential leukocyte and endothelial responses through VEGFR1 and VEGFR2. Invest Ophthalmol Vis Sci 2004;45:368-74.

Vaghela DJ, Kandaswamy D, Venkateshbabu N, Jamini N, Arathi G. Disinfection of dentinal tubules with two different formulations of calcium hydroxide as compared to $2 \%$ chlorhexidine: as intracanal medicaments against Enterococcus faecalis and Candida albicans. an in vitro study. J Conserv Dent 2011;14:182-6.

Valera MC, Salvia AC, Maekawa LE, Camargo SE, Carvalho CA, Camargo CH, Koga-Ito CY. Antimicrobial analysis of chlorhexidine gel and intracanal medicaments against microorganisms inoculated in root canals. Minerva Stomatol 2010;59:415-21.

Valera MC, Silva KCG, Maekawa LE, Carvalho CAT, Koga-Ito CY, Camargo CHR, Lima RS. 
Antimicrobial activity of sodium hypochlorite associated with intracanal medication for Candida albicans and Enterococcus faecalis inoculated in root canals. J Appl Oral Sci 2009;17:555-9.

Vaz M, Krebs RZ, Trindade EN, Trindade MRM. Fibroplasia after polypropylene mesh implantation for abdominal wall hernia repair in rats. Acta Cir Bras 2009;24:19-25.

Veldhoen M, Hocking RJ, Atkins CJ, Locksley RM, Stockinger B. TGF- $\beta$ in the context of an inflammatory cytokine milieu supports de novo differentiation of IL-17-producing $T$ cells. Immunity 2006;24:179-89.

Vianna ME, Horz HP, Conrads G, Zaia AA, Souza-Filho FJ, Gomes BP. Effect of root canal procedures on endotoxins and endodontic pathogens. Oral Microbiol Immunol 2007;22:411-8.

Visse $R$, Nagase $H$. Matrix metalloproteinases and tissue inhibitors of metalloproteinases: structure, function, and biochemistry. Circ Res 2003;92:827-39.

Wajant $\mathrm{H}$, Pfizenmaier $\mathrm{K}$, Scheurich P. Tumor necrosis factor signaling. Cell Death and Differ 2003;10:45-65.

Waltimo TM, Ørstavik D, Sirén EK, Haapasalo MP. In vitro susceptibility of Candida albicans to four disinfectants and their combinations. Int Endod J 1999;32:421-9.

Waltimo TM, Sirén EK, Torkko HL, Olsen I, Haapasalo MP. Fungi in therapy-resistant apical periodontitis. Int Endod J 1997;30:96-101.

Wang CS, Arnold RR, Trope M, Teixeira FB. Clinical efficiency of 2\% CHX gel in reducing intracanal bacteria. J Endod 2007;33:1283-9.

Wang X, Thibodeau B, Trope M, Lin LM, Huang GTJ. Histologic characterization of regenerated tissues in canal space after revitalization/revascularization procedure of immature dog teeth with apical periodontitis. J Endod 2010;36:56-63.

Williams JM, Trope M, Caplan DJ, Shugars DC. Detection and quantitation of E. faecalis by realtime PCR (qPCR), reverse transcription-PCR (RT-PCR), and cultivation during endodontic treatment. J Endod 2006;32:715-21.

Willis-Owen SAG, Flint J. The genetic basis of emotional behaviour in mice. Eur J Human Genetics 2006;14:721-8.

Windley W, Teixeira F, Levin L, Sigurdsson A, Trope M. Disinfection of immature teeth with a triple antibiotic paste. J Endod 2005;31:439-43.

Wuerch RMW, Apicela MJ, Mines P, Yancich PJ, Pashley DH. Effect of 2\% chorhexidine gel as an intracanal medication on the apical seal of the root-canal systen. J Endod 2004;30:788-91.

Yamanaka Y, Shigetani Y, Yoshiba K, Yoshiba N, Okiji T. Immunohistochemical analysis of subcutaneous tissue reactions to methacrylate resin-based root canal sealers. Int Endod J 2011;44:669-75.

Yamauchi N, Yamauchi S, Nakaoka H, Duggan D, Zhong S, Lee SM, Teixeira FB, Yamauchi M. 
Tissue engineering strategies for immature teeth with apical periodontitis. J Endod 2011;37:3907.

Yao JS, Shen F, Young WL, Yang GY. Comparison of doxycycline and minocycline in the inhibition of VEGF-induced smooth muscle cell migration. Neurochem Int 2007;50:524-30.

Young GR, Parashos $\mathrm{P}$, Messer $\mathrm{HH}$. The principles of techniques for cleaning root canals. Aust Dent J 2007;52:52-63.

Zachary I, Gliki G. Signaling transduction mechanisms mediating biological actions of the vascular endothelial growth factor family. Cardiovasc Res 2001;49:568-81.

Zamany A, Safavi K, Spangberg LSW. The effect of chlorhexidine as a endodontic disinfectant. Oral Surg Oral Med Oral Pathol Oral Radiol Endod 2003;96:578-81.

Zarella JA, Fouad AF, Spangberg LSW. Effectiveness of a calcium hydroxide and chlorhexidine digluconate mixture as disinfectant during retreatment of failed endodontic cases. Oral Surg Oral Med Oral Pathol Oral Radiol Endod 2005;100:756-61.

Zehnder M, Grawehr M, Hasselgren G, Waltimo T. Tissue-dissolution capacity and dentindesinfecting potencial of calcium hydroxide mixed with irrigating solutions. Oral Surg Oral Med Oral Pathol Oral Radiol Endod 2003;96:608-13. 


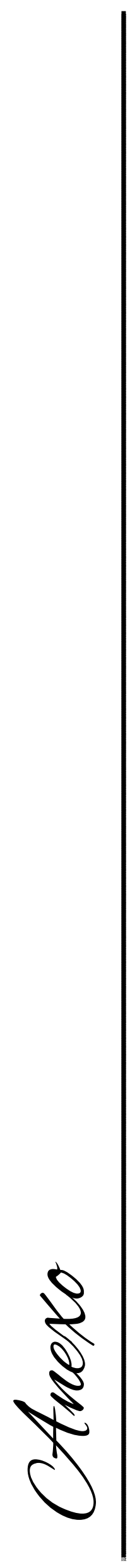


Anexo A - Certificado de aprovação do projeto pelo Comitê de Ética.

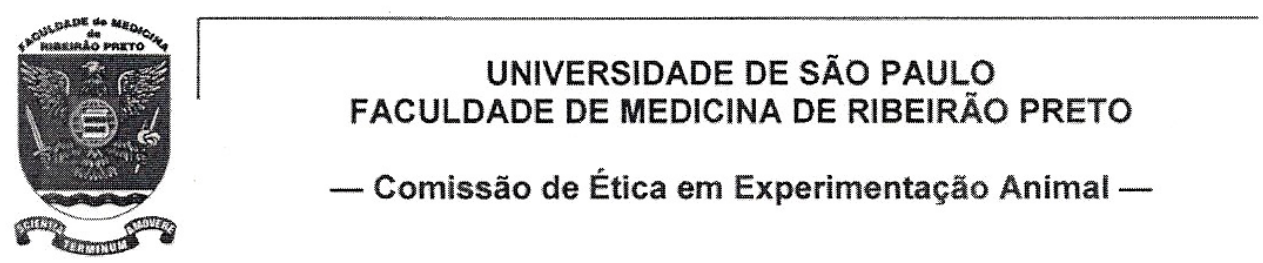

\section{CERTIFICADO}

Certificamos que o Protocolo para Uso de Animais em

Experimentação $\mathbf{n}^{\circ} \mathbf{1 8 5 / 2 0 0 9}$, sobre 0 projeto intitulado "Biocompatibilidade de substâncias utilizadas no tratamento endodôntico de dentes decíduos e permanentes", sob a responsabilidade do Professor Doutor Marcos Antonio Rossi está de acordo com os Princípios Éticos na Experimentação Animal adotado pelo Colégio Brasileiro de Experimentação Animal (COBEA) e foi $\boldsymbol{A P R O V} \boldsymbol{A D O}$ em reunião de 22 de fevereiro de 2010 .

(We certify that the protocol $n^{\circ} 185 / 2009$, about "Biocompatibility of substances used in endodontic treatment of deciduous and permanent teeth", agrees with the ETHICAL PRINCIPLES IN ANIMAL RESEARCH adopted by Brazilian College of Animal Experimentation (COBEA) and was approved "ad referendum" by the College of Medicine of Ribeirão Preto of the University of São Paulo - Ethical Commission of Ethics in Animal Research (CETEA) in 02/22/2010 meeting.

Ribeirão Preto, 22 de fevereiro de 2010. 